Florida International University FIU Digital Commons

2015

\title{
A Comparison Between Graphene and WS2 as Solid Lubricant Additives to Aluminum for Automobile Applications
}

Sara Rengifo

sreng002@fiu.edu

DOI: $10.25148 /$ etd.FI15032181

Follow this and additional works at: https://digitalcommons.fiu.edu/etd

Part of the Materials Science and Engineering Commons, and the Tribology Commons

\section{Recommended Citation}

Rengifo, Sara, "A Comparison Between Graphene and WS2 as Solid Lubricant Additives to Aluminum for Automobile Applications" (2015). FIU Electronic Theses and Dissertations. 1862.

https://digitalcommons.fiu.edu/etd/1862

This work is brought to you for free and open access by the University Graduate School at FIU Digital Commons. It has been accepted for inclusion in FIU Electronic Theses and Dissertations by an authorized administrator of FIU Digital Commons. For more information, please contact dcc@fiu.edu. 
FLORIDA INTERNATIONAL UNIVERSITY

Miami, Florida

A COMPARISON BETWEEN GRAPHENE AND WS2 AS SOLID LUBRICANT ADDITIVES TO ALUMINUM FOR AUTOMOBILE APPLICATIONS

A thesis submitted in partial fulfillment of the requirements for the degree of MASTER OF SCIENCE

in MATERIALS SCIENCE AND ENGINEERING

by

Sara Rengifo 
To: Dean Amir Mirmiran

College of Engineering and Computing

This thesis, written by Sara Rengifo, and entitled A Comparison Between Graphene and $\mathrm{WS}_{2}$ as Solid Lubricant Additives to Aluminum for Automobile Applications, having been approved in respect to style and intellectual content, is referred to you for judgment.

We have read this thesis and recommend that it be approved.

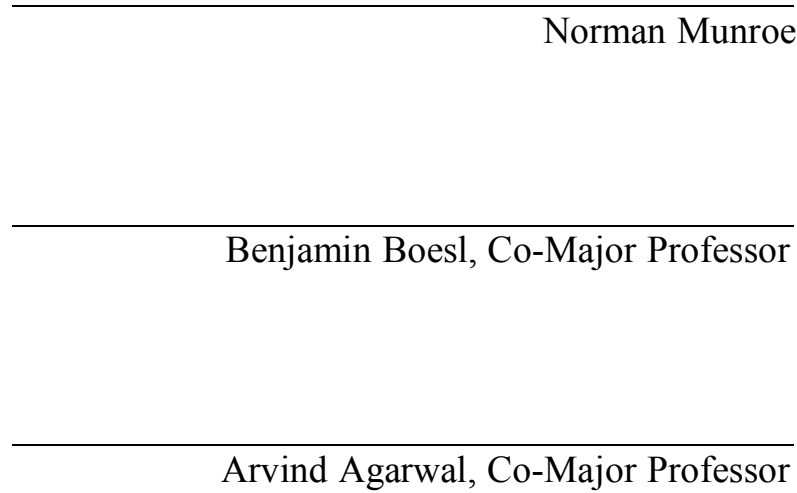

Date of Defense: March 20, 2015

The thesis of Sara Rengifo is approved.

Dean Amir Mirmiran

College of Engineering and Computing

Dean Lakshmi N. Reddi University Graduate School

Florida International University, 2015 


\section{DEDICATION}

This is just the beginning of an amazing career. I dedicate this thesis to my beautiful family and my lovely husband. Thank you for supporting me during this path, and being my main motivation to achieve all my professional goals. 


\section{ACKNOWLEDGMENTS}

I would like to acknowledge and sincerely thank all who contributed during the development of this thesis. Special thanks to Dr. Agarwal for his guidance, trust, understanding and most importantly his friendly advice during my graduate process. His mentorship was the mainstay of an excellent experience in the aim of reaching my goals as a scientist, not only helping me to grow in academia, but also as an independent thinker. Thank you Dr. Agarwal for giving me the opportunity to be part of your team. I thank all the members of the research group, Dr. Benjamin Boesl, Cheng Zhang, Sadegh Behdad and Chris Rudolf. Thank you all for your guidance, assistance and support on giving my graduate career the foundation of science.

I am very grateful with all the AMERI staff for your unconditional help and friendship especially Dr. Alex Franco, Dr. Yusuf Emirov, Ali Hadjikhani, and Neal Ricks. Also, I would like to thank my committee members Dr. Munroe, Dr. Boesl and Dr. Agarwal for providing helpful suggestions.

Finally, and most importantly, I would like to thank God for having my beautiful family and my lovely husband. You are my amazing miracle. You have taught me how to face challenges to find my inner strength and know that every step forward is a step towards achieving something bigger. All your love and support have given me the strength to never give up. I love you all and I owe you my deepest thanks. 


\author{
ABSTRACT OF THE THESIS \\ A COMPARISON BETWEEN GRAPHENE AND WS $\mathrm{W}_{2}$ AS SOLID \\ LUBRICANT ADDITIVES TO ALUMINUM FOR AUTOMIBILE APPLICATIONS
}

by

Sara Rengifo

Florida International University, 2015

Miami, Florida

Professor Arvind Agarwal, Co-Major Professor

Professor Benjamin Boesl, Co-Major Professor

The purpose of this thesis was to compare graphene nanoplatelets (GNP) and $\mathrm{WS}_{2}$ as solid lubricant additives to aluminum in order to reduce friction and wear. The central hypothesis of this work relied on lubricating properties of $2 \mathrm{D}$ materials, which consist layers that slip under a shear force.

Two aluminum composites were made (Al-2 vol.\% GNP and Al-2 vol.\% $\mathrm{WS}_{2}$ ) by spark plasma sintering. Tribological properties were evaluated by ball-on-disk wear tests at room temperature $(\mathrm{RT})$ and $200^{\circ} \mathrm{C}$.

$\mathrm{WS}_{2}$ not only presented the lowest COF (0.66) but also improved the wear resistance of aluminum by $54 \%$ at RT. Al-2 vol.\% GNP composite displayed poor densification (91\%) and low hardness resulting in poor wear resistance. The wear rate of Al-2 vol. $\%$ GNP composite increased by $233 \%$ at $\mathrm{RT}$ and $48 \%$ at $200^{\circ} \mathrm{C}$ as compared to pure aluminum. GNP addition also resulted in lower COF (0.79) as compared to pure aluminum (0.87). 


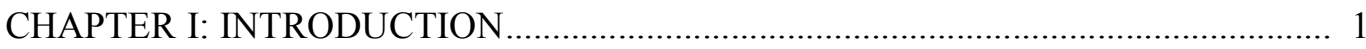

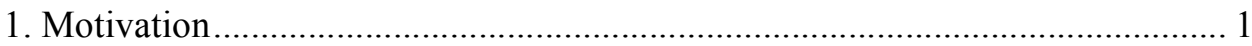

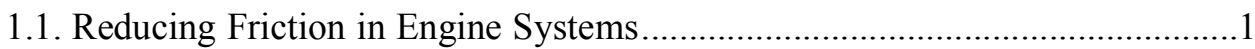

1.2. Fuel Saving and Reduction of Environmental Impact by Using Tribology Technology in Engine Parts. .......................................................................6

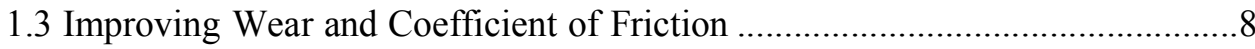

1.4. Novelty of 2D Materials as Reinforcement ......................................................

2. Research Objectives............................................................................... 10

CHAPTER II: REVIEW OF THE STATE OF THE ART ….................................... 12

1. Aluminum in Automotive Applications.......................................................... 12

2. 2D materials as Solid Lubricants ................................................................. 14

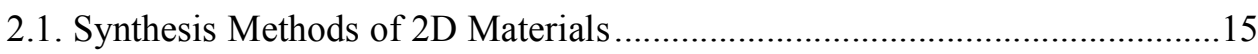

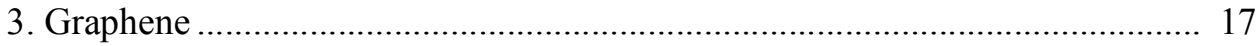

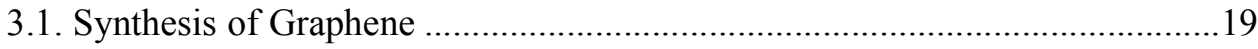

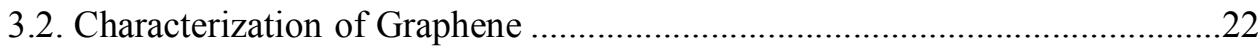

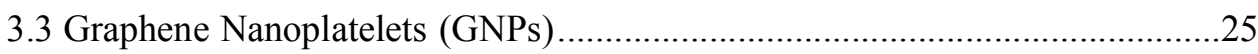

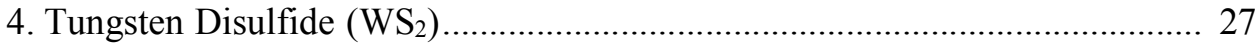

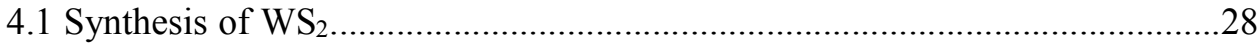

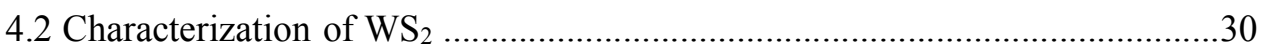

5. Comparison of GNP and $\mathrm{WS}_{2}$ for Tribological Applications ......................... 32

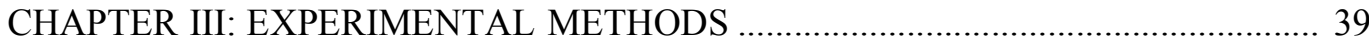

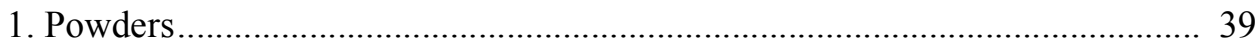

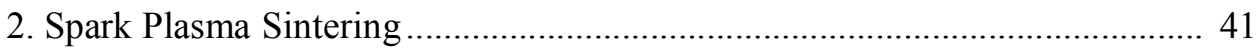

3. Characterization ............................................................................... 42

4. Hardness Measurement ............................................................................... 43

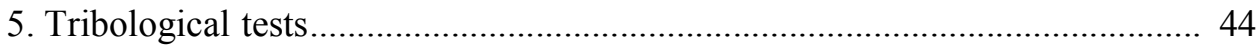

6. Post Wear Characterization............................................................................ 45

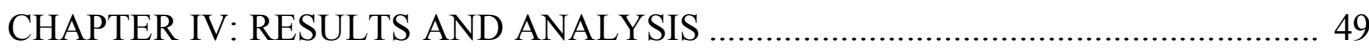

4.1. Microstructure of Sintered Al, Al-2 vol.\% GNP and Al-2 vol.\% $\mathrm{WS}_{2}$......... 49 


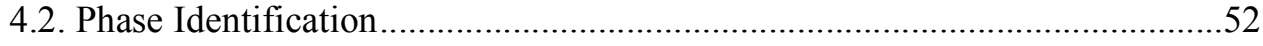

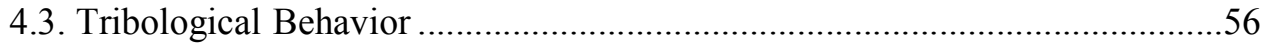

4.4. Wear Mechanisms at Room Temperature.....................................................61

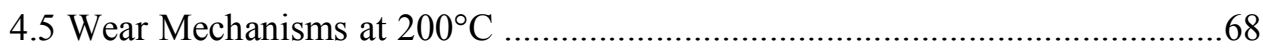

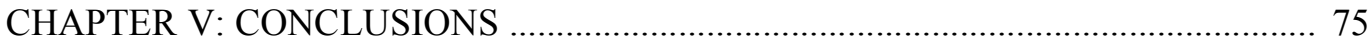

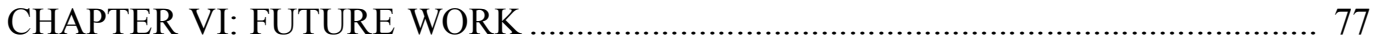

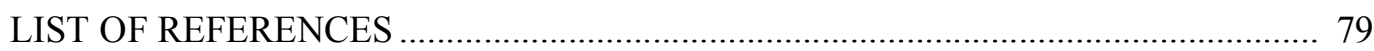

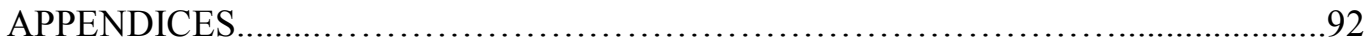




\section{LIST OF TABLES}

TABLES

PAGE

TABLE 1.1 Friction Losses in One Global Average Passenger Car According To Type of Tribocontact....

TABLE 2.1. Aluminum Applications in the Automotive Industry 14

TABLE 2.2 Tribological Mechanisms of GNP and $\mathrm{WS}_{2}$ 33

TABLE 4.1 Hardness and Percent of Desification Properties 52

TABLE 4.2 Reactants Products and $\Delta \mathrm{G}$ During Sintering Process ................................ 53

TABLE 4.3 Wear Rate and Coefficient of friction at Room Temperature and $200^{\circ} \mathrm{C} \ldots . .56$ 


\section{LIST OF FIGURES}

FIGURE

PAGE

Fig 1.1. Breakdown Of Passenger Car Energy Consumption 2

Fig 1.2. Piston Assembly and Piston Ring Function From An Internal Combustion Engine 3

Fig 1.3. Schematic Representation of Power Piston System 4

Fig 1.4. The Different Regimes of Lubrication According to Stribeck: Hydrodynamic (HD), Elastohydrodynamic (EHD), Mixed and Boundary Lubrication ................ 5

Fig 2.1. Historical Development of Thin Solid Lubricant Films 16

Fig 2.2 a) Graphene Hexagonal Lattice Sublattices A and B b) Representation of Hexagonal Layered Structure of Graphite Showing Three Staggered Layers ... 18

Fig 2.3. Single Layer Graphene Sheet Characterized by TEM....................................... 23

Fig. 2.4. a) Graphite and Graphene Few Layered Raman Spectra b) 2D Band Changes with Increment on Layers

Fig 2.5. Crystal Structure of $\mathrm{WS}_{2}$ 27

Fig 2.6. Schematic Representation of Exfoliation of $\mathrm{WS}_{2}$ Nanosheets

Fig 2.7. $\mathrm{WS}_{2}$ TEM Image at a) Low Resolution, b) High Resolution and c) Low-Pass Butterworth Filtering

Fig 2.8. HRTEM Image of $\mathrm{WS}_{2} \mathrm{~A}$ ) Orientation in the Coating and B) Random Orientation in the Transfer Film.

Fig 2.9: XRD of $\mathrm{WS}_{2}$ Obtained at a) $500^{\circ} \mathrm{C}$, b) $600^{\circ} \mathrm{C}$, c) $700^{\circ} \mathrm{C}$, d) $840^{\circ} \mathrm{C} \ldots \ldots \ldots \ldots \ldots . . . . . . . .32$

Fig 2.10. Typical Raman Spectra of $\mathrm{WS}_{2}$ on the Transfer Film ..................................... 32

Fig 3.1. SEM Image of As-Received Aluminum Powder. ............................................. 39

Fig 3.2. a) SEM b) TEM of as Received Graphene Nanoplatelet Powder ....................... 40

Fig 3.3. SEM Image of as Received $\mathrm{WS}_{2}$ Powder ...................................................... 40 
Fig 3.4. a) Wear Track of Al-2 vol.\% GNP Scanned at RT by Nanovea PS50 Optical Profilometer, b) Cross-Sectional Area of Wear Track 45

Fig 3.5. FIB Performed on The Surface of the Wear Track 47

Fig. 4.1. SEM of Cross-Section a) Pure Al, b) Al-2 vol. \% GNP, c) Al-2 vol.\% WS $2 . . .50$

Fig 4.2. SEM Fracture Surface a) Pure Al, b) Al-2 vol.\% GNP, c, d) Al-2 vol.\% WS $\mathrm{WS}_{2} \ldots 51$

Fig 4.3. X-Ray of Sintered Pellets of Al, Al-2 vol.\% GNP, and Al-2 vol.\% WS 2 .......... 53

Fig 4.4. Raman Spectroscopy for GNP Powder and Al-2 vol.\% GNP ........................... 54

Fig 4.5 Raman Spectroscopy for $\mathrm{WS}_{2}$ Powder and Al-2 vol.\% $\mathrm{WS}_{2} \ldots \ldots \ldots \ldots \ldots \ldots \ldots \ldots \ldots \ldots . . . . . . . . . . . . .55$

Fig 4.6. Wear Rate For Ball-on-disk Sliding Experiments at Room Temperature........... 57

Fig 4.7. Wear Rate For Ball-on-disk Sliding Experiments at $200^{\circ} \mathrm{C}$.............................. 57

Fig 4.8. Average COF and COF Variation During RT Tests ..................................... 59

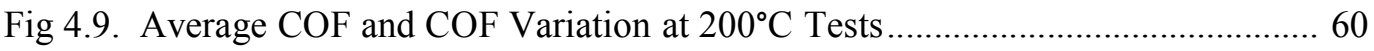

Fig 4.10. XRD After SPS, RT Test And HT Test a) Pure Al, b) Al-2 vol.\% GNP, c) Al-2 vol.\% $\mathrm{WS}_{2}$ 61

Fig 4.11. Schematic Representation of Behavior of Pure Al at RT. 62

Fig 4.12. SEM a) Wear Track, b) Wear Debris, c) Optical Microscope Image of The Sub-Surface of the Wear Track, d) FIB Image of the Sub-Surface of Wear Track for Pure Al After RT Tribological Test. 63

Fig 4.13. Schematic Representation of Behavior Of Al-2 vol.\% GNP At RT. 64

Fig 4.14. SEM Images of the a) Wear Track and b) Wear Debris, c) OM Image of the Sub-Surface, d) FIB of the Sub-surface for Al-2 vol.\% GNP After RT Test. ... 65

Fig 4.15. Schematic Representation of Behavior of Al-2 vol.\% $\mathrm{WS}_{2}$ at RT. 66

Fig 4.16. SEM a) Wear Track and b) Wear Debris, c) Optical Microscope Image of the Sub-burface of the Wear Track, d) FIB Image of Sub-surface of Wear Track for Al-2 vol.\% $\mathrm{WS}_{2}$ After RT Tribological Test. 67

Fig 4.17. Schematic Representation of Behavior of Pure Al at $200^{\circ} \mathrm{C}$ 68 
Fig 4.18. SEM Images of a) Wear Track and b) Wear Debris, c) Optical Microscope Image of the Sub-surface of the Wear Track, d) FIB Image of Sub-surface of Wear Track for Pure Al After HT Tribological Test.

Fig 4.19. Schematic Representation of Behavior of Al-2 vol.\% GNP At HT. 70

Fig 4.20. SEM Images of a) Wear Track and b) Wear Debris, c) Optical Microscope Image of the Sub-surface of the Wear Track, d) FIB Image of Sub-surface of Wear Track for Al- 2 vol.\% GNP After HT Tribological Test. 70

Fig 4.21. Schematic Representation of Behavior of Al-2vol.\% $\mathrm{WS}_{2}$ at HT. 71

Fig 4.22. SEM Images of a) Wear Track and b) Wear Debris, c) Optical Microscope Image of Sub-surface of the Wear Track, d) FIB Image of Sub-surface of Wear Track for Al- 2 vol.\% WS 2 After HT Tribological Test.

Fig 4.23. Schematic Representation of a) GNP and b) $\mathrm{WS}_{2}$ Wear Mechanism. 74 


\section{CHAPTER I: INTRODUCTION}

Overcoming friction in engine systems can significantly improve the fuel efficiency

of automobiles. As a consequence, a significant amount of research has been done to develop automotive materials and techniques that reduce friction in automobile components. Some potential solutions to reduce friction in automotive components include development of (i) novel aluminum alloys and composites, (ii) advanced surface engineering techniques and anti-friction coatings and (iii) solid lubricant additives. The introduction of solid lubricant as additives to coatings, bulk aluminum alloys and composite materials is an emerging technology for reducing friction. 2D materials such as graphene, $\mathrm{WS}_{2}$ and $\mathrm{MoS}_{2}$ have emerged as novel solid lubricants with a greater potential to reduce friction. The goal of this thesis is to study and compare the tribological performance of graphene and $\mathrm{WS}_{2}$ as solid lubricant additives to aluminum.

\section{Motivation}

\subsection{Reducing Friction in Engine Systems}

The principal motivation of this thesis focuses on tribological technology as a solution for reducing fuel energy consumption in passenger cars. Since 1966 the term "tribology" has caused apprehension among scientists, who defined tribology as "the science and practices relating to interacting surfaces in relative motion". It encompasses friction, lubrication and wear [1]. Research on tribology has far-reaching economic implications, having made possible significant savings in the US gross national product. By 1976 a survey established that if tribology program were applied, 11\% of total US energy consumption could be saved in the areas of road transportation, power generation, 
and industrial machinery; those areas count for about $80 \%$ of the total energy consumption in the US [1]. In the 90's, research on wear of metals brought a deeper understanding and help with progress in the tribology field [2]. However, nowadays in passenger cars, onethird of the fuel energy is used to overcome friction in the engine transmission, tires, and brakes [3]. In order to have a better view, friction loss distribution has been subdivided into four groups: $11.5 \%$ to overcome the rolling friction in the tire-road contact, $11.5 \%$ to overcome friction in the engine system, $5 \%$ in the transmission system, and $5 \%$ in the brakes (Fig 1.1).

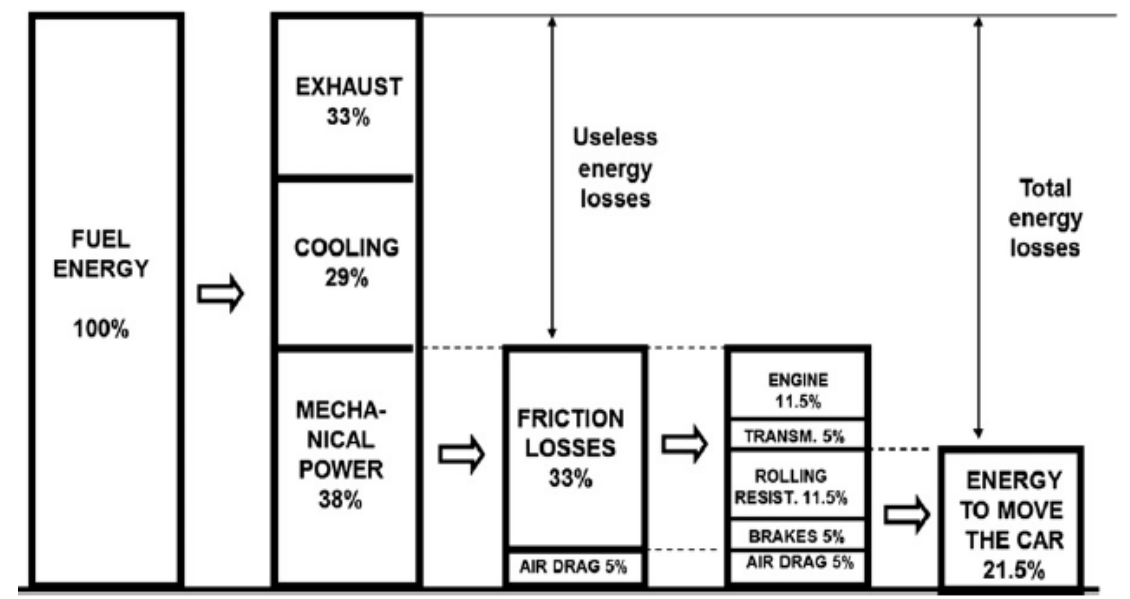

Fig 1.1. Breakdown of Passenger Car Energy Consumption [3]

The friction loss by engine systems in a passenger car can be sub-divided into four groups: (i) the piston assembly (45\%), (ii) the bearings and seals (30\%), (iii) the valve train (15\%), and (iv) the pumping and hydraulic (10\%) [3]. The piston assembly includes the most critical part (45\%) in tribological terms as it includes the ring pack. The ring pack has three main roles on piston's performance; the first is to maintain an effective gas seal between the combustion chamber and the crankcase, the second is to transfer heat from the 
piston into the cylinder wall, and then into the coolant, and the third function is to limit the amount of oil that is transported from the crankcase to the combustion chamber [4].
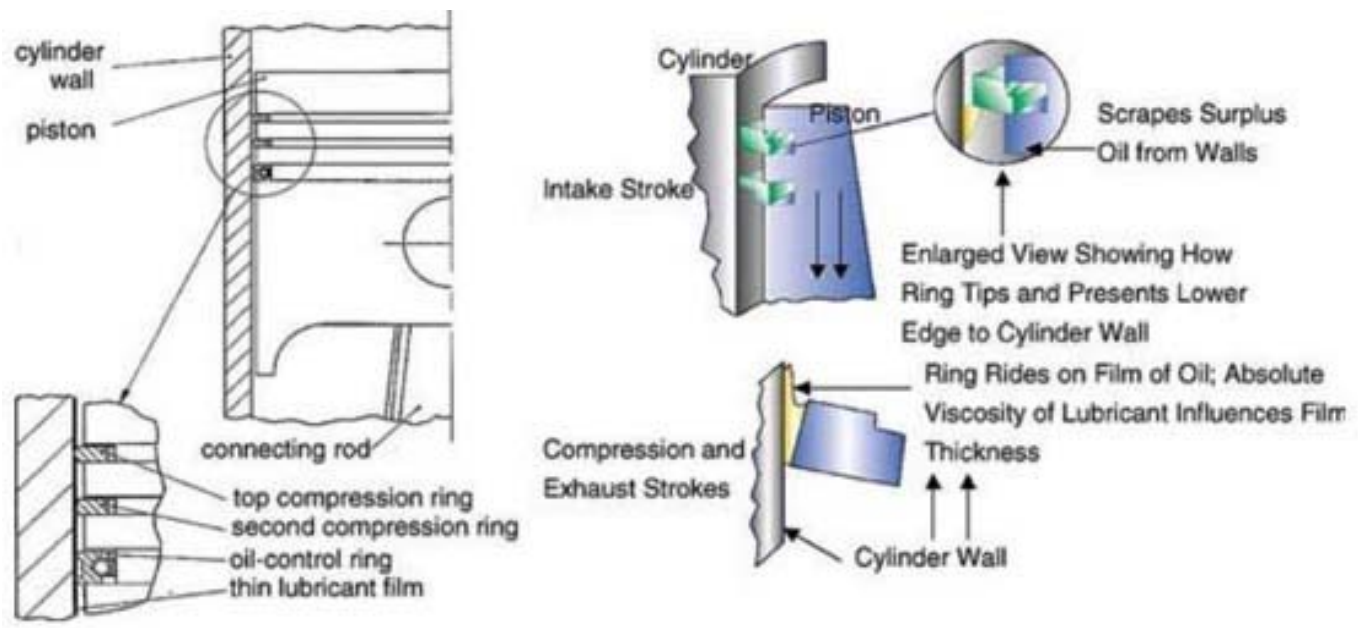

Fig 1.2. Piston assembly and Piston Ring Function from an Internal Combustion Engine [4].

A schematic representation of a piston assembly from a modern automotive engine is presented in Fig 1.2. The top two piston rings are denoted as the compression rings and the third as oil-control ring. Pressure of combustion pushes the two first rings out in order to seal the combustion chamber and prevent leaking, and the entire surface of the rings engages the cylinder wall. The oil-control ring is in charge of wiping excess oil from the cylinder wall [4]. Chong [5], who studied the piston ring forces without excluding the secondary motion (piston lateral motion) (Fig 1.3), determined the piston ring packs friction from the difference between the total friction force and the piston skirt friction force. Based on this finding, the piston posture is important in determining the piston ring friction force during the existence of piston secondary motion. In contrast, the same author [6] studied the piston forces excluding the secondary motion and concluded that the piston 
ring friction force only depends on the lubrication system when the piston secondary motion is excluded.

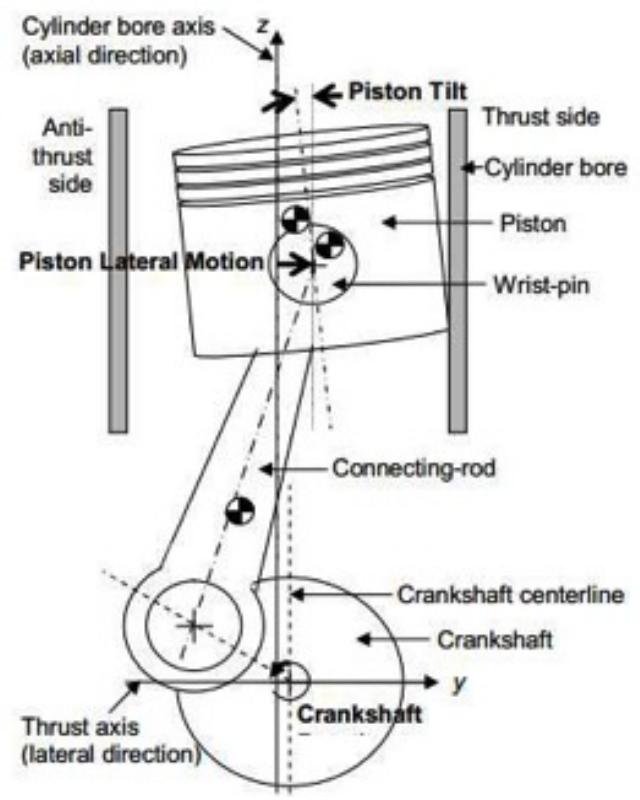

Fig 1.3. Schematic Representation of Power Piston System [7]

When investigating friction in bearings, the lubricant plays a decisive role (Fig 1.4), hence, the mechanism in charge of causing friction in bearings is very different from pistons. Allmaier [8] described hydrodynamic losses and losses due to the metal-metal contact as two main mechanisms which cause friction in bearings. In describing the two mechanisms, Allmaier underscored the fact that reducing the sliding surface area of the crankshaft or increasing bearing clearance is effective in reducing friction in bearings, however, these methods can increase the wear, seizure or knocking [9]. In addition, the method to reduce the inherent hydrodynamic losses is effective by reducing the viscosity itself. Nevertheless, the consequence of a thin oil increases the likelihood of asperity contact [10]. 


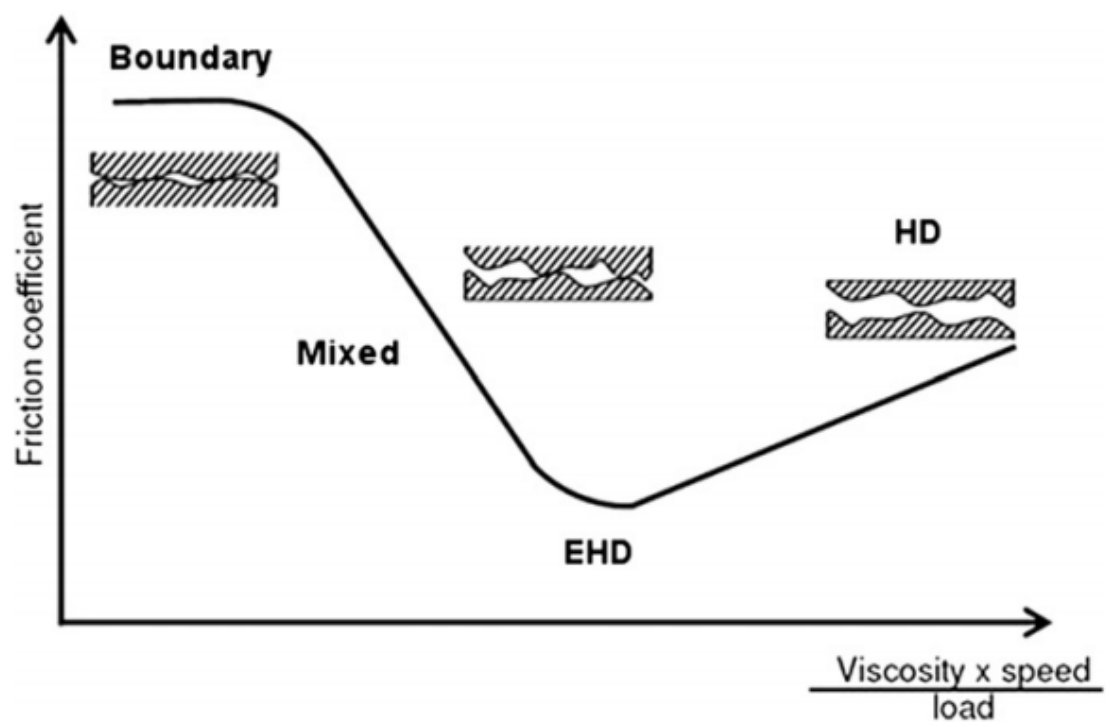

Fig 1. 4. The Different Regimes of Lubrication According to Stribeck: Hydrodynamic (HD), Elastohydrodynamic (EHD), Mixed and Boundary Lubrication [10]

In a valve train friction analysis, considerable efforts have been made in order to reduce friction. Some investigators have proposed the reduction of weight and size of the design of the valve train. However, the results are not so motivating and have shown that further reduction is very difficult to achieve [9]. Another attempt includes the investigation into new materials such as titanium and different ceramics, these materials have performed well in reducing friction and so in fuel cost saving. However, the cost of these materials is very high, which makes their construction in industry level very complicated [9]. Also, analytical investigations based on elastohydrodynamic lubrication theory has taken place to predict the cyclic variation of important parameters such as minimum film thickness, maximum Hertzian stress and power loss, and the results show that not only does hydrodynamic play a main role, but the chemical reactions in the thickness of the film related to temperature are vital as well [11]. Likewise, pumping and hydraulic losses are 
highly related to temperature. For instance, increased viscosity at low temperatures results in higher frictional consequences [12].

\subsection{Fuel Saving and Reduction of Environmental Impact by Using Tribology Technology in Engine Parts.}

An understanding of the tribology of the piston assembly, valve train, bearings and pumps in automobile engines points out that the most critical source of friction is in pistons and so in piston rings. The piston ring is the most complicated tribological component in the internal combustion engine to analyze because of large variations of load, speed, temperature and lubrication [4], thus challenges for engineers and designers in improving lubrication mechanisms to enhance energy efficiency with reduced environmental impact become a target for the automotive industry. Despite all the efforts and developments in engine design and oil formulation so far to reduce these, friction in engines remains an issue in both fuel saving and environmental impact.

Nowadays, the economy is deeply concerned with energy savings, and for this reason development of new automotive technologies and environmental impacts are being improved at the same time. However, worldwide, 208,000 million liters of fuel were used in 2009 to overcome friction in passenger cars [3]. With such large numbers of liters of fuel consumed, even the smallest improvement in engine efficiency, emission levels and durability of fuel can have a major effect on the worldwide fuel economy and the environment in the long-term (15-25 years) [4]. New technology for friction reduction in passenger cars, can result in a reduction in friction losses by $18 \%$ in the short term $(5-10$ years) and by $61 \%$ in the long term. This would represent in world economic savings the 
amount of 174,000 million euros in the short term and 576,000 million euros in the long term. Those numbers represent in fuel savings the total of 117,000 million and 385,000 million liters, respectively; and $\mathrm{CO}_{2}$ emission reduction of 290 million and 960 million tons, respectively [3].

The benefits of improving tribological properties in engines are [4]: reduced fuel consumption, increased engine power output, reduced oil consumption, reduction in harmful exhaust emissions, improved durability, reliability and engine life, reduced maintenance requirements and longer service intervals. However, in spite all these benefits, friction in one passenger car consumes an average of 340 liters of fuel per year Table 1.1 corresponding to a distance of $13,000 \mathrm{~km}$ [3].

\section{TABLE 1.1 Friction Losses in One Global Average Passenger Car According To Type of Tribocontact [3]}

\begin{tabular}{|l|c|c|c|}
\hline Friction loss & Energy consumed & Fuel used & Percentage \\
\hline source type & (MJ/car/a) & (liters/car/a) & (\%) \\
\hline Tire-road contact & 1452 & 119 & 16.8 \\
\hline Hydrodynamic lubrication & 1993 & 57 & 7.6 \\
\hline Mixed lubrication & 899 & 26 & 6.3 \\
\hline EHD lubrication, sliding & 747 & 21 & 8.2 \\
\hline EHD, sliding and rolling & 979 & 28 & 3 \\
\hline EHD lubrication, rolling & 356 & 10 & 1.6 \\
\hline Boundary lubrication & 187 & 5 & 6.5 \\
\hline Viscous losses & 771 & 22 & 15 \\
\hline Braking contact & 1779 & 51 & 100 \\
\hline Total & 11.863 & 340 & \\
\hline
\end{tabular}

Approximately, 10 million automobiles are disassembled each year in the US, and the environmental impact created is shocking. Even, when about $75 \%$ of the weight of a 
passenger car comes from recycled parts, and knowing that cleaner fuels generally result in lower emissions of toxics, there may be very harmful gases called heat trapping or greenhouse gases (GHG), in which some of their effects are severe weather patterns, ecosystem change, droughts and floods, sea level rise, and increases in incidence of infectious diseases [13].

It is the role of the materials engineers to research into new materials and meet humankind desire for energy and at the same time prevent the adverse environmental effects it produces, especially if it is known that only $21.5 \%$ of the fuel energy is used to move the car (Fig 1.1)[3].

\subsection{Improving Wear and Coefficient of Friction}

Aluminum alloys are widely preferred due to their light weight and excellent corrosion resistance, however the main limitations of these alloys are the lower fatigue strength and poor wear resistance [14]. In the effort of overcoming aluminum limitations in tribological performance, some hard ceramic particles have been used as reinforcement, such as $\mathrm{SiC}$ [14], $\mathrm{TiB}_{2}$ [15], $\mathrm{TiC}$ [16], also called aluminum matrix composites (AMCs) [17]. However, some investigators have reported that AMCs reduce wear resistance at high temperature in comparison with performance at room temperature [17]. Also, the addition of self-lubricating materials, such as graphene to Al, resulted in an enhancement of strength properties with excellent distribution [14].

Due to solid lubricants' intrinsic property of easy shear in addition to many advantages over liquid lubricants, GNP and $\mathrm{WS}_{2}$ are added to aluminum to find a better coefficient of friction and wear resistance. Graphene nanoplatelets (GNP), consisting of 
approximately $20-30$ graphene sheets and with a thickness of $5-10 \mathrm{~nm}$, is a $2 \mathrm{D}$ material that [18] exhibits many of graphene's unique properties. The increased thickness of GNP makes them less prone to agglomeration and entanglement as compared to single layer graphene [19]. GNPs have been explored as lubricants, both in liquid [20] and solid forms [19]. Likewise, $\mathrm{WS}_{2}$ is recognized for high lubricating performance under a high load, high pressure and high temperature. A large amount of $\mathrm{W}$ can give excellent anti-wear properties and reacts with the metal to generate a protective tribofilm [21]. The coefficient of friction of the WSx film decreases slightly with an increasing S/W ratio [22].

The biggest concern about $\mathrm{WS}_{2}$ as a lubricant is its high reactivity in humid environments and formation of $\mathrm{WO}_{3}$, which affects tribological performance [23]. The biggest drawback in the performance of GNP as a lubricant is the tendency to increase porosity due to agglomeration, affecting the tribological performance [24].

\subsection{Novelty of 2D Materials as Reinforcement}

Since the separation of graphene into atomic arrangement of carbon sheets, and the demonstration of the novelty properties of graphite, two dimensional materials have been in the sight of researchers. Two widely studied 2D materials are Boron nitride (BN) and Molybdenum disulfide $\left(\mathrm{MoS}_{2}\right)$. In comparison with GNP, Boron nitride (BN) exhibits many of graphene's astonishing properties in electrical applications [25]. Likewise, in comparison with $\mathrm{WS}_{2}$, Molybdenum disulfide $\left(\mathrm{MoS}_{2}\right)$ presents excellent performance in tribological and electrical fields, and works as an excellent solid lubricant, giving a low coefficient of friction and high wear resistance [26]. 


\section{Research Objectives}

The overall objective of this study is to compare graphene and $\mathrm{WS}_{2}$-based two dimensional (2D) materials as solid lubricant additives to aluminum in order to reduce the friction and improve energy efficiency of automobile engine components. This study involves the addition of $2 \mathrm{D}$ solid lubricant materials (GNP and nano size $\mathrm{WS}_{2}$ powders) to an aluminum matrix to synthesize a composite material with improved tribological properties. The mixed powders were consolidated by spark plasma sintering (SPS) into dense composites for studying their tribological behavior under ball-on-disk sliding wear conditions at room temperature and $200^{\circ} \mathrm{C}$. The specific novel scientific features include the following:

i. The effect of chemistry $\left(\mathrm{GNP} v \mathrm{vs} \mathrm{WS}_{2}\right)$ on wear and friction

ii. The effect of temperature on wear and friction. A higher temperature of $200^{\circ} \mathrm{C}$ is selected, as it is close to the operating temperature of gasoline engines [11,27].

In developing this thesis, six chapters are presented. Chapter one presents the introduction and background of the topics related with aluminum alloys, their usage in automotive engine components, and the benefits of developing anti-friction systems that can reduce gas consumption worldwide. The following chapter is Chapter 2, in which the state of art is presented. Some previous investigations on graphene and $\mathrm{WS}_{2}$ as solid lubricants are discussed. Chapter 3 details the experimental procedure, assumptions and evaluations that are made during the study of these novel materials. Chapter 4 provides the results obtained by applying the experimental procedure proposed in Chapter 3 . The mechanisms of wear and friction for each material are discussed and compared in this 
chapter. Finally, Chapter 5 presents the major conclusions and Chapter 6 sets some suggestions for future studies to expand knowledge about reduction of friction through solid lubricants' implementation. 


\section{CHAPTER II: REVIEW OF THE STATE OF THE ART}

\section{Aluminum in Automotive Applications}

The demand for aluminum composites in automotive applications has increased due to their lightweight, excellent corrosion resistance with good strength, and low density compared with steel [28]. The density of aluminum $\left(2700 \mathrm{~kg} / \mathrm{m}^{3}\right)$ is one third the density of steel, which allows $60 \%$ saving in weight in the engine and transmission parts, $50 \%$ in bumper systems and more than $30 \%$ in chassis and suspension parts [29]. Weight reduction of the car is strongly related with the energy consumption, and thus with environmental impact. Some reports assert that, on average, $100 \mathrm{~kg}(220.5 \mathrm{lbs}$.) of mass reduction can save 0.35 liters of fuel per every $100 \mathrm{~km}$ (62 miles), and 10 grams of $\mathrm{CO}_{2}$ per $\mathrm{km}$ in emission $[29,30]$. It translates that $10 \%$ in weight reduction improves the economy related with fuel consumption by $5.5 \%$ [31].

Currently, varieties of aluminum alloys are used [32] for different automotive components, as shown in Table 2.1 [33]. Al-Si alloys have presented high potential to be used in automotive, aerospace and mineral industries because of their enhanced properties such as strength, wear resistance, and stiffness [34]. Aluminum matrix composites (AMC) reinforced with ceramic particles or fibers have also been widely investigated to obtain higher specific modulus and strength, as compared with conventional alloys. It has been found that on increasing ceramic particles size or volume, AMCs exhibit higher wear resistance in applications such as automotive brake rotors, pistons, cylinder liners, and turbine compressors. However, wear resistance cannot be considered to be a core material property of these kinds of composites [34]. 
Reducing the friction between two surfaces can be achieved by introducing an intermediate lubricating layer, which effectively separates the two metals [35]. Most metals like aluminum get oxidized in air and create a thin oxide layer with 1 to $10 \mathrm{~nm}$ thickness [36]. This oxide layer creates a natural lubricant by allowing shear between metal contacts under low applied load, presenting features of low shear strength and ductility, resulting in low friction between the surfaces $[36,37,38]$. However, the layer becomes damaged under high loads, resulting in higher wear rate and coefficient of friction [36]. Since aluminum is a soft metal, its intrinsic properties do not present good wear resistance, and the high coefficient of friction can be attributed to the high contact area and small elastic recovery [36]. In order to keep the lubricating characteristics of oxide film, pure aluminum must be converted into an alloy or an additive should be used, which could provide improved lubrication while maintaining or improving the wear resistance. Surface engineering and solid lubricant addition to aluminum have been used for the same purpose. The addition of boron nitride (h-BN) to $\mathrm{Al}$ demonstrated that h-BN particles with size of $30 \mu \mathrm{m}$ and concentration up to $10 \%$, presents a wear rate decrease of $25 \%$ in comparison with pure grease [39]. Likewise, $5 \mathrm{wt} \%$ graphite resulted in a reduction in COF in the 7075 Aluminum matrix, while enhancing wear resistance with increments in sliding distance [40]. Some other researchers have demonstrated the formation of the lubricious tribofilm on the sliding surface, preventing surface damage and reducing wear and friction on aluminum alloys such as 6061 [41] and Al-Si [42]. 


\section{TABLE 2.1. Aluminum Applications in the Automotive Industry [33].}

Aluminum Applications in the Automotive Industry (1993 North American Car)

Powertrain (Casting)

Pistons $(100 \%)$

Engine blocks (19\%), oil pans, engine cover, water pumps

Cylinder heads $(75 \%)$

Intake manifolds $(85 \%)$

Transmission: cases $(100 \%)$, valve bodies,

and channel plates $(90 \%)$; rear axle and

differential housings; driveshafts

Chassis (castings)

Wheels $(40 \%)$

Brackets

Brake components: master brake cylinders

Suspension: control arms, supports

Steering components: air-bag supports, steering shafts, wheels

knuckles, housings

Instrument panels

Electric motor, alternator, and pump housings

Chassis (wrought)

Wheels

Heat shields

Bumper reinforcements

Body (wrought)

Hoods $(9 \%)$

Hoods, front fenders, and doors

Body structure

Air conditioning (wrought)

Condensers, evaporators/compressors (90\%)

Heater cores, radiators $(72 \%)$

\section{2D materials as Solid Lubricants}

Solid lubricants are those materials that present very low friction and low wear, when rubbed against another material in the absence of a liquid lubricant [36]. The most studied solid lubricants are graphite and molybdenum disulfide $\left(\mathrm{MoS}_{2}\right)[36,43]$. Both materials present hexagonal layered structures (lamellar structure), in which the atoms 
within each layer are held by strong covalent bonds. The individual layers have significant distances between one another and are held by weak Van der Waals bonding. The interplanar bond energy is about $1 / 10$ to $1 / 100$ of that between atoms within the layers [36]. These two materials share many of solid lubricant's properties, however, in many applications, graphite performs quite superior to $\mathrm{MoS}_{2}$ [43]. Molybdenum disulfide belongs to the family of binary compounds, known as metals dichalcogenides. These metals present excellent self-lubricating properties. Some of these metals are $\mathrm{WS}_{2}, \mathrm{MoSe}_{2}$, $\mathrm{NbSe}_{2}[43,44]$. A brief review of synthesis technique and properties of 2D materials used as solid lubricants is discussed in the following sub-sections.

\subsection{Synthesis Methods of 2D Materials}

In the 1920s, Langmuir introduced the single molecular layer to investigate the airwater interface in a hydrophobic field [45]. Then, Blodgett used the same monomolecular layer method, but this time to study the air-water interface onto solid surfaces [45]. Since then, research regarding monoatomic surfaces has grown for multiple interests in engineering applications, such as corrosion protection, the increasing of wear life in tools and solid lubricants, among others. In accordance with Erdemir [46], the historical development of very thin solid lubricants is composed of three stages (Fig 2.1): (i) the

research of specific material compositions, (ii) the development of the deposition processes, and (iii) the development of successive generations of films. The development of the vacuum deposition techniques, such as plasma vapor deposition (PVD), chemical vapor deposition (CVD), and ion-beam-assisted deposition (IBAD) has made it possible to deposit thin layers with a thickness of a few nanometers [46]. In the application of these 
techniques, the geometrical shape of the powder is conserved and so is the ability to shear $[47,48]$.

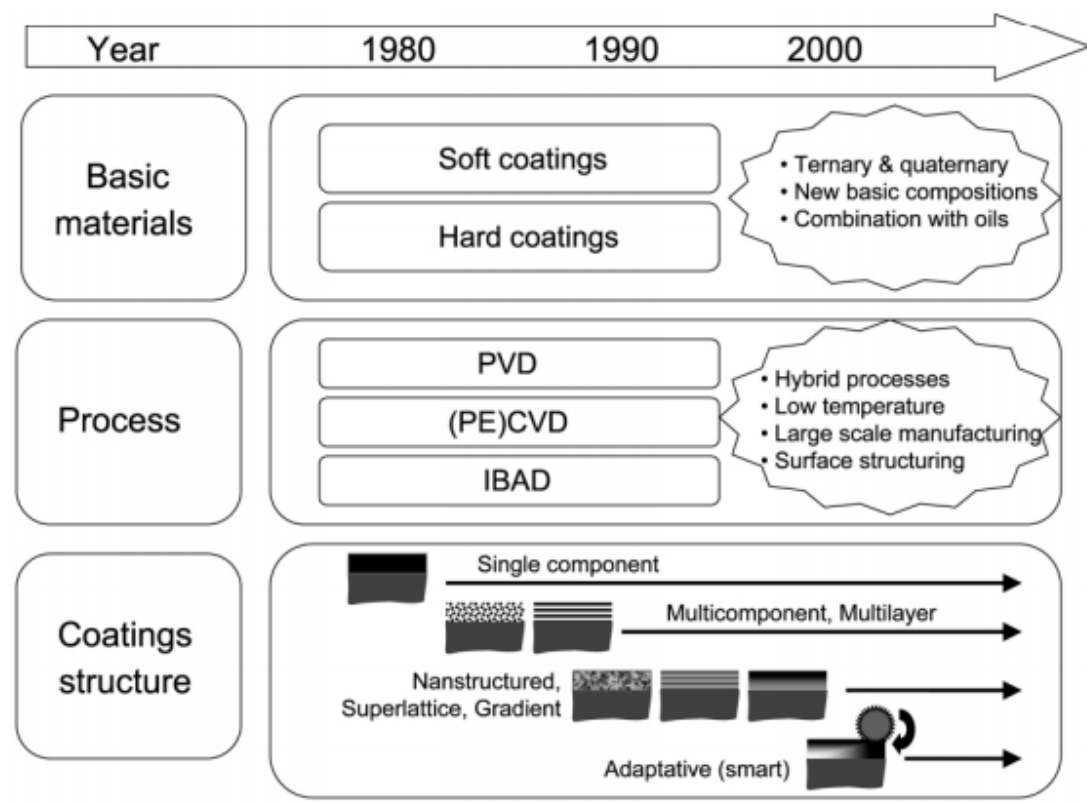

Fig 2.1. Historical Development of Thin Solid Lubricant Films [46]

In principle, the layered structure of $2 \mathrm{D}$ materials is what gives the lubricating feature. This structure is achieved due to the synthesis of 2D sheets, which are largely formed by micromechanical cleavage, chemical exfoliation, chemical vapor deposition, and surface-assisted epitaxial growth [49]. Micromechanical cleavage was initially used to peel off graphene from graphite. This method requires repeatedly peeling off sheets of 1 to 10 atomic layers from the top layer. Nevertheless, this method is not used for large-scale synthesis due to poor yield. Chemical exfoliation is another synthesis process, which involves sonication of layered bulk materials in polar solvents, resulting in separation into thin layers by centrifugal forces. This method is used for large scale synthesis of 2D materials. The third method is chemical vapor deposition (CVD), which allows the 
production of 2D materials by high-temperature chemical reactions of molecular precursors on a surface. This method also has limitations for large scale production. The fourth method, which is surface-assisted epitaxial growth, is a modification of the CVD method. Here, the substrate surface serves as a seed crystal other than a template or a catalyst. This method has achieved the formation of monoatomic thick Si sheets [49].

The focus of the present work is on using Graphene and $\mathrm{WS}_{2} 2 \mathrm{D}$ materials as solid lubricant additives to $\mathrm{Al}$ alloy. Hence, a brief review of Graphene and $\mathrm{WS}_{2}$ is provided in the following sections.

\section{Graphene}

Graphene is a 2D allotrope of carbon consisting of a single sheet of hexagonal arrangements with a pseudo-two-dimensional sp2 bonding (Fig 2.2 b) [50, 51]. The

Bravais lattice of graphene is triangular, where the lattice vector a $\approx 1.42 \AA$ is the nearest distance between carbon-carbon atoms. The hexagonal lattice contains two atoms A and B per unit cell. It consists of two sublattices, where A is surrounded by three atoms from sublattice B, and B is surrounded by three atoms of the lattice A (Fig 2.2 a) [52]. Graphene is an isolated plane or monolayer of graphite (one atom thickness). Although graphite was been used 6000 years ago to decorate pottery, it was in 2004 that one atom sheet of graphene was obtained by peeling graphite off with an adhesive tape [53]. Since then, the unique electronic and physical properties of graphene have been extensively studied for a myriad of application, such as electrical devices, chemical and biological sensors, solid lubricant additives in liquid and solid state, composites and alloys, preventing materials to be corroded, and photovoltaic cells [50]. 
a)

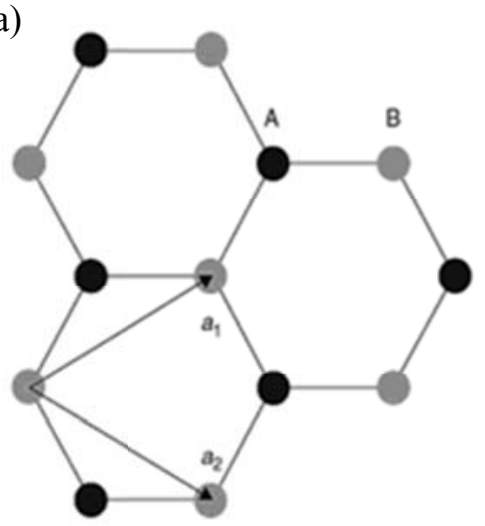

b)

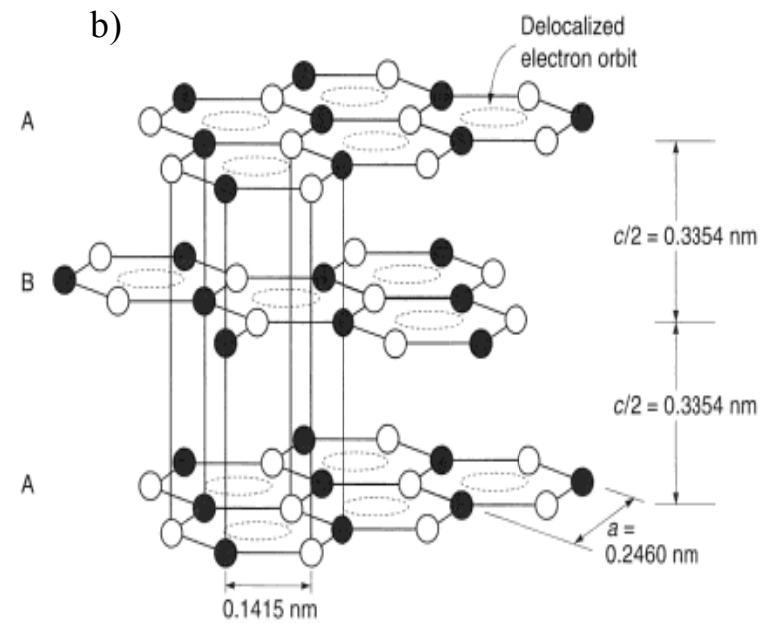

Fig 2.2 a) Graphene Hexagonal Lattice with Sublattices A and B [52] b) Representation of Hexagonal Layered Structure of Graphite Showing Three Staggered Layers [36]

The theoretical density of graphene is $1.822 \mathrm{~g} / \mathrm{cm}^{3}$ with a very high Young's modulus $(0.5-1 \mathrm{TPa})$ and tensile strength $(130 \mathrm{GPa})$ in the planar direction [54]. These properties of graphene make it an ideal reinforcement for light-weight and high-strength composite materials. Graphene nanoplatelets (GNPs) are another version of graphene, which consist of approximately $20-30$ graphene sheets with a thickness of 5-10 nm [18]. GNPs present hydrogen or covalent bonding capability on the edges of the platelets; allowing them to present enhancement barrier properties and excellent mechanical properties, such as stiffness, strength, and surface hardness [55]. In addition, these nanoplatelets have shown excellent performance in electrical and thermal applications due to their carbon-carbon composition. The multilayer structure of GPNs makes them very useful for tribological applications and ideal as additives with metals [56], polymers [57], and ceramics [58]. GNPs retain several of graphene's unique properties and provide a lowcost alternative for development of novel materials and composites. Some of the 
theoretical properties of GNPs that have been previously measured are: the tensile modulus $(1000 \mathrm{GPa})$, the tensile strength $(5 \mathrm{GPa})$, and the electrical conductivity $\left(10^{7} \mathrm{Siemens} / \mathrm{m}\right)$ measured parallel to the surface [55]. These mechanical properties allow GNPs to improve barrier properties and scratch resistance without reducing toughness. Moreover, the increased thickness of GNPs makes them less prone to agglomeration and entanglement, compared to single layer graphene [19]. GNPs have been explored as lubricants, in both liquid [20] and solid forms [19].

\subsection{Synthesis of Graphene}

The primary methods used to produce graphene in the large-scale are: (i) epitaxial growth of graphene, (ii) chemical vapor deposition (CVD), (iii) chemically derived graphene and (iv) electro-chemical exfoliation.

Epitaxial growth of graphene is used in both semi-conductive and metallic materials that have good lattice matching with the hexagonal structure of graphene [59]. The growth of epitaxial graphene is influenced by thermal decomposition of carbide ( $\mathrm{SiC}$ ), decomposition of hydrocarbon gas on carbide substrates (TiC, TaC, WC, etc.) or metallic substrates $(\mathrm{Ni}, \mathrm{Pt})$, and segregation of the atoms of carbon from the bulk [59]. Epitaxial growth on $\mathrm{SiC}$ is based on thermal decomposition of the $\mathrm{SiC}$ substrate, so, $\mathrm{Si}$ atoms sublimate and the remaining carbon atoms become activated, thus the $\mathrm{C}$-face is fully relaxed and adopts the bulk graphite parameter at the high temperature of $1350^{\circ} \mathrm{C}$. This fact describes the weak interaction between graphite and the SiC substrate due to Van der Waals epitaxy, where the substrate is in charge to orient the epitaxial layer while the lattice parameters remain intact, and the interfaces between $2 \mathrm{D}$ and $3 \mathrm{D}$ materials are free from 
defects $[53,60]$. Graphene has also been grown by decomposition of hydrocarbons, which are compounds made of $\mathrm{C}$ and $\mathrm{H}$ atoms [61]. Some of these hydrocarbons can be found in the natural state from crude oil and natural gas. Others are obtained by synthesis, for instance: $\mathrm{CH}_{4}, \mathrm{C}_{2} \mathrm{H}_{6}, \mathrm{C}_{2} \mathrm{H}_{4}, \mathrm{C}_{3} \mathrm{H}_{6}$, and $\mathrm{C}_{3} \mathrm{H}$ and some plastics. When these hydrocarbons get oxidized, carbon dioxide and water are produced with a significant release of energy; therefore, they are widely used as fuels [62]. 2D bands of monolayer graphene have been successfully obtained by hydrogen intercalation (sublimation of Si from the substrate) and characterized by a honeycomb structure with lattice constant of $2.5 \pm 0.1 \mathrm{~A}^{\circ}[63]$.

Chemical vapor deposition (CVD) has become the most promising method to grow graphene. Since 2006, when the first successful monolayer of graphene was obtained by CVD, this process has been widely explored and it was subdivided into three categories, thermal CVD, plasma enhanced CVD, and thermal decomposition on $\mathrm{SiC}$ and other substrates [53]. The first subdivision can be made with high carbon solubility $(>0.1$ atomic $\%)$ and low carbon solubility $(<0.001$ atomic $\%)$. The growth mechanism of graphene with high carbon solubility utilizes substrates, such as Co and Ni. The process works through the diffusion of the carbon into the metal; a thin film of carbon goes out of the bulk metal during the cooling. A typical CVD process is performed using $\mathrm{Ni}$ as a substrate. In this case, carbon is dissolved into nickel substrate, and finally the carbon is precipitated on the substrate by cooling. The characteristics of the process include a CVD chamber, where the Ni substrate is placed at a vacuum of $10^{-3}$ Torr with a temperature $<1000{ }^{\circ} \mathrm{C}$, while the hydrocarbon gas is diluted. Similar to the carburization process, CVD starts with the diffusion of a specific number of carbon atoms into the Ni substrate at low temperatures [53]. The second subdivision of CVD is plasma enhanced CVD deposition (PECVD), 
which offers another way of acquiring thin layered graphene. The first use of PECVD successfully obtained ultrathin sheet-like carbon nanostructure by synthesizing $\mathrm{CH}_{4}$ diluted in $\mathrm{H}_{2}$ by radio-frequency plasma. These graphene sheets were produced from a gas mixture of 5-100\% $\mathrm{CH}_{4}$ in $\mathrm{H}_{2}$ atmosphere while varying the temperature of the substrate from 600 $900^{\circ} \mathrm{C}$ [64]. The last subdivision of CVD, called thermal decomposition on $\mathrm{SiC}$ and other substrates, is commonly preferred for the semiconductor industry. The $\mathrm{SiC}$ substrate is heated under ultrahigh vacuum (UHV). Silicon atoms are extracted from the substrate. The removal of Si allows the formation of carbon surface into graphene layers. Depending on time and temperature (approximately $1200^{\circ} \mathrm{C}$ ), the thin thickness of graphene layers is obtained. Vapor phase annealing has shown improvement on the homogeneity of the few graphene layers, typically at $400{ }^{\circ} \mathrm{C}$ above of ultrahigh vacuum temperature [53].

Graphene is also synthesized by reduction of Graphene oxide (GO), which is a chemically derived compound from carbon molecules and oxidizers [53]. Graphite oxide was first prepared almost 150 years ago, by replacing graphite for a mixture of potassium chlorate and nitric acid [65]. Years later, Hummers and Offemann developed a much safer mixture of sodium nitrate, potassium permanganate and concentrated sulfuric acid to grow GO $[50,65,66]$. Hummers' method is broadly used in laboratories nowadays. Graphite oxide is similar to graphite from the chemical properties' point of view (carbonaceous), however, is worth noting that the structures are different $[50,53]$. Different methods have been used for reduction of graphene oxide, including hydrazine, and sodium borohydrate. The first mentioned method, hydrate, demonstrated excellent results in the production of very thin sheets. During the reduction process, the hydrazine does not react with water and the reduced sheets are precipitated; the color of the dispersed graphene oxide goes from 
brown to black, thus removing oxygen, the reduced graphene oxide becomes less hydrophilic [53].

The mechanical exfoliation process could be the simplest of all processes to synthesize graphene. It arises from the fact that graphene layers are held by weak interlayer Van der Waals forces. The interlayer Van der Waals energy $2 \mathrm{eV} / \mathrm{nm}$, which translates to a force of $300 \mathrm{nN} / \mu \mathrm{m}^{2}$ necessarily exfoliates or isolates a monolayer of graphene [67]. This $\left(300 \mathrm{n} \mathrm{N} / \mu \mathrm{m}^{2}\right.$ ) was the same required force by the adhesive-tape process in 2004 , when the first graphene layer was obtained [53]. Mechanical exfoliation techniques have been able to extract $\sim 10$ micron graphene flakes [68]. Therefore, this process is commonly preferred for electronic applications and devices as it readily provides high quality of a single layered graphene [67]. However, despite all investigations, even nowadays, the production of highquality large area monolayer graphene remains very challenging.

\subsection{Characterization of Graphene}

Characterizing one atom thick sheets represent an enormous challenge. Various techniques are used in the characterization of graphene, such as transmission electron microscopy (TEM), scanning electron microscopy (SEM), Raman spectroscopy, atomic force microscope (AFM) and X-ray diffraction (XRD). In general, TEM is a technique, which works at the nano and micro scale by using a beam of electrons and transmitting it through an ultra-thin sample. The image is formed when the electrons pass through the specimen and interact with the detector. TEM is a very accurate tool when characterizing graphene. The atomic scale of graphene can be depicted (Fig 2.3). 


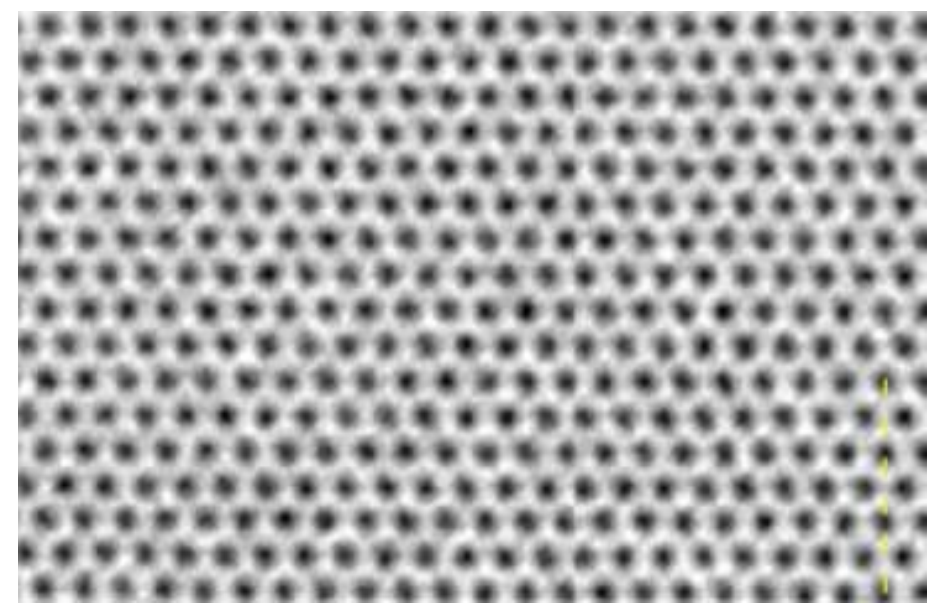

Fig 2.3. Single Layer Graphene Sheet Characterized by TEM [53]

TEM has allowed researchers to appreciate graphene and GNPs dispersion properties with composites [69]. Significant observations of the graphene monolayer of carbon atoms have been reported for TEM. Overlapped GNPs with a thickness of about 20 $\mathrm{nm}$ have been observed between two grains by TEM [70]. The nature of interface bonding between GNP/matrix can be obtained by TEM to understand load transfer behavior between GNPs and the matrix [70]. Also, researchers can observe imperfections and abnormal topology on graphene sheets [53] and the number of layers by using TEM [71]. However, the use of TEM in the atomic scale has the restriction of low operating voltage; otherwise, at high voltage, it can be very harmful to the monolayer [69].

Raman spectroscopy is a very important tool to characterize the structure of graphene, by giving information regarding interactions of phonons and electrons in the material while measuring the wavelength and intensity of light scattered of the molecules. Raman spectra of graphite and a few layers of graphene is shown in Fig. 2.6 a. Typically, Carbon allotropes present three distinguished peaks G $\left(1580 \mathrm{~cm}^{-1}\right), \mathrm{D}\left(1350 \mathrm{~cm}^{-1}\right)$, and 2D 
$\left(2700 \mathrm{~cm}^{-1}\right)[53,73]$. The $\mathrm{G}$ peak $\left(\sim 1580 \mathrm{~cm}^{-1}\right)[53,73,74]$ is the crystallization peak of graphene and arises due to the in plane vibration of the $\mathrm{sp}^{2}$ carbon atoms. The $\mathrm{G}$ peak is present in all carbon materials but the peak intensities and widths can vary. The D peak $\left(\sim 1360 \mathrm{~cm}^{-1}\right)$ is related with defects in the layer and can, therefore, be used to observe damage in the graphene structure [73]. The absence of the D peak implies a high quality single layer defect free graphene. In the G', also called 2D band $\left(\sim 2650 \mathrm{~cm}^{-1}\right)$, intensity decreases with increasing numbers of graphene layers [75]. This 2D peak is the second order of the $\mathrm{D}$ peak. The $2 \mathrm{D}$ peak in bulk graphite consists of two components, $2 \mathrm{D}_{1}$ and $2 D_{2}$, measuring $1 / 4$ and $1 / 2$ the height of the G peak, respectively. An increment in layers leads to a decrease of intensity of the lower frequency $2 \mathrm{D}_{1}$ peaks (Fig $2.4 \mathrm{~b}$ ) [74].

a)

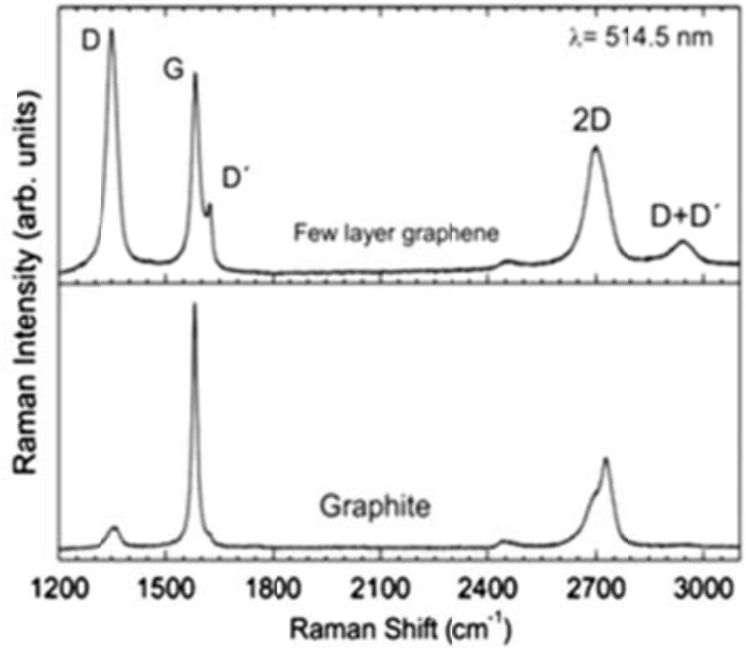

b)

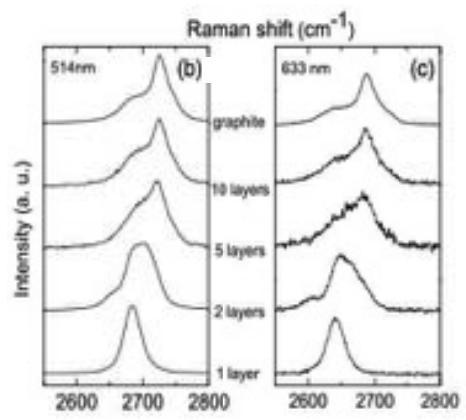

Fig. 2.4. a) Graphite and Graphene few Layered Raman Spectra [73] b) 2D Band Changes with Increment on Layers [74]

The ratio of the intensity of the D peak divided by the intensity of the G peak $(\mathrm{I}(\mathrm{D}) / \mathrm{I}(\mathrm{G}))$ gives a measure of the level of defects in a graphene structure[73, 74]. The intensity ratio of peak (I (2D)/ $/(G)$ ) is almost 4 for single-layer graphene and decreases 
when the number of layers increases $[53,73,74]$. Raman spectroscopy can also provide information about the presence of mechanical strain at the molecular level [76]. Tsoukleri [76] reported that in tension; the $2 \mathrm{D}$ peak decreases with strain and the peak tends to be shifted to the left. In contrast, the peak is shifted to the right side in compression and presents higher frequency than tension.

\subsection{Graphene Nanoplatelets (GNPs)}

Graphene nanoplatelets (GNPs) consist of approximately 20-30 graphene sheets held by week Van der Waal forces and with a thickness of 5-10 $\mathrm{nm}$ [18]. Due to their unique structure, these carbon-based sheets are an excellent representation of 2D materials. GNP presents very high surface area and higher thickness. These two properties allow GNPs to have higher interfacial energy and make them less prone to agglomeration and entanglement as compared to single layer graphene. [19]. Due to their high surface area, these platelet-like sheets also presents strong interfacial bonding, making GNPs an excellent nano filler in composite with a very tough bonding mechanism. An astonishing property of $2 \mathrm{D}$ materials is the high strength connection due to the high surface area. This ability provides higher resistance when propagating cracks in comparison with 1D materials. The increased area of GNPs is effective under applied load, meaning the shear force needed to pull a GNP layer out has to be higher than the amount of force (higher energy) needed for another material (1D for instance). This phenomenon can be understood as an effective and tougher mechanism to prevent crack propagation.

Recent studies have posed fundamental questions like how friction behavior depends on the number of graphene layers. That is why GNPs are being explored as 
lubricants, both in liquid [20] and solid states [19,77]. Wenzheng et al. [77] revealed that the addition of small amounts of GNPs in the $\mathrm{Ni}_{3} \mathrm{Al}$ matrix composite helps to radically reduce the friction coefficient and wear rate at both room and high temperatures $\left(400^{\circ} \mathrm{C}\right)$. Also, the authors explained that the ability of GNPs sheets to slip easily provides a source of stress dissipation. Moreover, GNPs create a protective layer while sliding. This protective layer leads to the reduction of wear rate as well as the friction coefficient [77].

The 2D nature of GNP also enables an easier dispersion and processing, as compared to their 1D counterpart carbon nanotubes. Some studies have even shown that the easy-dispersion characteristic of GNPs works as an excellent stress dissipator by creating a smooth worn surface and randomly disperses GNPs on this worn surface during tribological tests [77]. The stress concentrates along the edge of the wrinkles and folds during the sliding process, so the initial shape with wrinkles becomes a laminated-like shape. This characteristic combined with enough thickness, allows GNPs to avoid becoming curled up or rolled up into CNT-like tubes, as occurs with single-layer graphene. The 2D nature of graphene also benefits during sintering processes that employ high pressures. During the high-pressure sintering process, these 2D materials get oriented in one direction during axial compression while reorienting the sheets before the fracture with minimum damage. Andy et al [78] found that GNPs endured the spark plasma sintering (SPS) process at a very high temperature of $1850{ }^{\circ} \mathrm{C}$ and a pressure of $80 \mathrm{MPa}$, presenting minimum damage to the structure [78]. GNPs are much cheaper and easier to consolidate than single-layer graphene, but still exhibit many of the amazing properties of graphene. 


\section{Tungsten Disulfide $\left(\mathrm{WS}_{2}\right)$}

Tungsten disulfide $\left(\mathrm{WS}_{2}\right)$ is a transition metal made up of $\mathrm{WS}_{2}$ sheets. These sheets are characterized by an S-W-S sandwich-like structure, in which the elements form a hexagonal crystal structure. The adjacent layers along [ $\left[\begin{array}{lll}0 & 0 & 1\end{array}\right]$ direction are held by weak Van der Waals forces, while the bonding between the same elements is characterized to be a strong covalent interaction $[79,80]$. $\mathrm{WS}_{2}$ 's lamellar structure is characterized by a silvery-gray-black color, a space group $\mathrm{P}_{3} / \mathrm{mmc}$ and parameters $\mathrm{a}=3.154 \AA$ and $\mathrm{c}=12.362$ $\AA$ A (Fig 2.5) at room temperature conditions [80]. This anisotropic material has shown high potential in applications such as catalysis, lithium batteries, photoconductors and semiconductors, shock absorbers, solar cell films, wet and solid lubricants [80, 81]. Selvi [80] demonstrated that the $\mathrm{WS}_{2}$ structure is dependent on the pressure, showing an a-axis decrease by $3.8 \%$ and a c-axis decrease by $10.2 \%$ when $25.5 \mathrm{GPa}$ pressure was applied at room temperature. It was concluded that c-direction of the hexagonal structure is much more compressible than the a-direction. It can be explained by analyzing the Van der Waals

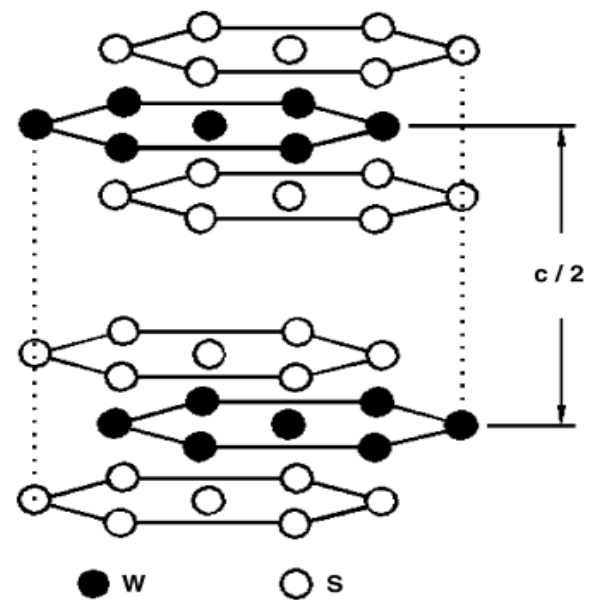

Fig 2.5. CrystalSstructure of $\mathrm{WS}_{2}[80]$ 
bonding at lower pressure. For instance, at 3.3 GPa, Van der Waals bonds are very weak, so it permits larger compression, different from a high pressure, where the force between S-S planes increases due to repulsive forces. This ability has made of $\mathrm{WS}_{2}$ one of the most promising lubricous material ever known. $\mathrm{WS}_{2}$ presents a lower coefficient of friction and improvement in oxidation resistance and thermal stability, even for about $100^{\circ} \mathrm{C}$ above the well-known $\mathrm{MoS}_{2}[82]$.

\subsection{Synthesis of $\mathrm{WS}_{2}$}

The growth of thin-layered $\mathrm{WS}_{2}$ has mainly been performed by different types of exfoliation such as liquid exfoliation mechanical exfoliation [83], exfoliation of bulk [84] and chemical vapor condensation (CVC) [85]. $\mathrm{WS}_{2}$ samples used for this project were grown through liquid exfoliation, where the powder is sonicated in a range of liquid solvents, such as benzyl benzoate, isopropanol, acetone, and methanol. Although metal dichalcogenides can be exfoliated by liquid exfoliation, this is a very time-consuming method, which is extremely sensitive to the environment [86]. Fang [83], obtained singlelayer $\mathrm{WS}_{2}(\sim 0.7 \mathrm{~nm}$ thickness $)$ by mechanical exfoliation from a bulk crystal on $\mathrm{Si} / \mathrm{SiO}_{2}$ substrate. It was noticed that the surface roughness of $\mathrm{WS}_{2}$ is analogous to $\mathrm{Si} / \mathrm{SiO}_{2}$, indicating that the layer is uniform with minimum roughness. This method has also proved successful under vacuum and at high temperatures $\left(750-950^{\circ} \mathrm{C}\right)$, to create a monolayer of $\mathrm{WS}_{2}$ with an area of $\sim 1 \mathrm{~cm}^{2}$ [84]. Other researchers, have obtained nanosheets of $\mathrm{WS}_{2}$ through exfoliation of bulk, in which $\mathrm{WS}_{2}$ powders were sonicated in $\mathrm{N}$ Dimethylformamide (DMF) (Fig 2.6) [87]. 


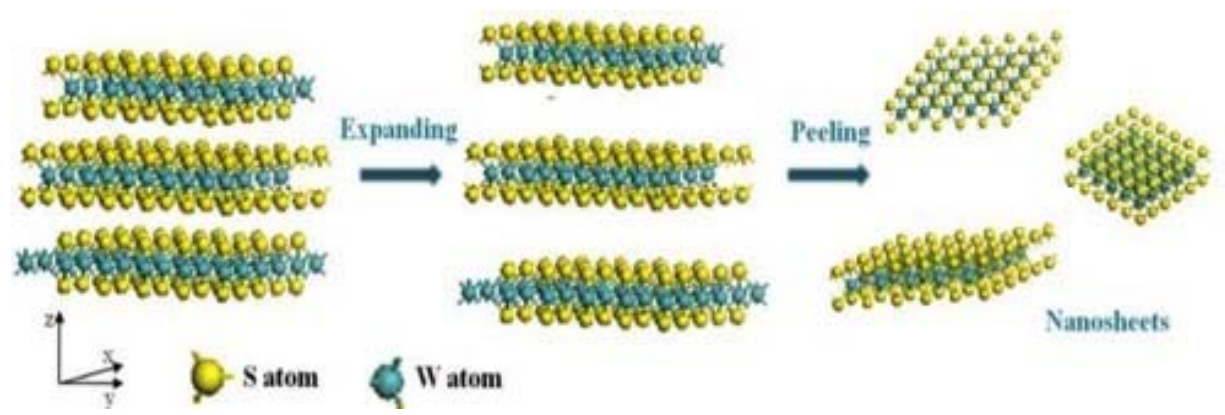

Fig 2.6. Schematic Representation of Exfoliation of $\mathrm{WS}_{2}$ Nanosheets [87]

Gas phase reactions of the chemical vapor condensation process have been used to successfully synthesize $\mathrm{WS}_{2}$ nanosheets. This method has the ability of producing $2 \mathrm{D}$ material with little agglomeration. During this process, the decomposition of tungsten hexacarbonyl $\mathrm{W}(\mathrm{CO})_{6}$ is conducted at temperatures from 420 to $1000^{\circ} \mathrm{C}$; the following is the expression of the decomposition: $\mathrm{W}(\mathrm{CO})_{6} \rightarrow 6 \mathrm{CO}+\mathrm{W}$. The process includes two main zones. In the first zone, the vapor of sulfur is mixed with carbonyl vapor and then this mixture is transferred to the second zone, which has been heated. Here, the carbonyl pyrolysis process takes place. Therefore, the formation of nanopowder is achieved in the sulfur [85].

Ultrathin-film of $\mathrm{WS}_{2}$ can be grown and deposited as well by other techniques like sputtering, pulsed laser deposition (PLD) [88, 89], and chemical bath deposition (CBD) [90]. In 1994, the PLD technique was used to grow single layer $\mathrm{WS}_{2}$. The results showed a high-quality monolayer, fully dense, which presented excellent performance in tribological applications with a low coefficient of friction. Since then, PLD has been widely used for growing $\mathrm{WS}_{2}$ thin layers in coatings [89]. Thin films of $\mathrm{WS}_{2}$ growth by PLD demonstrated only $3 \%$ structural mismatch occurs with the strontium titanate $\mathrm{SrTiO}_{3}$ (STO) 
substrate at temperatures between $200-400^{\circ} \mathrm{C}$ [88]. Hankare [90] successfully obtained thin film of $\mathrm{WS}_{2}(0.35 \mu \mathrm{m})$ by chemical bath deposition in an aqueous alkaline environment, with uniform shape and well adherent characteristics. It is worth noting that in growing polycrystalline films, the substrate plays a major role in the crystal formation. $\mathrm{WS}_{2}$ has a minuscule tolerance for the lattice mismatch. It is not a surprising to end up with an amorphous film of $\mathrm{WS}_{2}$ [88]. In order to characterize the lattice of the film and the defect zones, it is important to know effective characterization tools for $\mathrm{WS}_{2}$.

\subsection{Characterization of $\mathrm{WS}_{2}$}

The techniques used in characterization of $\mathrm{WS}_{2}$ particles are transmission electron microscopy (TEM), X-ray diffraction (XRD), scanning electron microscopy (SEM), Raman spectroscopy, and atomic force microscope (AFM). The typical observation of $\mathrm{WS}_{2}$ through TEM is a $2 \mathrm{D}$ thin flake or nanosheet. Fig 2.7 a shows a $\mathrm{WS}_{2}$ nanosheet with a lateral size of about 100 to $500 \mathrm{~nm}$. Fig $2.7 \mathrm{~b}$ displays the hexagonal structure of $\mathrm{WS}_{2}$ with some defects. Fig 2.7c allows a higher magnification of the structure by using low-pass Butterworth filtering to make the measurement of distance or width of the hexagon which was $3.8 \AA$ [87]. Wang [91] confirmed the formation of the hexagonal structure of $\mathrm{WS}_{2}$ through HRTEM, with a distance equal to $0.276 \mathrm{~nm}$ in (100) plane, and compared with the results obtained from XRD. Another researcher [92] implemented HRTEM to characterize the $\mathrm{WS}_{2}$ solid lubricant coating (Fig 2.8a) and the transfer film formed by $\mathrm{WS}_{2}$ (Fig 2.8b). Randomly oriented $\mathrm{WS}_{2}$ lattice planes were observed in the transfer film, with no evidence of reorientation of the basal planes with the c-axis. It is worth noting that TEM and XRD work conjointly in characterizing $\mathrm{WS}_{2}$-based materials. 

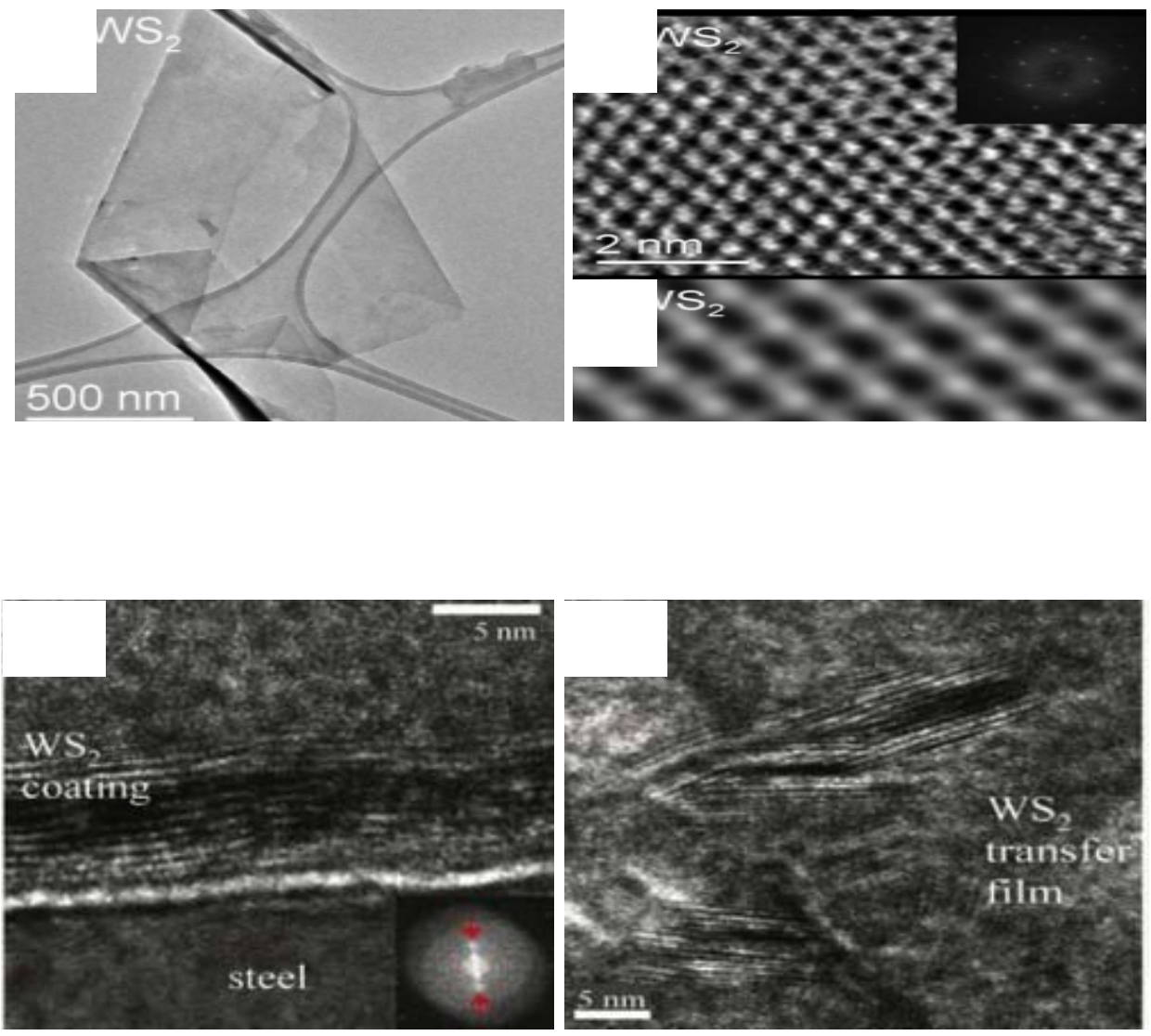

Fig 2.8. HRTEM Image of $\mathrm{WS}_{2}$ a) Orientation in the Coating and b) Random Orientation in the Transfer Film [92]

Wang [81] synthesized $\mathrm{WS}_{2}$ nanosheets $(10 \mathrm{~nm}$ thickness) by the mechanical activation process at different temperatures $\left(500^{\circ} \mathrm{C}, 600^{\circ} \mathrm{C}, 700^{\circ} \mathrm{C}\right.$, and $\left.840^{\circ} \mathrm{C}\right)$, and implemented XRD to characterize and confirm the presence of hexagonal layers. The typical (002) peak was present in all the samples, which reveals the presence of $\mathrm{WS}_{2}$. However, at synthesis temperature greater than $840{ }^{\circ} \mathrm{C}$, the phase $\mathrm{WO}_{2}$ appears due to the lack of sulfur, which is evaporated at high temperature (Fig 2.9). 


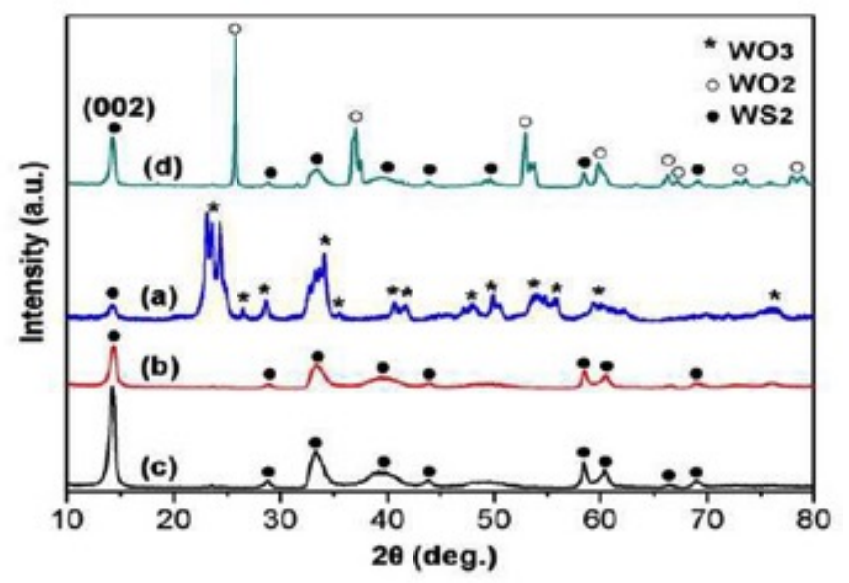

Fig 2.9. XRD of $\mathrm{WS}_{2}$ Obtained at a) $500^{\circ} \mathrm{C}$, b) $600^{\circ} \mathrm{C}$, c) $700^{\circ} \mathrm{C}$, and d) $840^{\circ} \mathrm{C}$ [81]

Raman spectroscopy is another technique used to characterize the structure of the 2D material, such as $\mathrm{WS}_{2}$. The typical Raman spectra obtained from $\mathrm{WS}_{2}$ is depicted in Fig 2.10. $\mathrm{WS}_{2}$ is represented by two main peaks located at $355 \mathrm{~cm}^{-1}$ and $420 \mathrm{~cm}^{-1}$. Tungsten trioxide $\left(\mathrm{WO}_{3}\right)$ shows up with peaks at $715 \mathrm{~cm}^{-1}$ and $809 \mathrm{~cm}^{-1}$ [93].

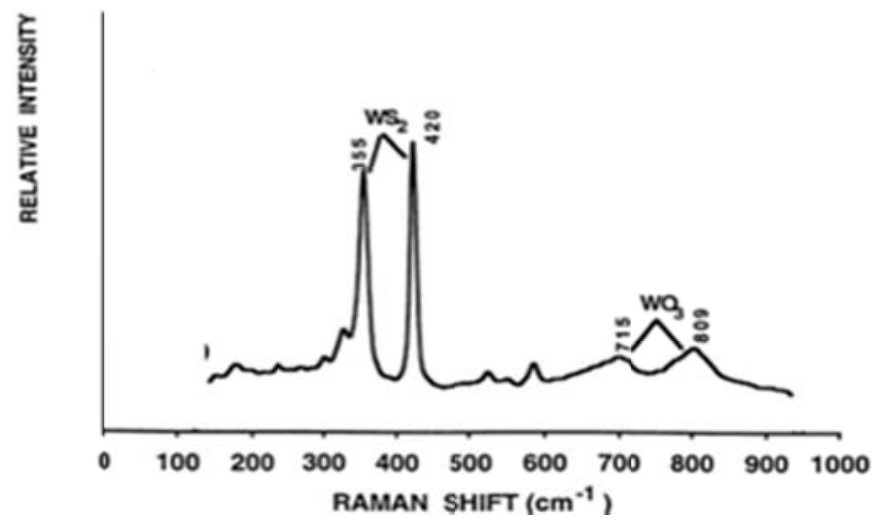

Fig 2.10. Typical Raman Spectra of $\mathrm{WS}_{2}$ on the Transfer Film, after Tribological Test Run at $300^{\circ} \mathrm{C}[93]$

\section{Comparison of GNP and $\mathrm{WS}_{2}$ for Tribological Applications}

Graphene and $\mathrm{WS}_{2}$ are 2D materials, which are well known for their intrinsic properties of wear and coefficient of friction reduction [95, 95]. In order to better 
understand the behavior of these 2D materials under applied force, it is important to know their tribological mechanisms at both the micro and nano scale.

\begin{tabular}{|c|c|c|}
\hline FEATURE & GNP & $\mathbf{W S}_{2}$ \\
\hline Structure & $\begin{array}{l}\text { Monolayer of carbon atoms } \\
\text { arranged in a hexagonal } \\
\text { structure with the } \mathrm{SP}_{2} \text { bounding } \\
\text { between carbon atoms. The } \\
\text { sheets are held with Van de } \\
\text { Waals forces [96] } \\
\text { Consists of approximately } 20- \\
30 \text { graphene sheets with } \\
\text { thickness among } 5-10 \mathrm{~nm}[18]\end{array}$ & $\begin{array}{l}\mathrm{WS}_{2} \text { has crystal structure which is } \\
\text { composed of layers held by weak } \\
\text { interlayer Van der Waals. Bonding } \\
\text { between W-W is covalent, between } \\
\mathrm{S}-\mathrm{S} \text { is covalent and between W-S is } \\
\text { covalent too. The sandwich-like } \\
\text { structures are held by weak Van der } \\
\text { Waals forces [80] }\end{array}$ \\
\hline Characteristics & $\begin{array}{l}\text { - Less prone to agglomeration } \\
\text { in comparison with graphite } \\
\text { [97] } \\
\text { - Excellent corrosion } \\
\text { protection [97] }\end{array}$ & $\begin{array}{l}\text { - Excellent erosion and corrosion } \\
\text { resistances } \\
\text { - High reactivity in humid } \\
\text { environment [23] }\end{array}$ \\
\hline $\begin{array}{l}\text { Pros for } \\
\text { Tribological } \\
\text { applications }\end{array}$ & $\begin{array}{l}\text { - High flexibility and } \\
\text { mechanical stiffness under } \\
\text { applied loads, preventing the } \\
\text { direct contact between } \\
\text { asperities on the steel ball } \\
\text { counterpart and the surfaces } \\
{[98]} \\
\text { - Absorbs energy generated by } \\
\text { compression and shear } \\
\text { during friction sliding [98] }\end{array}$ & $\begin{array}{l}\text { - Formation of thin coating during } \\
\text { wear that helps to increase } \\
\text { durability and wear resistance } \\
\text { - Higher lubricity than Graphite, } \\
\mathrm{MoS}_{2}[26] \\
\text { - Long wear life in dry } \\
\text { environments } \\
\text { - Lubricity capacity can last for } \\
\text { many cycles }\end{array}$ \\
\hline $\begin{array}{l}\text { Cons for } \\
\text { Tribological } \\
\text { applications }\end{array}$ & $\begin{array}{l}\text { - Needs from a } \\
\text { environment to provide } \\
\text { lubrication [20] }\end{array}$ & $\begin{array}{l}\text { - Rapidly degrade in humid } \\
\text { conditions [23] }\end{array}$ \\
\hline
\end{tabular}




\begin{tabular}{|l|l|l|}
\hline & $\begin{array}{l}\text { Easy folding and wrinkling } \\
{[99]}\end{array}$ & $\begin{array}{l}\text { Better tribological performance } \\
\text { in vacuum than in humid } \\
\text { environments [80] }\end{array}$ \\
\hline $\begin{array}{l}\text { Anti-wear } \\
\text { Mechanism }\end{array}$ & $\begin{array}{l}\text { The localized, temporary } \\
\text { warping creates a protective } \\
\text { coating. With fewer layers, the } \\
\text { top layer deflects more, and the } \\
\text { friction per unit rises. The top } \\
\text { surface of the stack becomes } \\
\text { less yielding and more slippery } \\
\text { as graphene layers are added } \\
{[94,98]}\end{array}$ & $\begin{array}{l}\text { Under a shearing force the basal } \\
\text { planes slide back and forth over one } \\
\text { another by intracrystalline slip } \\
\text { creating the transferfilm which } \\
\text { cleaves to the counterface. This } \\
\text { transferfilm provides lower shear } \\
\text { stress between the rubbed surfaces } \\
{[100]}\end{array}$ \\
\hline
\end{tabular}

In the aim of comparing these two solid lubricants, important research has been conducted. As mentioned before, the number of layers is very important for these solid lubricants. In the case of GNP sheets, the ability to easily slip provides a source of stress dissipation and allows GNPs to create a protective layer while sliding [77]. Thus, with fewer layers, the top layer deflects more, and the friction per unit rises. The top surface of the stack becomes less yielding and more slippery as graphene layers are added [98]. The 2D nature of GNP also enables a very easy dispersion that helps GNPs to work as an excellent stress dissipator [77]. Some of the disadvantages of graphene in tribological performance are folding and wrinkling [99]. Another disadvantage, such as free edges, can be reduced in GNPs due to the multilayered structure. Two of the remarkable capabilities of GNPs are the unusual flexibility and the ability of kinking; these two astonishing abilities have never been observed in other atomic-sized carbon materials [99]. Also, the weak interlayer bonds allow slippage when GNPs are kinked, becoming an affective stress releaser during applied load without fracture. Therefore, instead of plastic deformation, GNPs experience layer sliding or layer buckling to reduce the stress. GNPs present two 
important behaviors, which are wrinkling and tearing. Wrinkling is the deflection effect of the thin sheets, and it is unable to recover the initial shape due to insufficient elasticity of the material. On the other hand, tearing is an effect of unusual fracture behavior of GNPs. All those characteristics regarding deformation and fracture behavior can help to better understand anti-wear properties of graphene nanoplatelets. GNPs present unique flexibility and mechanical stiffness under the application of loads. The structure of GNPs works by absorbing the energy generated by compression and shear during frictional performance [98]. A probable explanation for this mechanism is the formation of a protective layer on the sliding contact interfaces. This fact is due to the two dimensional shape of the membrane, which acts a facilitating shear and considerably reduces the wear [20].

$\mathrm{WS}_{2}$ has crystal structure formed by the hexagonal of S-W-S sandwich. These three layers are held by weak interlayer VDWs interactions, while the bonding in-between the layers is covalent $[79,80] . W_{2}$ has excellent tribological properties due to the ability of the layers to slide back and forth by intercrystalline slip under a shear force. This mechanism allows a surface to rub against another surface by creating a smooth transfer film. This transfer film, working in conjunction with the intercrystalline slip of the layers, provides incredible lubricating properties [101]. Some researchers [93, 102] attribute this fact to the assertion that it is a synergistic effect more than lubricating itself. Some other hypotheses have been made to explain the tribological performance of tungsten disulfide. Prasad [93] hypothesized how the crack propagation effect influences the tribological behavior of $\mathrm{WS}_{2}$. A crack in $\mathrm{WS}_{2}$ film will generate a breakdown in the covalent bonds, creating activated surfaces with unsaturated bonds. The formation of these unsaturated bonds accelerates the crack propagation and also leads to the formation of $\mathrm{WO}_{3}$. This 
response of $\mathrm{WO}_{3}$ is due to the dangling bonds of $\mathrm{WS}_{2}$ when reacting with oxygen. It has been proved that the presence of $\mathrm{WO}_{3}$ highly affects the friction coefficient during tribological performance at room temperature [23]. Prasad [95] and coworkers explained that hard particles, randomly distributed in the $\mathrm{WS}_{2}$ substrate, are able to deflect or end crack propagation. Thus, an excellent opportunity to improve the performance of the solid lubricant is through the formation of secondary phase protrusions, which provides the growth of microscopic reservoirs of the solid lubricant improving the quality and life of the transfer film.

The growing demand for reducing friction makes graphene and $\mathrm{WS}_{2}$ composite materials a target-research for materials engineers. It is important to understand the tribological mechanism at the nanoscale as well. By exploring the entire range of available tensile orientations in graphene, it is found that this material presents a quasi-isotropic behavior for all tensile angles. This behavior is different from fracture response, where graphene behaves anisotropic [103]. It is worth noting that GNPs tend to align perpendicularly to the pressure, resulting in anisotropic mechanical properties of composites [104]. It has been demonstrated that the structure of graphene is unstable due to the atomic thickness [105], however, the sp2 bonding in graphene yields to effective lubricating properties of easy shearing and delamination of the $2 \mathrm{D}$ graphene planes. By observing the atomistic thickness of the layer, it is possible to explain the microscopic origin of friction and tribological properties of graphene. Mechanical energy is the beginning of the tribological process, and here the interfacial forces play a main role. Thus, it is demonstrated that the friction behaves differently for one layer than for multilayergraphene, showing that the higher friction on 1 layer could be caused by higher interfacial 
forces as compared with 2 or multi layered graphene [51]. When the counterpart exerts compressional force on the graphene layer, the energy between counterpart and graphene is higher than the energy between graphene layers, this effect leads to the attachment of the top layer with the counterpart, forming a conformal layer around it [106].

At small scale $\mathrm{WS}_{2}$ tribological behavior is explained by the crystal reorientation of the layers, forming the transfer film on the counterpart and providing long wear life and lowering friction coefficient $[100,107]$. When pressure is exerted on a $\mathrm{WS}_{2}$ layer, the cdirection of the hexagonal structure is much more compressible than the a-direction, where c-direction is the distance reduction between S-S planes. It can be explained by analyzing the Van der Waal bonding at lower pressure. For instance at $3.3 \mathrm{GPa}$, the Van der Waals bond is very weak. It permits larger compression different from a high pressure where the force between S-S planes increases due to repulsive reaction [80]. It was found that the variation in the flake sizes of $\mathrm{WS}_{2}$ layers can make a difference in tribological properties. It has been observed, that in different conditions such as high pressure or high temperature, nanoparticles of $\mathrm{WS}_{2}$ react with the metal substrate generating a thick tribofilm. These nano-particles fill the gaps and disperse themselves through the reacted tribofilm, and reduce the friction at the boundaries [108].

Both materials graphene and $\mathrm{WS}_{2}$ present intrinsic properties as solid lubricants. However, it is important to notice a big difference between them. $\mathrm{WS}_{2}$ works as an effective lubricant in air, inert gases, and high vacuum over a wide temperature range $\left(-190^{\circ} \mathrm{C}\right.$ to over $800^{\circ} \mathrm{C}$ ). This fact, represents and advantage over graphene, which losses its low 
friction properties in environments in absence of condensable vapors or water [80]. However, $\mathrm{WS}_{2}$ in humid conditions forms $\mathrm{WO}_{3}$ and degrades its tribological behavior.

The next chapter discusses experimental procedures to synthesize GNP and $\mathrm{WS}_{2}$ reinforced aluminum composites and their tribological behavior. 


\section{CHAPTER III: EXPERIMENTAL METHODS}

In this chapter, the experimental methods of the preparation and consolidation of powders, tribological testing and characterization of the samples is described. The spark plasma sintering process (SPS) is utilized to consolidate aluminum composites with 2D additives such as GNP and $\mathrm{WS}_{2}$. The tribological tests are conducted at room and high temperature $\left(200^{\circ} \mathrm{C}\right)$. Microstructural characterization of the powder, composite and post wear samples is performed at every stage using different methods such optical microscope (OM), scanning electron microscope (SEM), electron diffraction spectroscopy (EDS), Xray diffraction (XRD), Raman spectroscopy and transmission electron microscope (TEM).

\section{Powders}

Spherical atomized aluminum powder (H3, Valimet Inc., Stockton, CA, USA) with an average particle size of $2-10.5$ microns and purity greater than $99.7 \mathrm{wt} . \%$ was used as the matrix material and control sample. Fig $3.1(a, b)$ show SEM images of the appearance of the as-received $\mathrm{H} 3$ aluminum powder at low and high magnification.
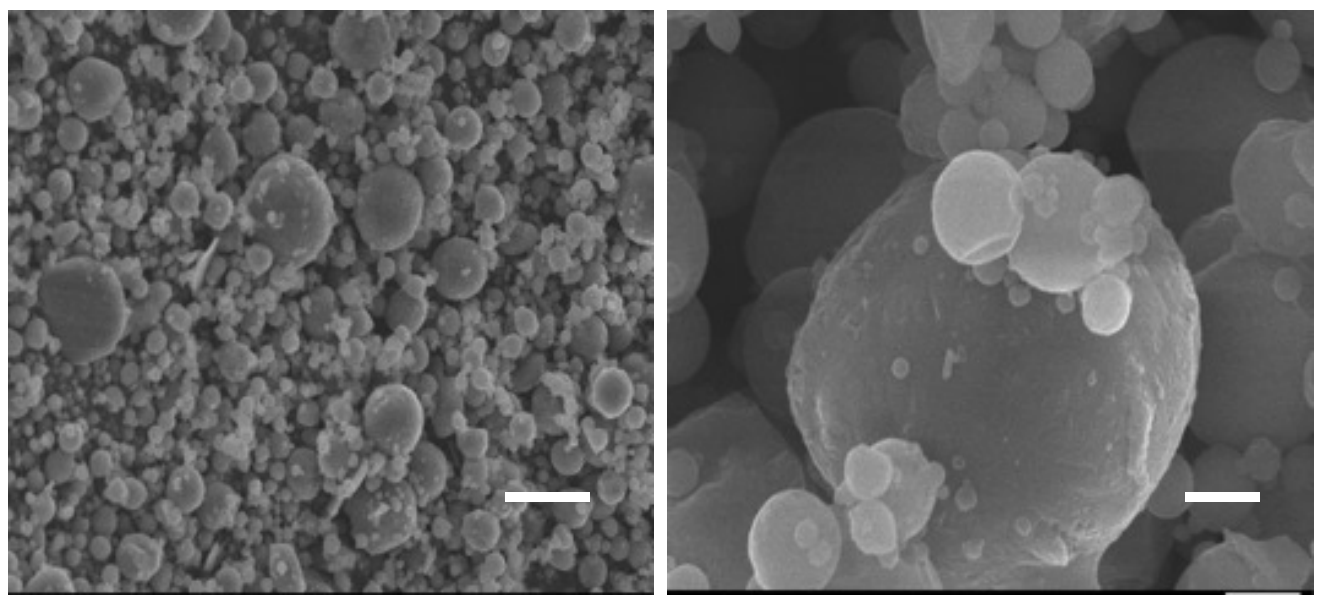

Fig 3.1. SEM Image of As-received Aluminum Powder at a) Low and b) High Magnification. 
Graphene nanoplatelets ((xGNP-M-5)) were obtained from XG Sciences, Lansing, MI, USA. The GNPs have a thickness of 6-8 nanometers with and average diameter of about 15 microns and the average platelet consists of 20 graphene sheets (Fig 3.2).
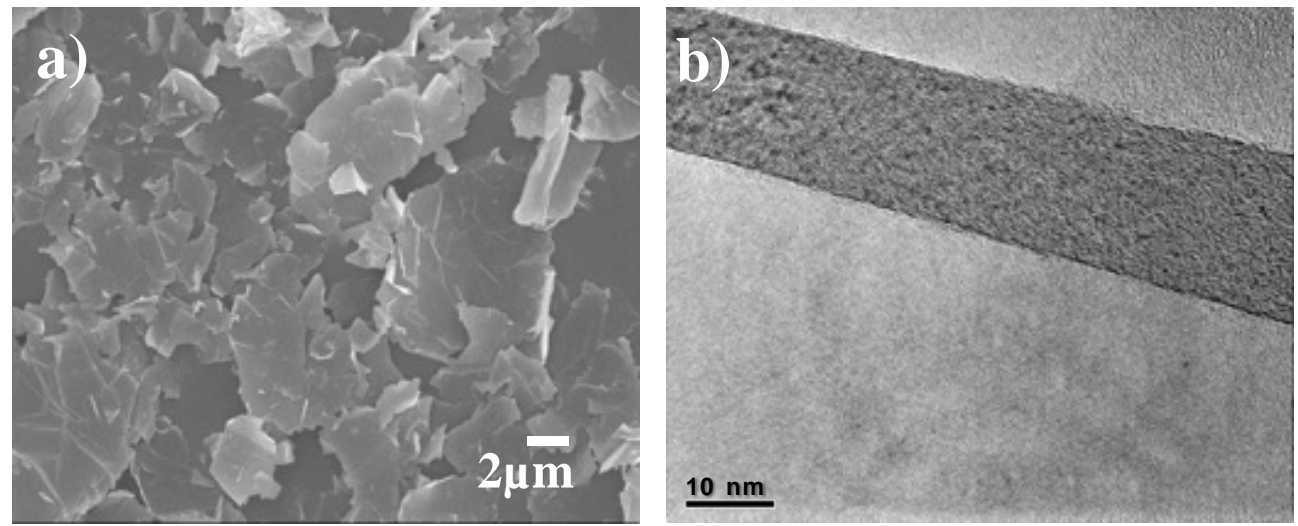

Fig 3.2. a) SEM Image and b) TEM Image of as Received Graphene Nanoplatelet Powder

Nano-powder of tungsten disulfide $\left(\mathrm{WS}_{2}\right)$ was obtained from Graphene Supermarket, USA. Preliminary characterization of nano- $\mathrm{WS}_{2}$ powder as received is obtained by SEM (Fig 3.3a). The nano-powder used in this study has an average size of 90 $\mathrm{nm}$ with hexagonal morphology. The average surface area of nano- $\mathrm{WS}_{2}$ particles is $\sim 30$ $\mathrm{m}^{2} / \mathrm{g}$ with a true density of $7.5 \mathrm{~g} / \mathrm{cm}^{3}[18]$.
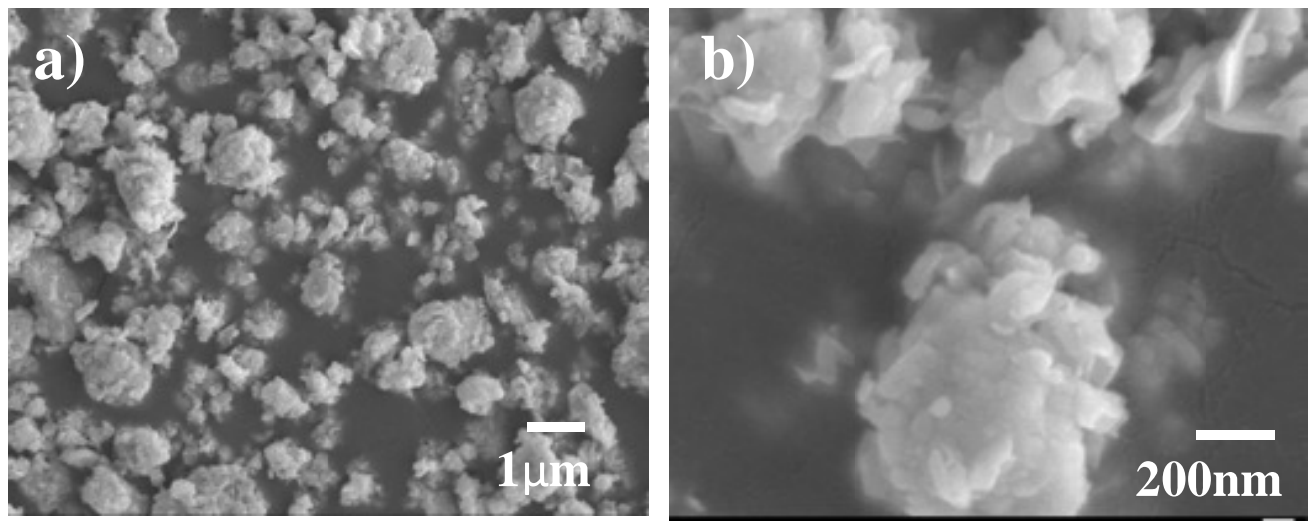

Fig 3.3. SEM Image of as Received $\mathrm{WS}_{2}$ Powder at a) Low and b) High Magnification 
Our objective was to synthesize powders containing 2 vol.\% of $2 \mathrm{D}$ additives to $\mathrm{Al}$ powder. The powders were mixed by the wet chemistry technique. Pure Al powder was added to acetone and ultrasonicated for 90 minutes using Branson 3510 Ultrasonic Cleaner. Similarly, GNPs and $\mathrm{WS}_{2}$ powders were added to acetone and sonicated in two different beakers for 90 minutes. The amount of GNP, $\mathrm{WS}_{2}$ and $\mathrm{Al}$ powders added were computed to result in 2 vol.\% composite. After sonication of GNP and $\mathrm{WS}_{2}$, the slurries were respectively added to the separate beakers containing sonicated Al powder. Al-GNP and $\mathrm{Al}-\mathrm{WS}_{2}$ slurries were further sonicated for 60 minutes. Three mixtures pure Al, Al-2 vol.\% GNP, and Al-2 vol.\% $\mathrm{WS}_{2}$ slurries were put into oven at $75^{\circ} \mathrm{C}$ for 24 hours for drying.

\section{Spark Plasma Sintering}

Sintering is a fundamental process in which the powder is compacted. During spark plasma sintering, an electric pulse is conducted through the powder while exerting compression in a graphite die, providing high densification in a very short time $[109,110]$. The significant advantage of SPS is the fast heating rate and uniform heating condition with significant saving of time during densification, which allows retention of the nanosized grains reducing coarsening.

During this study, the mixed powders were consolidated at Oklahoma State University (OK, USA), using a Spark Plasma Sintering 10-3 model. The consolidation was carried out in a $20 \mathrm{~mm}$ diameter graphite die using a holding pressure of $50 \mathrm{MPa}$. The maximum temperature used during sintering was of $500{ }^{\circ} \mathrm{C}$ with a holding time of 10 minutes. A heating rate of $50^{\circ} \mathrm{C} / \mathrm{min}$ in vacuum was used. The consolidated samples were cooled in the furnace. 


\section{Characterization}

The characterization process has been made by three steps which are (i) density measurements, (ii) microstructural and chemical composition and (iii) phase identification. Density Measurement: The density of a powder and sintered composite was measured using AccuPyc II 1340 Series Pycnometer utilizing Helium gas. Helium atoms fill the vacancies and pores up to $2 \AA$ providing more accurate results $[111,112]$. The density obtained via helium pycnometer was qualitatively compared using image analysis technique from the polished cross-section of the sintered compacts.

Microstructure and Chemical Composition: The cross-sections of the sintered samples were grinded and metallographically polished up to $0.5 \mu \mathrm{m}$ alumina powder. A Buehler Versamet 3 Optical Microscope was used to observe the cross-sectional microstructure and the sub-surface formed after wear test. Scanning electron microscopy (JEOL JSM-633OF field emission scanning electron microscope (FE-SEM)) with an operating voltage of $15 \mathrm{kV}$ was used to characterize the powders, microstructure of the sintered pellet and the fracture surfaces. A combination of low and high magnification SEM images provided information about dispersion of the additives into the matrix and morphology of the 2D GNPs and $\mathrm{WS}_{2}$ additives. Also, these images allow to identify how these additives interact with $\mathrm{Al}$ matrix, giving information about grain size and trapped porosity of the sintered samples. Energy-dispersive Spectroscopy (EDS) was carried out using a JEOL JIB 4500 SEM to study the chemical composition and elemental analysis in the sintered composites, as well as analysis of phases formed and oxygen content after wear. 
Phase Identification: X-ray diffraction is a completely non-destructive technique for identification of phases. A D5000 Siemens diffractometer was used for $2 \theta$ scan between 10 and 90 degrees. Scan speed was set at $2 \mathrm{deg} / \mathrm{min}$. The operating voltage and current are $40 \mathrm{kV}$ and $35 \mathrm{~mA}$ respectively. The radiation used is $\mathrm{Cu} \mathrm{K \alpha}$ which has a wavelength of $1.542 \AA$. This technique is used to obtain information about phases present in the powder and pellets and if any phase transformation occurred during SPS.

Raman spectroscopy was used to characterize the structure of graphene and $\mathrm{WS}_{2}$. Raman spectroscopy is a technique where the incident light produces inelastic scattering in which the interaction of phonons and electrons forms the Raman spectra. Micro-Raman spectroscopy analysis was conducted using a Spectra Physics (Model 3900S, California, USA) with Ti-sapphire crystal as the target $(514 \mathrm{~nm})$, a laser power of $18 \mathrm{~mW}$ and a detector

\section{Hardness Measurement}

Hardness of a material provides useful information which can be correlated to its tensile strength, wear resistance, ductility, and other physical characteristics. Hardness of the sintered pellets was measured using Vickers Microhardness tester and a nanoindeter at micro and nano-scale respectively. For the microhardness tests, 100 gram load was used in 15 different attempts and the average was taken. Vickers pyramid hardness number (HV) is calculated as shown in Eqn. (3.1), where $\mathrm{L}$ is the average length of the diagonal of the indent produced in square shape, and $\mathrm{P}$ is the load.

$$
\mathrm{HV}=\frac{1.854 \mathrm{p}}{\mathrm{L}^{2}}
$$


Nanoindentation experiments were carried out using Hysitron TI 900 Triboindenter with a $100 \mathrm{~nm}$ Diamond Berkovich tip. The tip-area calibration was done using a standard fused quartz substrate of known modulus (69.6 GPa). The triboindenter was used in quasistatic indentation mode in order to measure the elastic modulus and hardness of the sintered compacts. Nanoindentations were performed on top surface, a total of 16 indentations were made with separation of $5 \mu \mathrm{m}$ from one another. The indentation process consisted of a 10 second period to reach a load of $1500 \mu \mathrm{N}$, with a holding time of 3 seconds, followed by a 10 second unloading to $0 \mathrm{~N}$. The elastic modulus was calculated from the load-displacement unloading curves using Oliver-Pharr method.

\section{Tribological tests}

Tribological test were conducted in rotative Mode (ASTM G99). The wear tests were conducted using a ball-on-disk tribometer (Nanovea, Irvine, CA), using a static $3 \mathrm{~mm}$ diameter alumina oxide ball as the counter material. Sintered samples rotated at $100 \mathrm{rpm}$ making $4 \mathrm{~mm}$ diameter wear track during a total period of 30 minutes. A normal load of $1 \mathrm{~N}$ was applied. A real-time coefficient of friction was also recorded using LVDT method. Wear tests were conducted at room temperature and $200^{\circ} \mathrm{C}$. High temperature tests were conducted at $200^{\circ} \mathrm{C}$ to better simulate gasoline operated engines [11, 27]. For high temperature conditions a furnace surrounding the sample was preheated until it reaches $200^{\circ} \mathrm{C}$, and subsequently wear tests were started. The initial surface roughness determines the rate at which the asperities from the softer surface are either fractured or deformed during sliding [113]. All samples were polished to obtain very similar surface roughness $(\mathrm{Ra}=0.62-0.69 \mathrm{um})$ prior to wear tests. 


\section{Post Wear Characterization}

After wear, all the tracks were scanned by a noncontact three-dimensional (3-D) optical profilometer PS50 (Nanovea). Wear depth was obtained using a line profile with SPIP software (Image Metrology A/S, Horsholm, Denmark). Five different curves of the cross-section of the wear track are measured. Then, using Origin 6.0 and taking the integral of these curves the average cross-section area of the track and its standard deviation are computed. After getting the average this new cross-sectional area is multiplied by 2.rr. $\mathrm{r}$, where $r$ represents the half of the diameter of the wear track. Thus, the volume loss during wear test is found. Fig 3.4a, b depicts the cross section of the wear scar. Likewise, wear volume was computed and subsequently wear rates.

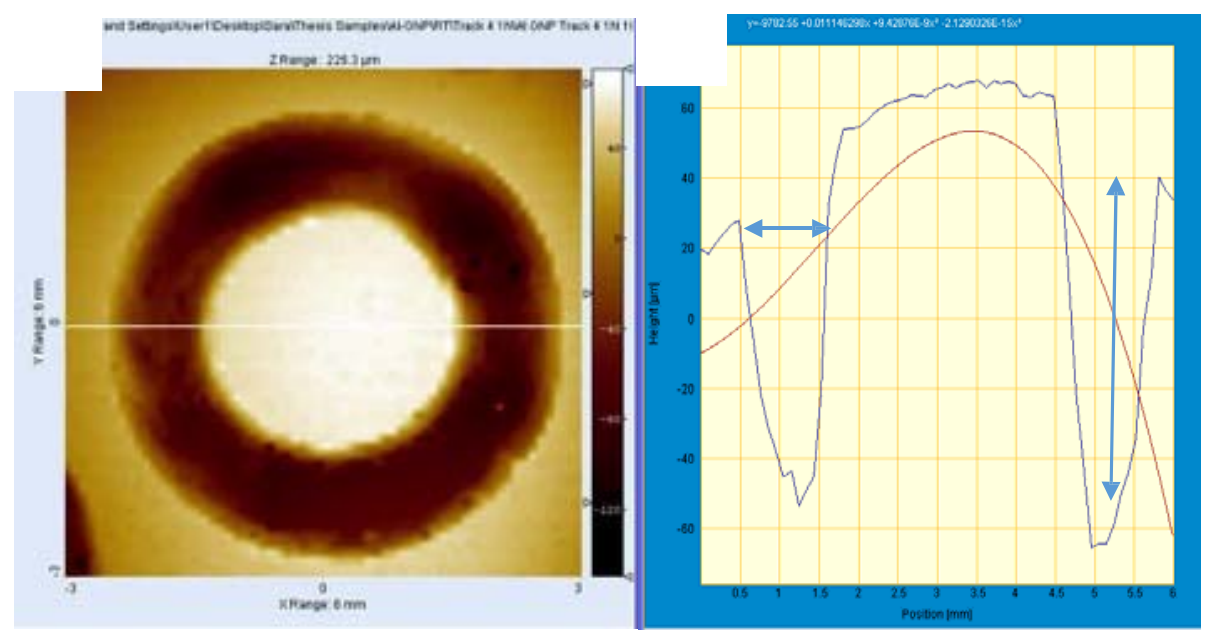

Fig 3.4. a) Wear Track of Al-2vol.\%GNP scanned at RT by Nanovea PS50 Optical Profilometer, b) Cross-sectional area of wear track (width and height are specified)

Each sample is weighed before and after conducting the wear tests, and the weight loss is obtained as well as the sliding distance. All these parameters define the wear rate as shown in Eqn. (3.2), where $\mathrm{V}$ is volume loss $\left(\mathrm{mm}^{3}\right)$, S represents sliding distance $(\mathrm{mm})$ 
and $\mathrm{P}$ is the applied load $(\mathrm{N})$ during wear test. In addition, some other calculations are made to better understand the wear mechanisms of the different samples i.e effective surface area $\left(\mathrm{m}^{2}\right)\left(\right.$ Eqn. (3.3)), where $\mathrm{r}_{\mathrm{i}}$ is the radius of the counterface $\left(\mathrm{Al}_{2} \mathrm{O}_{3}\right.$ ball) and $\mathrm{w}$ is the width (See Fig 3.5), and lateral stress (Pa), where $\mu$ is the average coefficient of friction ( Eqn.

$$
\begin{gathered}
\text { Wear rate }\left[\mathrm{mm}^{3} /(\mathrm{Nmm}]=\frac{\mathrm{V}}{* \mathrm{p}}\right. \\
\text { Effective surface area }\left(\mathrm{E}_{\mathrm{sa}}\right)\left[\mathrm{mm}^{2}\right]=\frac{\mathrm{rr} * \mathrm{r}_{\mathrm{i}} * \frac{\mathrm{w}}{2}}{\mathrm{r}_{\mathrm{i}}}{ }^{2} \\
\text { Lateral stress }[\mathrm{pa}]=\frac{* \mathrm{p}}{\mathrm{E}_{\mathrm{sa}}}
\end{gathered}
$$

JEOL-JIB 4500 Multi Beam Focused Ion Beam (FIB) is a technique used to characterize nanoparticles and observe subsurface. This tool helps to observe the subsurface characteristics, such as crack distribution, crack propagation, formation of the tribofilm and wear mechanisms after tribological test is performed. The use of this tool helps to understand how stress contributes to the formations of the tribofilm and how the grains are deformed and the cracks are distributed due to stress. The way to use this technique is making a trench in the middle of the wear track (Fig 3.5) with ions using tungsten gas nozzles. After protective layer deposition a rough cut was performed by introducing a high dosage of ions $\sim 3000 \mathrm{~Pa}$ and then it was followed by a smooth polish using a lower dosage of ions $\sim 500 \mathrm{~Pa}$. The dimensions of the trenches were $\sim 40 \times 40$ microns. The whole procedure takes about 5 hours and then the cross-section of the wear 
track is exposed and can be characterized using SEM. Fig 3.5 depicts the use of the focused ion beam tool, showing the location of the trench (by the red circle) and also a higher magnification image of it (observe the red arrow). The trench observed in this figure belongs $\mathrm{Al}-2$ vol. $\% \mathrm{WS}_{2}$ sample.
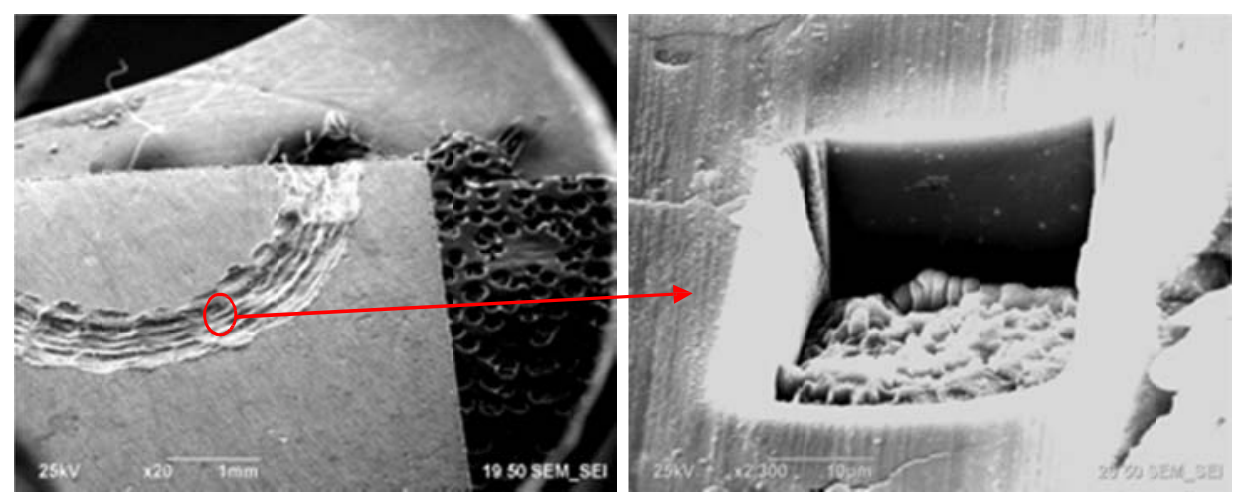

Fig 3.5: FIB Performed on the Surface of the Wear Track

$\mathrm{XRD}$ analysis is performed between 10 and 90 degrees in the $2 \theta$ menu. Scan type is set as locked-coupled and the scan speed is set at $2 \mathrm{deg} / \mathrm{min}$. The operating voltage and current are $40 \mathrm{kV}$ and $35 \mathrm{~mA}$ respectively. The radiation used is $\mathrm{Cu} \mathrm{K} \alpha$ which has a wavelength of $1.542 \AA$. The sample has to fit within the holder and the top of the sample is positioned flat against the pin located in the sample mount. This technique is used to obtain information about phases present in the pellets and any phase transformation occurred during SPS, also this tool helps to visualized if any phase is formed after wear.

Energy-dispersive Spectroscopy (EDS) was carried out using a JEOL JIB 4500. This tool works by bombarding a specimen with an incident electron beam inside of a scanning electron microscope. Qualitative analysis of the results involves identification of wear morphology and prediction of wear mechanism as well as formation of tribolayers. 
Scanning electron microscopy (SEM) is used to characterize the powders, the composites or pellets, the fracture surface of each pellet and the wear track. The equipment implemented was JEOL JSM-633OF field emission scanning electron microscope (FESEM) with an operating voltage of $15 \mathrm{kV}$. After wear, this tool allows the observation of mechanism in charge of wear, formation of tribolayers, formation of cracks and porosity of wear surface. 


\section{CHAPTER IV: RESULTS AND ANALYSIS}

This chapter presents experimental results and discussions on the effect of adding GNP and $\mathrm{WS}_{2}$ as solid lubricant additives to aluminum matrix. The overall microstructure of $\mathrm{Al}, \mathrm{Al}-2$ vol.\% GNP and $\mathrm{Al}-2$ vol.\% $\mathrm{WS}_{2}$ is described in terms of densification, and dispersion of GNP and $\mathrm{WS}_{2}$ in aluminum matrix. The phases present in the composites are characterized by x-ray diffraction and Raman spectroscopy. Subsequently, tribological behavior of $\mathrm{Al}-2$ vol.\% GNP and $\mathrm{Al}-2 \mathrm{vol} . \% \mathrm{WS}_{2}$ is presented in terms of wear rate, and coefficient of friction at room temperature and $200^{\circ} \mathrm{C}$. Wear mechanisms are described in terms of tribolayer formation. Pure aluminum pellet is used as a point of reference for the sake of comparison.

\subsection{Microstructure of Sintered $\mathrm{Al}, \mathrm{Al}-2$ vol.\% $\mathrm{GNP}$ and $\mathrm{Al}-2$ vol. $\% \mathrm{WS}_{2}$}

The overall cross-sectional microstructure of Al, Al-2 vol.\% GNP and Al-2 vol.\% $\mathrm{WS}_{2}$ is shown in low magnification SEM micrographs in Fig 4.1. Pure Al (Fig 4.1a) and Al-2 vol.\% GNP (Fig 4.1b) show sintered spherical aluminum particles with high degree of porosity. However, Al-2 vol.\% $\mathrm{WS}_{2}$ shows a very dense structure with fine $\mathrm{WS}_{2}$ particles homogeneously dispersed in the matrix (Fig 4.1c). The poor density in Al-2 vol.\% GNP is attributed to agglomeration of GNPs in the starting powder which caused a barrier in the sintering. Agglomerated GNPs are observed as long stringers in Fig. 4.1b. The high density of $\mathrm{Al}-2$ vol.\% $\mathrm{WS}_{2}$ sample is attributed to nanosize $\mathrm{WS}_{2}$ powder which tends to fill in the pores between spherical $\mathrm{Al}$ powders resulting in a better packing density due to bimodal powder size distribution. Pure Al displays poor sintering due to large spherical particles which forms small necks during sintering but leaves large trapped pores. 

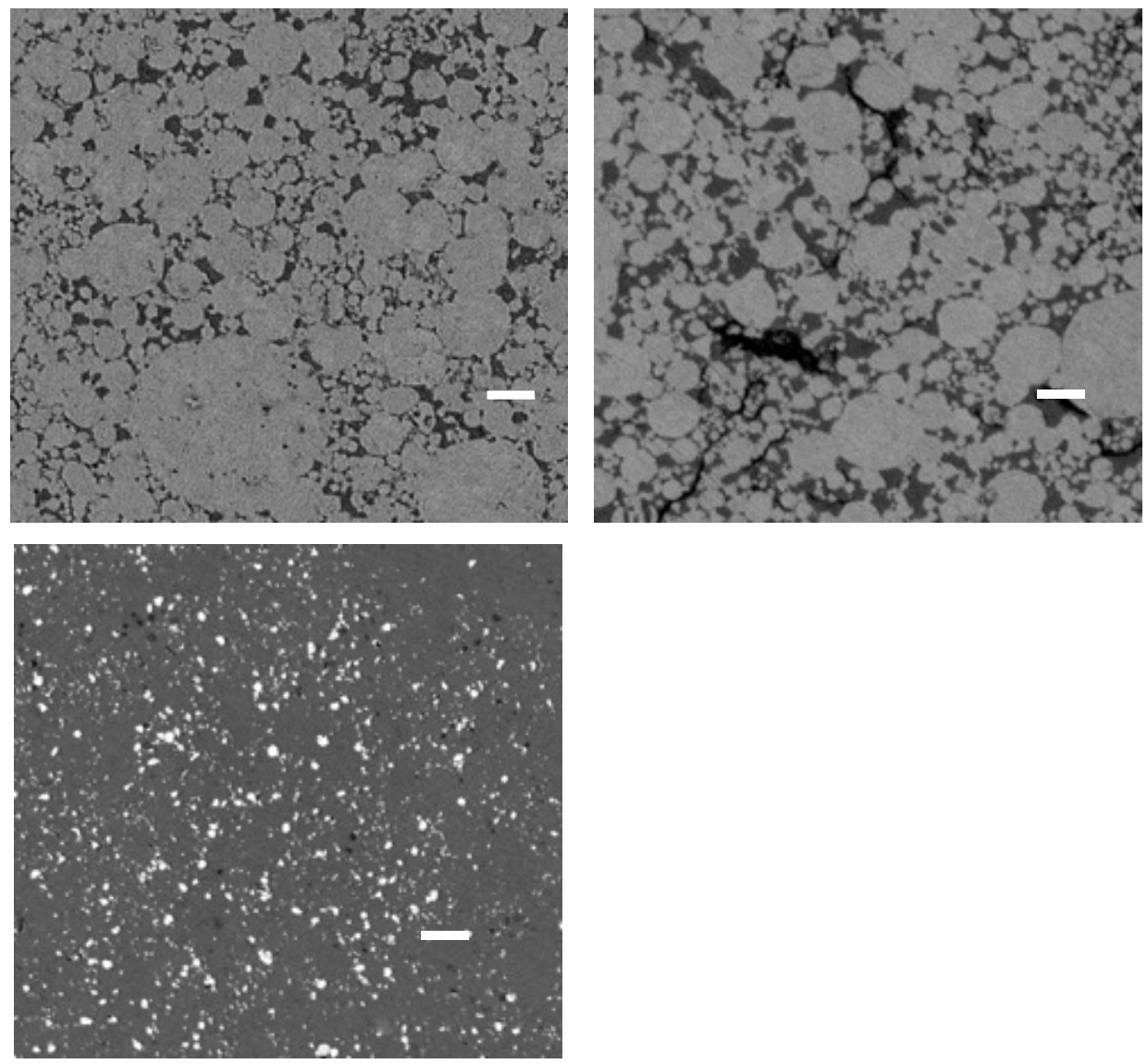

Fig. 4.1. SEM of Cross-section for a) Pure Al, b) Al-2 vol. \% GNP, c) Al-2 vol. $\% \mathrm{WS}_{2}$

A similar phenomenon is observed in fracture surface of three samples as shown in

Fig 4.2. Fig 4.2 a, shows large aluminum spherical particles which are poorly sintered particles. Fig $4.2 \mathrm{~b}$ shows an agglomerated GNP stringer surrounded by poorly sintered aluminum particles. The GNPs are wrinkled and agglomerated. Although the wrinkled structure indicates that GNPs may have experienced damage, it also has the ability to transfer the load to the matrix, leading to stronger interfaces in the sintered sample. However, due to poor sintering of surrounding aluminum particles will results in weak interface. Fig 4.2c is a low magnification SEM image of Al-2 vol.\% $\mathrm{WS}_{2}$ showing highly 
dense structure as compared to pure $\mathrm{Al}$ and $\mathrm{Al}-2$ vol.\% GNP samples. The high magnification image of $\mathrm{Al}-2$ vol.\% $\mathrm{WS}_{2}$ clearly shows $\mathrm{WS}_{2}$ nanoparticles in the void region between $\mathrm{Al}$ particles which leads to denser packing.

Table 4.1 shows the density of sintered pellets and their hardness measured using
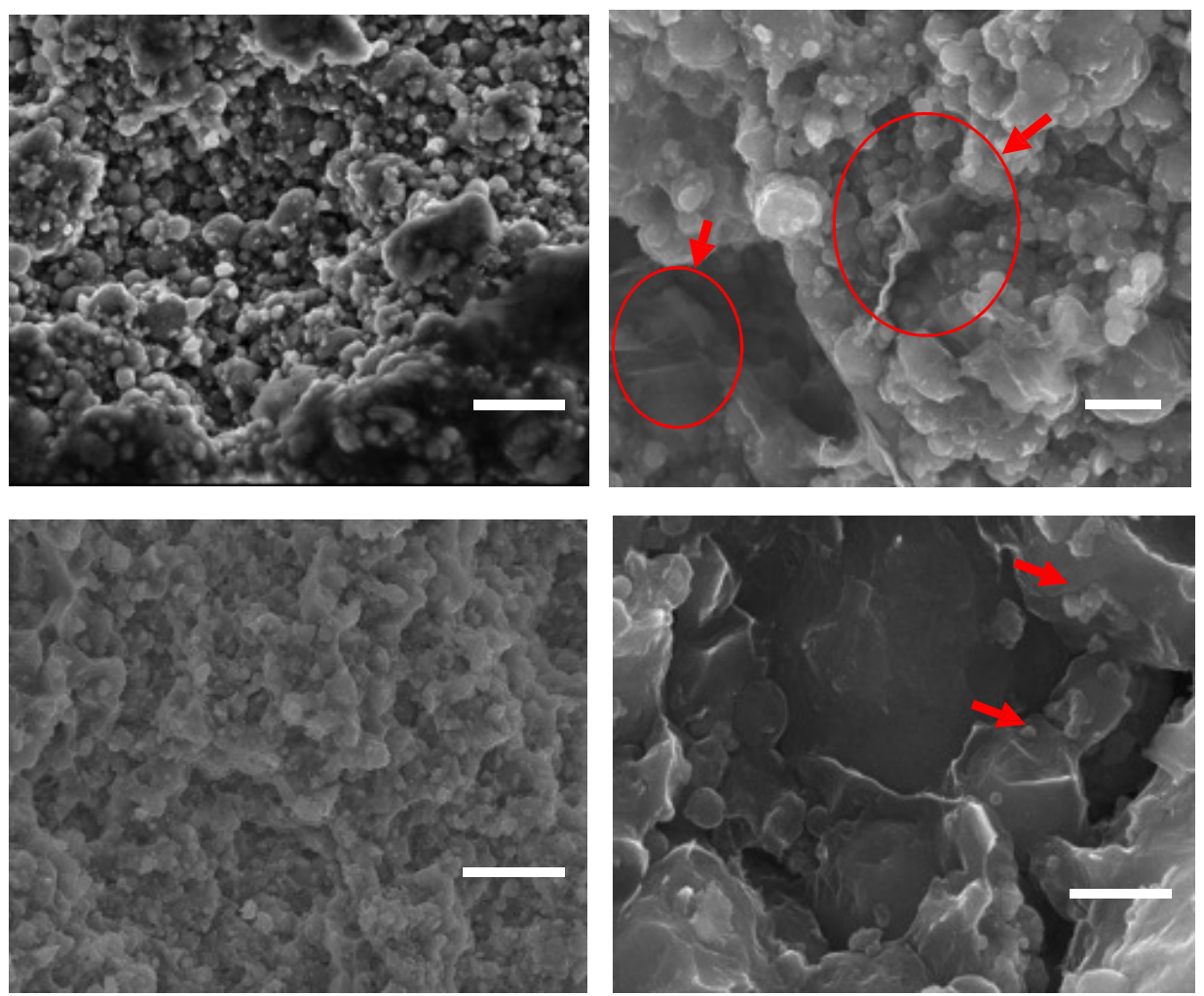

Fig 4.2. SEM of Fracture Surface for a) Pure Al, b) Al-2 vol.\% GNP, c,d) Al2 vol. $\% \mathrm{WS}_{2}$

microhardness tester and nanoindenter. The densification measured by helium pycnometer is a reflection of microstructure described earlier. The lowest hardness is observed for Al2 vol.\% GNP, which is attributed to the low percent of densification caused by agglomeration of GNPs. It has been known that GNPs tend to agglomerate and restack allowing the formation of porosity [56]. The highest hardness and percent of densification 
are observed for $\mathrm{Al}-2$ vol.\% $\mathrm{WS}_{2 .}$. Although absolute hardness values measured by nanoindenter and microhardness tester are different due to measurement at different length scales, they show a similar trend.

\subsection{Phase Identification}

\section{TABLE 4.1}

Hardness and Percent of Densification Properties

\begin{tabular}{|l|c|c|c|}
\hline Composition & $\begin{array}{l}\text { Nanohardness } \\
\text { (GPa) }\end{array}$ & $\begin{array}{l}\text { Microhardness } \\
\text { (HV) }\end{array}$ & $\begin{array}{l}\text { Percent of } \\
\text { densification (\%) }\end{array}$ \\
\hline Pure Al & $1.1 \pm 0.3$ & $59.2 \pm 3.9$ & 96.9 \\
\hline Al- 2 vol.\% GNP & $0.8 \pm 0.2$ & $55.7 \pm 4.9$ & 91.0 \\
\hline Al-2 vol.\% WS $\mathrm{WS}_{2}$ & $1.2 \pm 0.1$ & $59.4 \pm 5.1$ & 99.9 \\
\hline
\end{tabular}

X-Ray diffraction of sintered pellets was carried out to observe if any new phase(s) were formed during sintering. All major peaks representing pure $\mathrm{Al}$ are located at $2 \theta$ equals to $38.74^{\circ}, 44.96^{\circ}, 65.29^{\circ}, 78.29^{\circ}$ and 82.81 in three samples. Pure Al also shows trace amount of $\mathrm{Al}_{2} \mathrm{O}_{3}$ formation as observed from the lower portion of Fig 4.3. Al-2 vol.\% GNP sample resulted in the formation of trace amount of $\mathrm{Al}_{2} \mathrm{O}_{3}$ and $\mathrm{Al}_{4} \mathrm{C}_{3}$ phases as shown in Table 4. 2. In addition, the main peak representing the retention of carbon-base material can be also observed at (006) plane. $\mathrm{WS}_{2}$ peaks at $2 \theta$ equals to $14.17^{\circ}(002), 34.79^{\circ}(100)$, and $39.87^{\circ}(103)$ confirm the retention of the hexagonal structure in sintered Al-2 vol.\% $\mathrm{WS}_{2}$ sample. Trace amount of $\mathrm{WO}_{2}$ and $\mathrm{WO}_{3}$ oxides are also formed due to oxidation of $\mathrm{WS}_{2}$ as shown in Table 4.2. It must be recalled oxide amounts are in trace due to spark plasma sintering processing done under vacuum condition. 


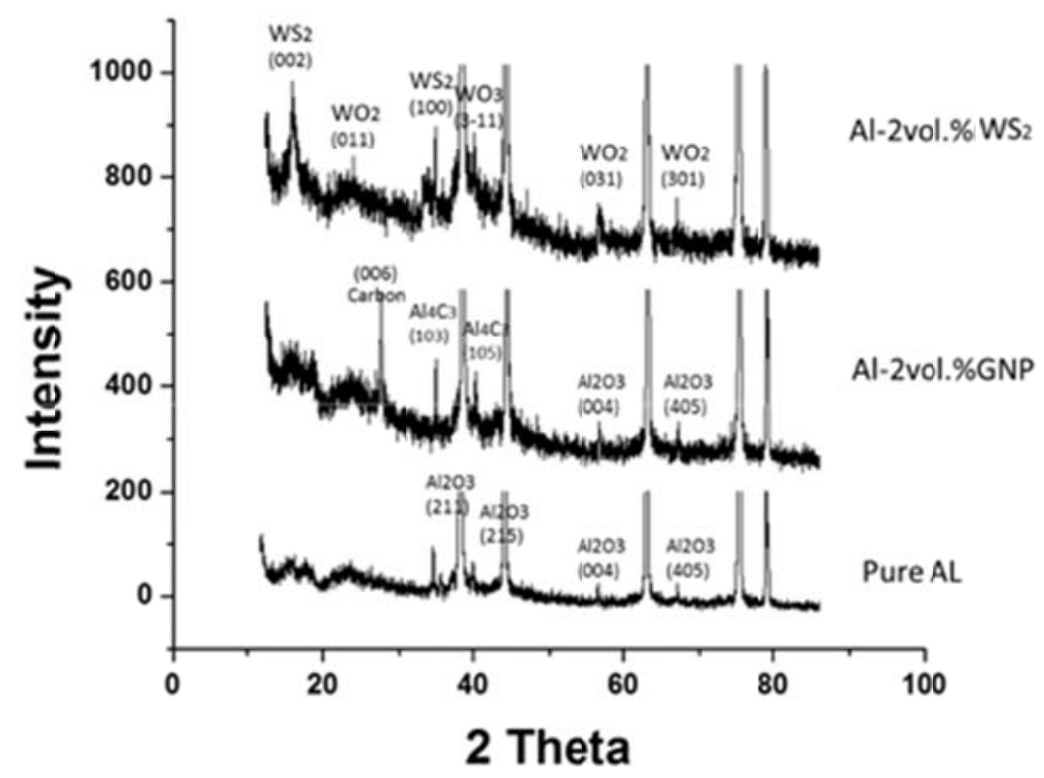
Al-2 vol.\% ${ }^{\text {ray }}$. $\mathrm{S}_{2}$.

TABLE 4.2

Reactants Products and $\Delta \mathrm{G}$ During Sintering Process

\begin{tabular}{|c|c|}
\hline Reaction & $\begin{array}{l}\text { Delta Gibbs Free Energy At Sintering } \\
\text { Temperature (500 } \mathbf{C})(\mathbf{J})\end{array}$ \\
\hline $2 \mathrm{Al}+{ }_{z}^{3} \mathrm{O}_{2} \rightarrow \mathrm{Al}_{2} \mathrm{O}_{3}$ & -1433270.1 \\
\hline $\mathrm{WS}_{2}+0_{2} \rightarrow \mathrm{WO}_{2}+2 \mathrm{~S}$ & -221244.3 \\
\hline $\mathrm{WS}_{2}+{ }_{2}^{3} \mathrm{O}_{2} \rightarrow \mathrm{WO}_{3}+2 \mathrm{~S}$ & -415865.5 \\
\hline $4 \mathrm{Al}+3 \mathrm{C} \rightarrow \mathrm{Al}_{4} \mathrm{C}_{3}$ & -183260.1 \\
\hline $\mathrm{H}_{2}+\mathrm{S} \rightarrow \mathrm{H}_{2} \mathrm{~S}$ & -45340.5 \\
\hline
\end{tabular}


In order to have a better understanding of the retention of the $2 \mathrm{D}$ structure of the solid lubricants (GNP and $\mathrm{WS}_{2}$ ) after SPS, the Raman spectroscopy was performed on the starting powders and sintered pellets. Fig 4.4 shows Raman spectra from the starting GNP powder and sintered Al-2 vol.\% GNP pellet. Three representative peaks of carbon are known as D, G, and 2D located around $1336 \mathrm{~cm}^{-1}, 1583 \mathrm{~cm}^{-1}$ and $2702 \mathrm{~cm}^{-1}$ respectively.

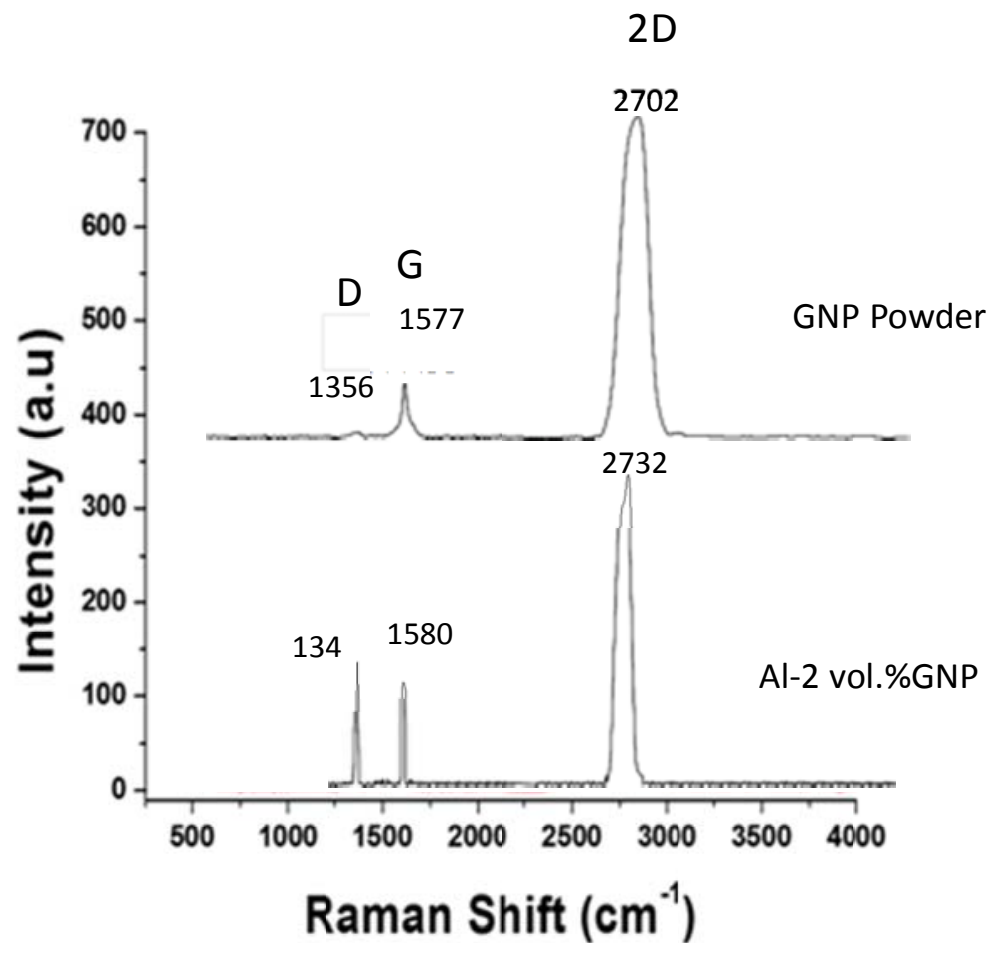

Fig 4.4. Raman Spectroscopy for GNP Powder and Al-2 vol.\%GNP

The $\mathrm{D}$ peak represents the presence of edges of graphene, ripples, and atomic disorder. The G peak is associated to the doubly degenerated E2g phonon mode at the Brillouin zone center and represented the in-plane vibration of the $s p 2$ carbon atoms, and the third peak (2D) presents more intensity in comparison with peak $\mathrm{D}$ and represents the second order 
Raman scattering process giving information about the number of graphene layers present in the structure [46]. The number of graphene layers is determined by the observation of the band's width (2D peak), the sharper the peak the fewer layers the structure has $[46$, 114]. The intensity ratio between $2 \mathrm{D}$ and $\mathrm{G}$ bands $\left(\mathrm{I}_{2 \mathrm{D}} / \mathrm{I}_{\mathrm{G}}\right)$ is a measure of graphitic vs. graphene nature. An $\mathrm{I}_{2 \mathrm{D}} / \mathrm{I}_{\mathrm{G}}$ ratio of less than 1 indicates graphite. $\mathrm{I}_{2 \mathrm{D}} / \mathrm{I}_{\mathrm{G}}$ ratio for the starting GNP powder is $\sim 5.5$ indicating few layered structure (Fig. 4.4). The $\mathrm{I}_{2 \mathrm{D}} / \mathrm{I}_{\mathrm{G}}$ ratio for the sintered Al-2 vol.\% GNP composite is $\sim 2.85$ which shows that more layers are present in the GNP's structure in the composite. This could be due to stacking of several GNPs under high pressure of SPS. From Fig 4.4 the ratio $\mathrm{I}_{\mathrm{D}} / \mathrm{I}_{\mathrm{G}}$ for starting GNP is $\sim 0.079$, which increases to 1.19 in the composite showing that defects has increases due to sintering process. It can be concluded from Raman Spectroscopy that GNP structure is retained with some damage after SPS consolidation. A typical Raman spectra of $\mathrm{WS}_{2}$ shows two main peaks located at $355 \mathrm{~cm}^{-1}$ and $420 \mathrm{~cm}^{-1}$, which correspond to the $E_{2 \mathrm{~g}}$ and $\mathrm{A}_{1 \mathrm{~g}}$ modes [115].

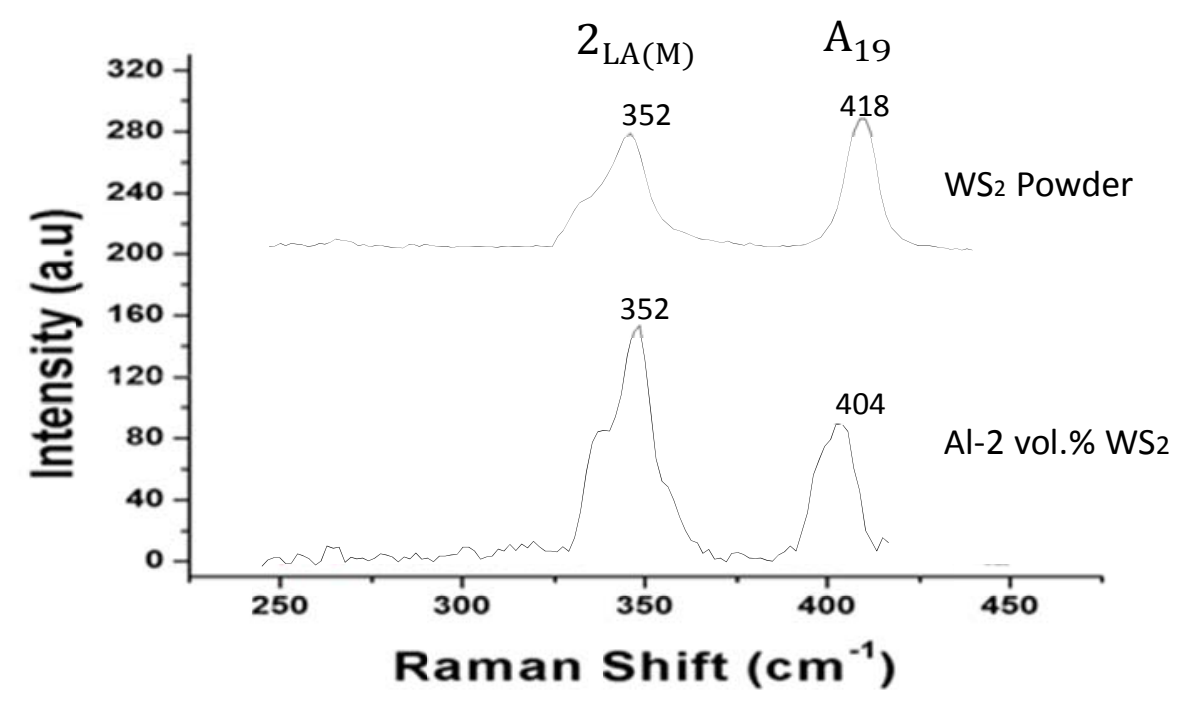

Fig 4.5 Raman Spectroscopy for $\mathrm{WS}_{2}$ Powder and $\mathrm{Al}-2$ vol. $\% \mathrm{WS}_{2}$ 
The $\mathrm{A}_{1 \mathrm{~g}}$ peak represents the $\mathrm{S}-\mathrm{S}$ vibration between two different $\mathrm{WS}_{2}$ layers. The relative intensity of the $A_{1 g}$ peak suggests that the vibration energy is small and that the particles, therefore, contain only a few stacked layers. It has been demonstrated that the ratio $\mathrm{I}_{2 \mathrm{LA}} / \mathrm{I}_{\mathrm{A} 1 \mathrm{~g}}$ is always greater than 2 for monolayer films [116]. In the present study, the ratio $\mathrm{I}_{2 \mathrm{LA}} / \mathrm{I}_{\mathrm{A} 1 \mathrm{~g}}$ for the powder is $\sim 0.86$ and for the composite is $\sim 1.68$ indicating the presence of few layered structure in both $\mathrm{WS}_{2}$ powder and Al-2 vol.\% $\mathrm{WS}_{2}$ composite (Fig 4.5).

Based on all results obtained from microstructural characterization and phase identification, it was confirmed that $2 \mathrm{D}$ solid lubricants are retained in the composite. The following section will discuss wear behavior of these composites with solid lubricant additives.

\subsection{Tribological Behavior}

\subsubsection{Wear Rate}

Wear resistance of pure $\mathrm{Al}, \mathrm{Al}-2$ vol.\% GNP and $\mathrm{Al}-2 \mathrm{vol} . \% \mathrm{WS}_{2}$ is characterized in terms of wear rate $\left(\frac{\mathrm{V}}{*}\right)$, which is expressed as volume loss $(\mathrm{V})$ divided by the sliding

\section{TABLE 4.3}

Wear Rate and Coefficient of friction at Room Temperature and $200^{\circ} \mathrm{C}$

\begin{tabular}{|c|c|c|c|c|}
\hline $\begin{array}{l}\text { Sample } \\
\text { Composition }\end{array}$ & $\begin{array}{l}\text { Wear Rate-RT } \\
\left(\mathbf{m m}^{3} / \mathbf{N} \mathbf{~ m m}\right)\end{array}$ & $\begin{array}{l}\text { Wear Rate (200 } \\
\left.{ }^{\circ} \mathrm{C}\right)\left(\mathrm{mm}^{3} / \mathrm{N} \mathrm{mm}\right)\end{array}$ & COF-RT & $\operatorname{COF}\left(200^{\circ} \mathrm{C}\right)$ \\
\hline Pure Al & $5.7 \pm 1.6 \mathrm{E}^{-6}$ & $7.5 \pm 1.9 \mathrm{E}^{-6}$ & $0.87 \pm 0.04$ & $0.82 \pm 0.03$ \\
\hline Al- 2 vol. $\%$ GNP & $1.9 \pm 0.28 \mathrm{E}^{-5}$ & $1.1 \pm 0.31 \mathrm{E}^{-5}$ & $0.79 \pm 0.09$ & $0.69 \pm 0.10$ \\
\hline $\mathrm{Al}-2$ vol. $\% \mathrm{WS}_{2}$ & $2.6 \pm 0.17 \mathrm{E}^{-6}$ & $5.3 \pm 0.56 \mathrm{E}^{-6}$ & $0.66 \pm 0.09$ & $0.55 \pm 0.10$ \\
\hline
\end{tabular}


distance (S) and applied normal load (P). Wear track is scanned using optical profilometer which provides wear depth and cross-sectional area of the track to enable estimation of wear volume. The wear rate for $\mathrm{Al}, \mathrm{Al}-2$ vol.\% $\mathrm{GNP}$ and $\mathrm{Al}-2$ vol.\% $\mathrm{WS}_{2}$ at room

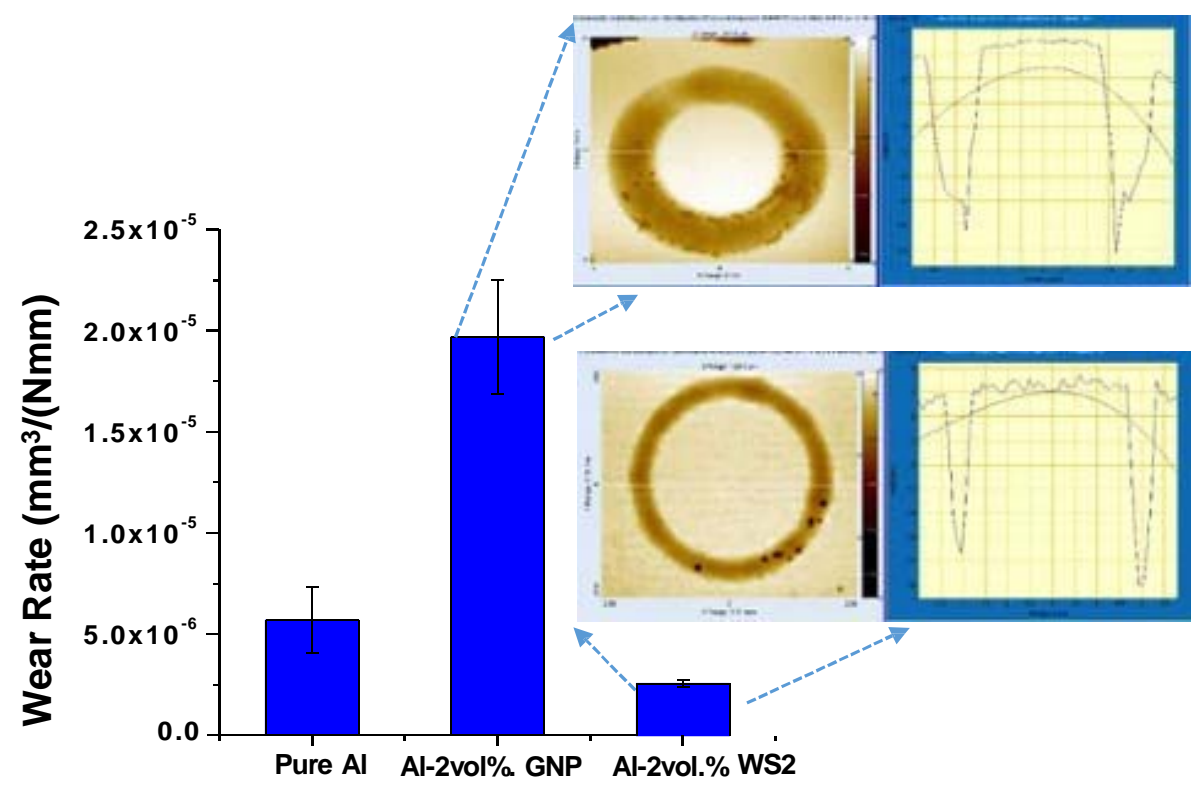

Fig 4.6. Wear rate for Ball-on-disk sliding Experiments at Room Temperature.

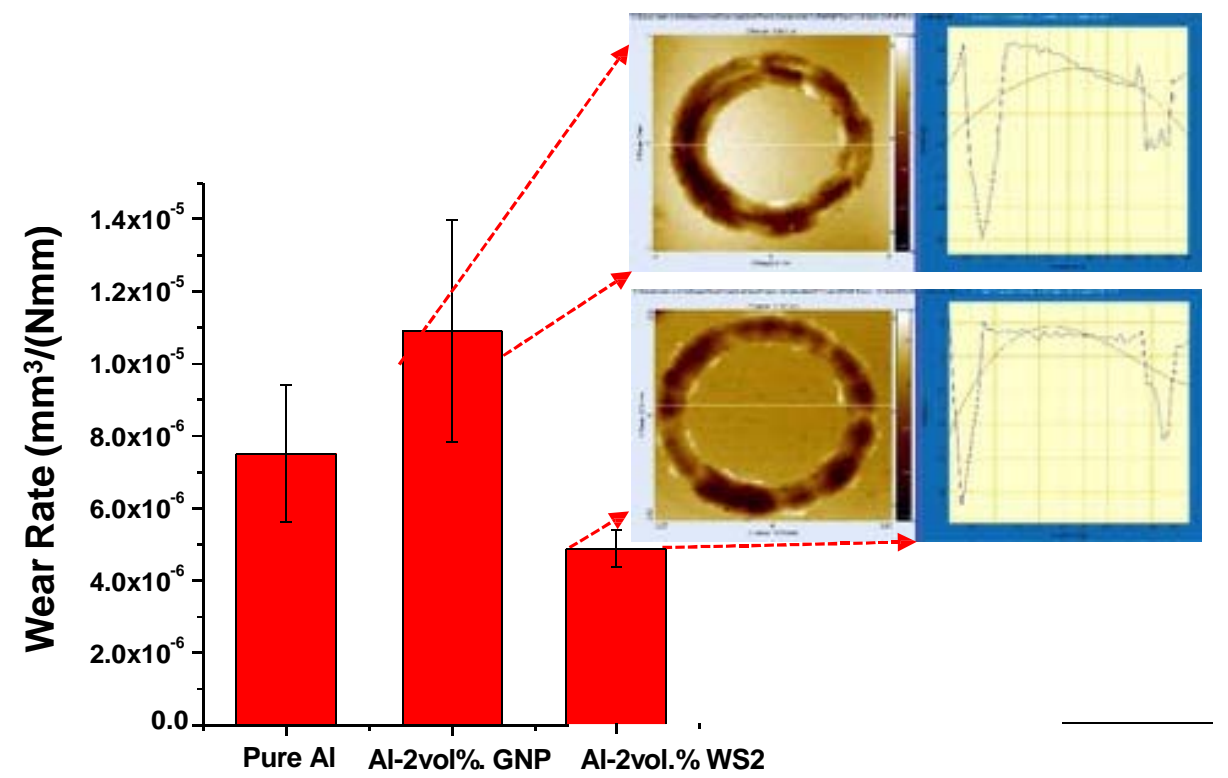

Fig 4.7.Wear rate for Ball-on-disk Sliding Experiments at $200^{\circ} \mathrm{C}$ 
temperature and $200^{\circ} \mathrm{C}$ are presented in Fig 4.6 and 4.7 respectively. The data for wear rates is also presented in Table 4.3 .

It was observed that Al-2 vol.\% GNP shows the highest wear rate among three samples whereas $\mathrm{Al}-2$ vol.\% $\mathrm{WS}_{2}$ shows the lowest wear rate. Al- 2 vol.\% $\mathrm{WS}_{2}$ shows $54 \%$ improvement in the wear rate at room temperature as compared to pure aluminum. At $200^{\circ} \mathrm{C}, \mathrm{Al}-2$ vol. $\% \mathrm{WS}_{2}$ shows $29 \%$ improvement in the wear rate as compared to pure aluminum. This can be attributed to densification and hardness of three samples as listed in Table 4.1. Al- 2 vol.\% $\mathrm{WS}_{2}$ shows highest densification (99.8\%) and hardness resulting in the lowest wear rate. Al-2 vol.\% GNP presents the lowest densification (91.0\%), and is the softest sample among three. Archard's equation illustrates that: the harder the material, better the wear resistance will be [118]:

$$
d V \quad \frac{k P}{H} d x
$$

In Eqn $1, \mathrm{dV}$ is the wear volume loss, $\mathrm{P}$ and $\mathrm{H}$ are the load and the hardness respectively, $\mathrm{k}$ is called the wear resistance factor, and $\mathrm{dx}$ is the wear distance. The overall wear behavior and trend of three samples is similar at room temperature and $200^{\circ} \mathrm{C}$. Table 4.3 shows that wear rate increases at higher temperature except with the Al-2 vol.\% GNP sample. It is well know that materials become softer at higher temperature resulting in more wear. However, the GNP-containing sample displayed the contradictory behavior at high temperature which is explained by two phenomenon: (i) localized sintering and densification of $91 \%$ dense Al-GNP sample at high temperature, in which the plastic deformation and the soft characteristic due to high temperature contribute to compact the 
sample due to stress from the counterball and (ii) the ability of GNPs to act as sealers against oxygen which contributes to improve wear [119].

\subsubsection{Coefficient of Friction}

In addition to the wear rate, coefficient of friction (COF) is the critical parameter to obtain an indirect measurement of energy efficiency in automotive materials. Fig 4.8 shows the coefficient of friction variation during the room temperature wear test along with the average value for $\mathrm{Al}, \mathrm{Al}-2$ vol. $\% \mathrm{GNP}$ and $\mathrm{Al}-2$ vol. $\% \mathrm{WS}_{2} . \mathrm{COF}$ at $200^{\circ} \mathrm{C}$ is shown in Fig 4.9. The average values of COF are listed in Table 4.3.

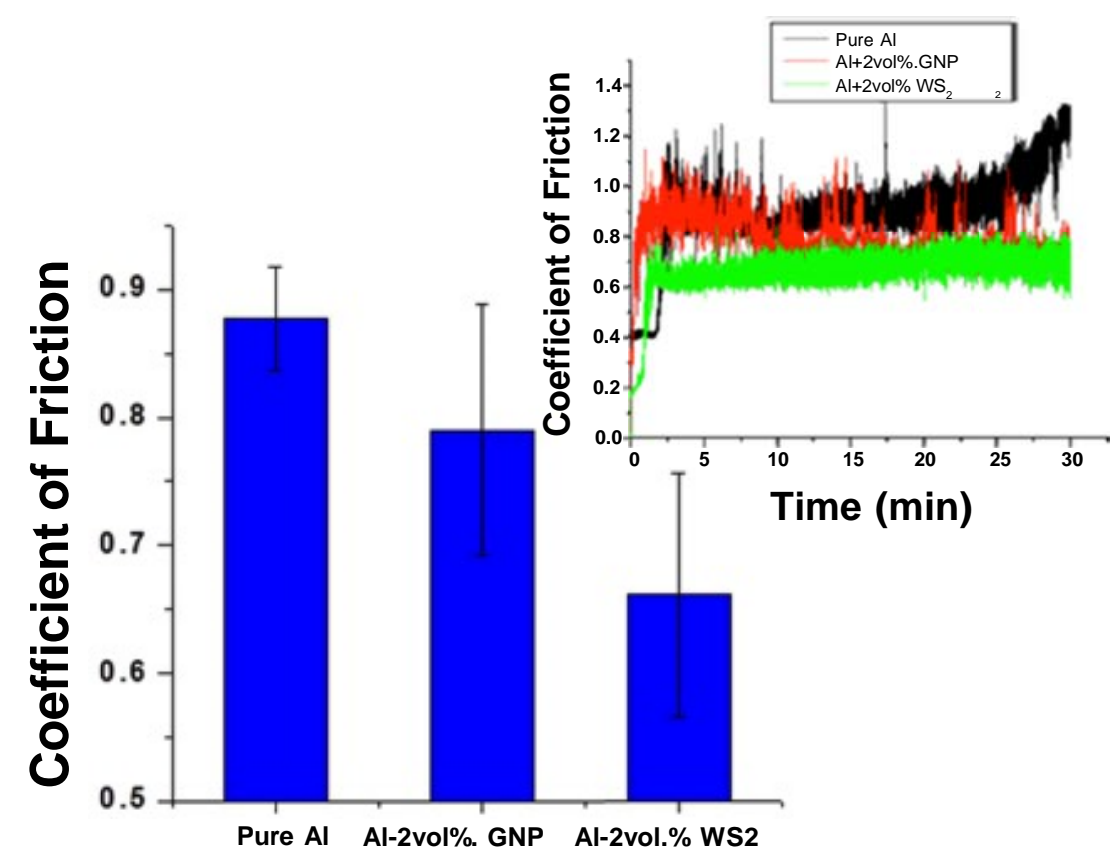

Fig 4.8. Average COF and COF Variation During RT Tests

It was observed that aluminum has the highest $\mathrm{COF}(0.87)$ whereas $\mathrm{Al}-2$ vol.\% $\mathrm{WS}_{2}$ has the lowest COF (0.66) at room temperature. A similar trend is observed for average $\mathrm{COF}$ at $200^{\circ} \mathrm{C}$; however COF values are lower than those at room temperature (Table 4.3). 
It is also observed that COF variation is more stable at $200^{\circ} \mathrm{C}$ as compared to RT tests. However, Al-2 vol.\% $\mathrm{WS}_{2}$ sample displayed most stable COF without significant oscillations both at RT and $200^{\circ} \mathrm{C}$. It is worth noting that $\mathrm{Al}-2$ vol.\% GNP presents an improvement in $\mathrm{COF}$ in comparison with pure $\mathrm{Al}$ in spite of having the highest wear rate. This is largely due to the presence of GNP sheets which act as solid lubricant and contribute to reduce friction.

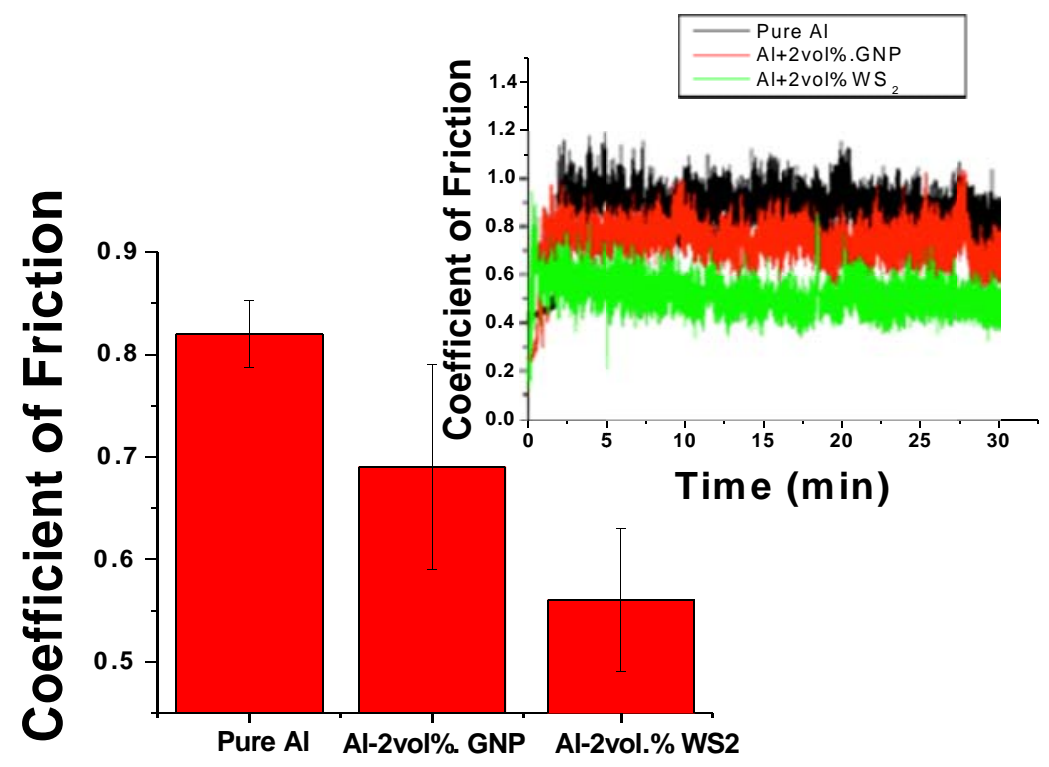

Fig 4.9. Average $\mathrm{COF}$ and $\mathrm{COF}$ Variation at $200^{\circ} \mathrm{C}$ Tests

The worn surfaces of the samples were studied using SEM and x-ray diffraction. The SEM images of the worn surfaces provide important information to understand wear mechanisms of the different samples. The sub-surface of the wear was studied using FIB and optical microscopy to understand the formation of tribolayer and dynamic wear features such as cracks progression. Fig 4.10 is that x-ray diffraction of the wear surface of $\mathrm{Al}, \mathrm{Al}-2$ vol.\% GNP and $\mathrm{Al}-2$ vol.\% $\mathrm{WS}_{2}$ before and after wear. It provides information about the phase(s) formed during wear at RT and $200^{\circ} \mathrm{C}$. 

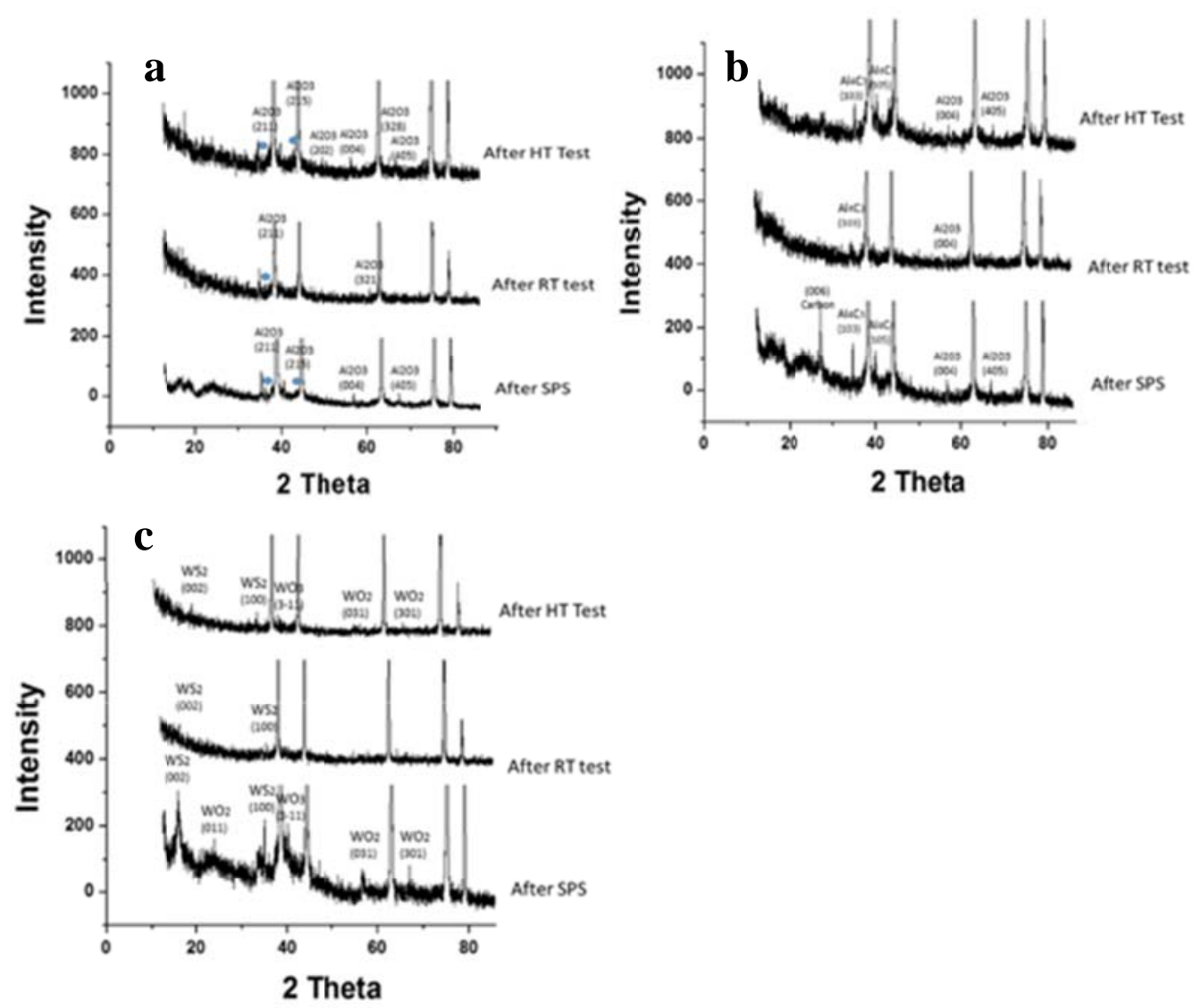

Fig 4.10. XRD after SPS, RT Test and HT Test for a) Pure Al, b) Al-2vol.\%GNP, c) $\mathrm{Al}-2 \mathrm{vol} . \% \mathrm{WS}_{2}$

\subsection{Wear Mechanisms at Room Temperature}

\subsubsection{Wear mechanism of pure Al at room temperature}

A common type of wear in $\mathrm{Al}$ is adhesive wear $[113,120]$, which occurs when two surfaces are initially rubbed against each other. However, due to localized heating and oxygen diffusion, the surface forms $\mathrm{Al}_{2} \mathrm{O}_{3}$ layer which is brittle in nature and undergoes abrasive wear. It is expected that hard and brittle $\mathrm{Al}_{2} \mathrm{O}_{3}$ phase will generate large particles 
of wear debris, thus increasing wear rate and COF. Fig. 4.11 shows a schematic of wear mechanisms of pure $\mathrm{Al}$ at room temperature.

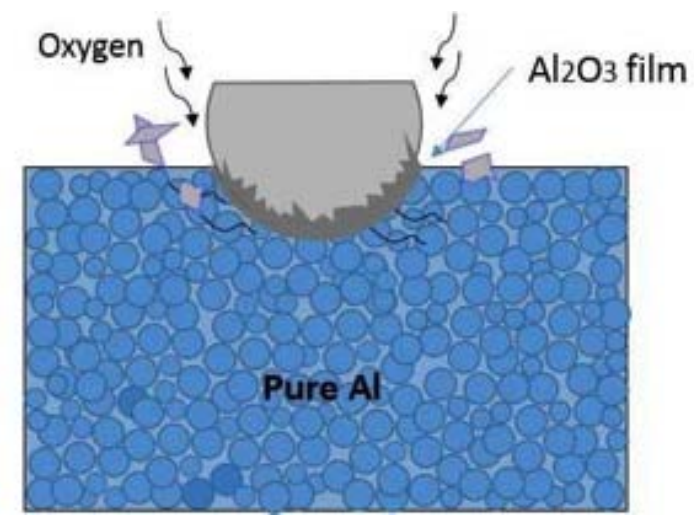

Fig 4.11. Schematic Representation of Behavior of Pure Al at RT

Figure 4.12a shows the wear track of pure Al which is very rough and presents formation of cracks. The surface of the wear track, reveals crack formation, and the EDS (Appendix 1) shows high amount of oxygen. The brittle $\mathrm{Al}_{2} \mathrm{O}_{3}$ surface layer generates large amount of wear debris (Fig. 4.12b). These wear debris present average bimodal size distribution of $20 \mu \mathrm{m}$ and $60 \mu \mathrm{m}$. These big detachments reveal adhesive wear for pure Al, which is a very common type of wear in this material $[113,117]$, whereas finer debris is indicative of mixed nature due to presence of brittle $\mathrm{Al}_{2} \mathrm{O}_{3}$. The wear particles are lifted up and allow the observation of some cracks propagating through the grain boundaries, which can be attributed to surface crack propagation [120]. Fig 4.12c exposes surface crack propagation of the wear track. The thickness of the tribofilm in a range of 5-10 $\mu \mathrm{m}$ as indicated by the red arrow in Fig. 4.12c and 4.12d. The formation of subsurface zone is the result of severe contact stresses during the wear [121]. Aluminum forms a brittle $\mathrm{Al}_{2} \mathrm{O}_{3}$ tribofilm which is rough due to cracks resulting in a higher COF as observed earlier. 

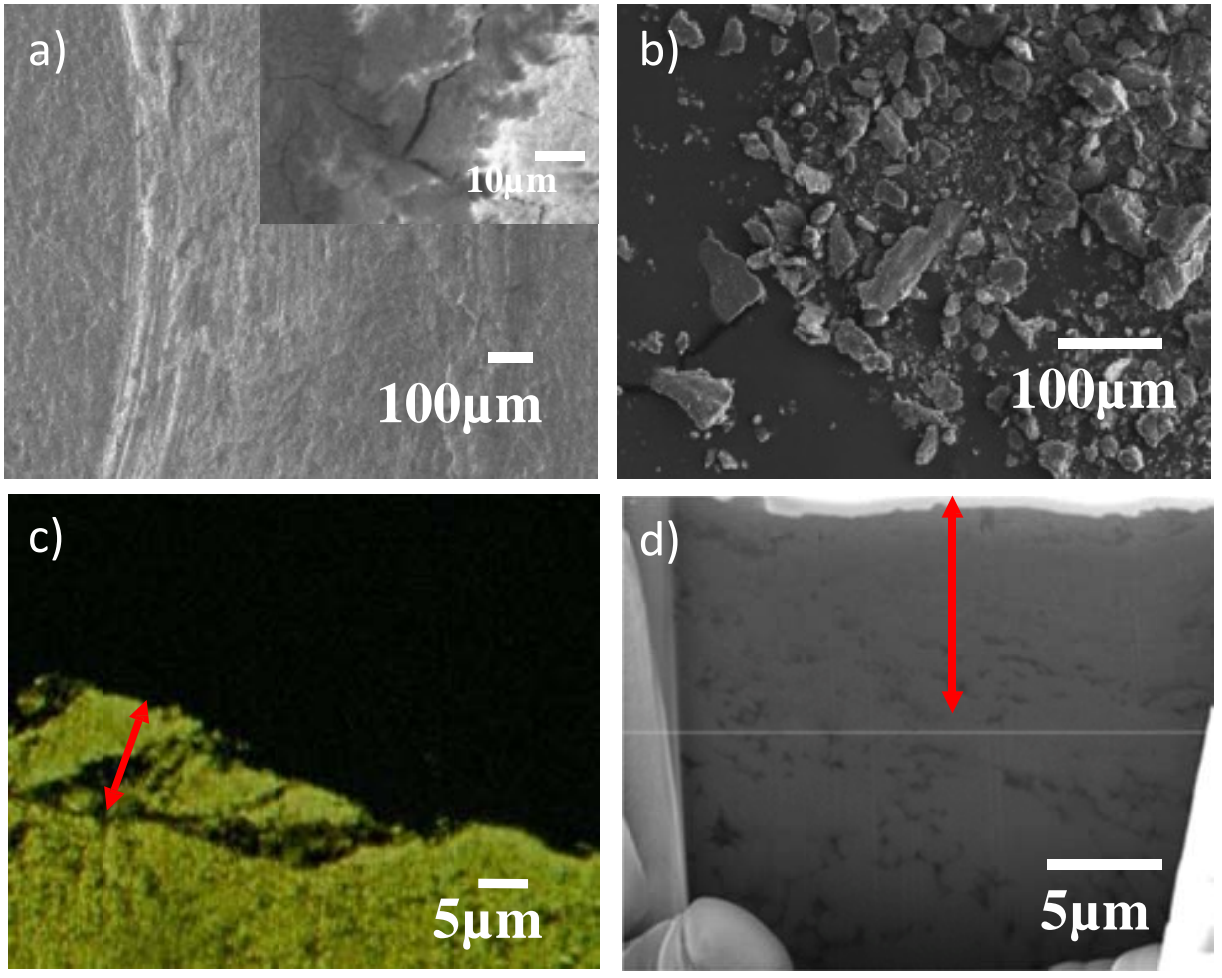

Fig 4.12. SEM Images of the a) Wear Track and b) Wear Debris, c) Optical Microscope Image of the Sub-surface of the Wear Track, d) FIB Image of the Subsurface of the Wear Track for Pure Al after RT Tribological Test

\subsubsection{Wear mechanism of Al-2 vol.\% GNP at room temperature}

The addition of GNP to Al matrix is expected to promote the formation of lubricious tribofilm that will reduce $\mathrm{COF}$ and wear rate of $\mathrm{Al}$ composites [14, 21]. The stated hypothesis of GNP in Al matrix expects to find lower wear rate and COF than for pure Al. However, it was seen in section 4.1 that Al-2 vol.\% GNP displayed lowest wear resistance and intermediate COF. Fig 4.12 shows a schematic of the proposed wear mechanism in Al-2 vol.\% GNP at RT. Figure 4.14 a shows the wear track of Al-2 vol.\% 
GNP. The smooth region indicates formation of a tribofilm. However this tribofilm is not homogeneous and contains rough region indicating large wear. The red arrow marks the thickness of the tribofilm which is $\sim 5 \mu \mathrm{m}$ (Fig $4.14 \mathrm{c}$ and d). Fig $4.14 \mathrm{c}$ also shows the

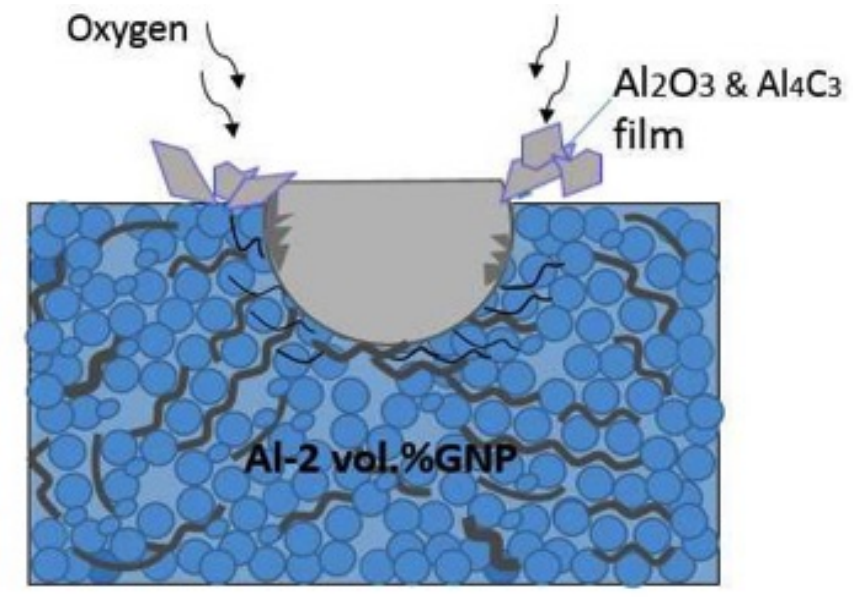

Fig 4.13. Schematic Representation of Behavior of Al-2 vol.\%GNP at RT crack-end and the beginning of the new tribofilm formed by deflection as pressure from the counterball is exerted during wear. This tribofilm consists of $\mathrm{Al}_{2} \mathrm{O}_{3}$ and $\mathrm{Al}_{4} \mathrm{C}_{3}$ in addition to smooth region of graphene as indicated in x-ray diffraction pattern shown in (Fig 4.10). In addition, the EDS of the worn surface (Appendix 1) shows higher oxygen, suggesting that oxide formation occurs due to faster oxygen diffusion in low density (91\%) composite. Homogeneous detachments are found as wear debris with average size of 60 $\mu \mathrm{m}$ (Fig 4.14b). No plastic deformation is observed in debris particle, suggesting that the wear debris is lifted up before plastic deformation. Thus, it is clear that GNPs are detached from the surface by delamination and crack propagation (Fig 4.14c, d). These GNPs undergo high contact stress under the wear counter face and forms a tribofilm which is shown as smooth region in Fig 4.14a. Weak interlayer forces between graphene layers 
enable sliding or layer buckling to reduce the stress [99]. Hence, COF for Al-2 vol.\% GNP is lower than pure $\mathrm{Al}$.
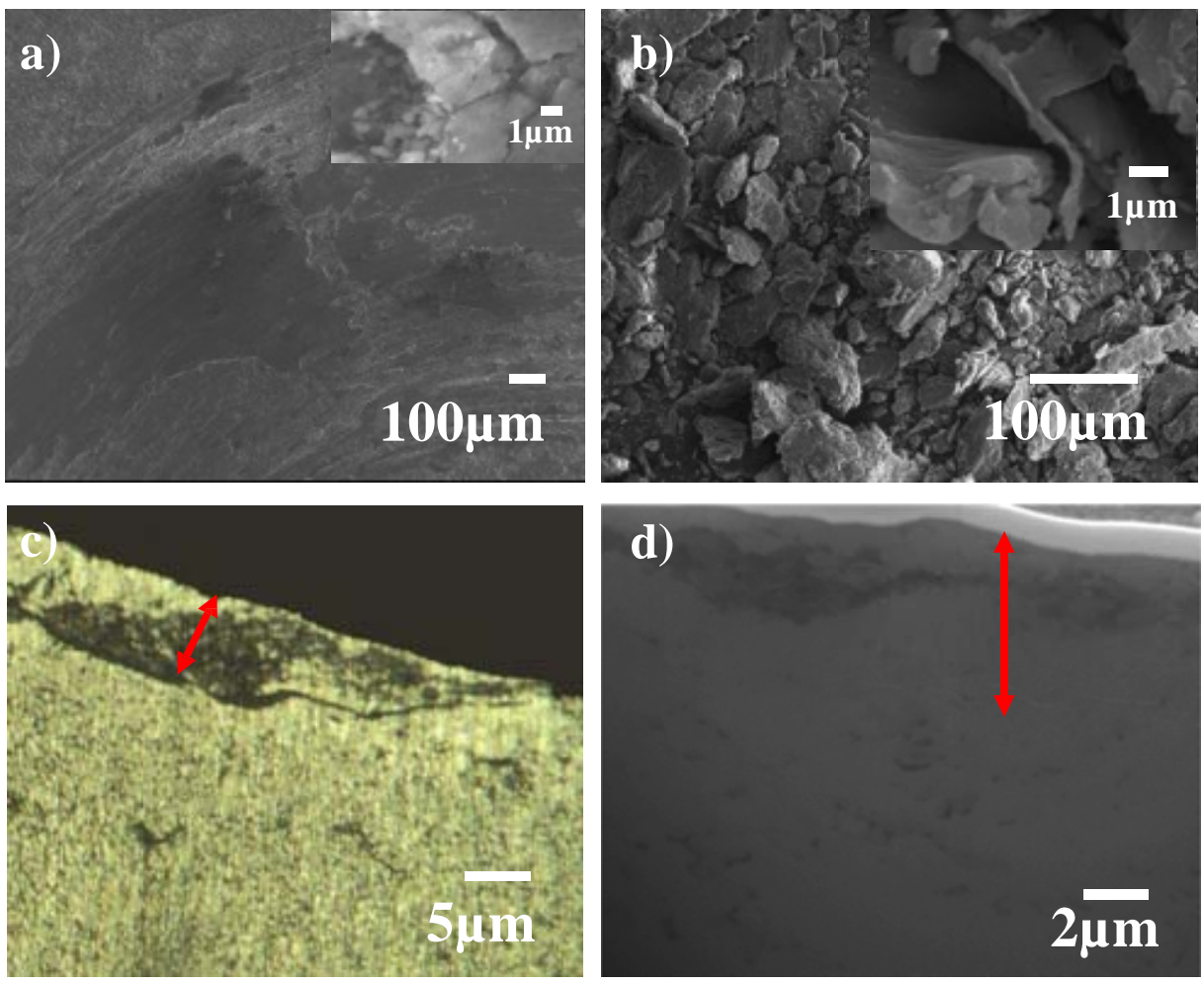

Fig 4.14. SEM images of the a) Wear Track and b) Wear Debris, c) Optical Microscope Image of the Sub-surface of the Wear Track, d) FIB Image of the Subsurface of the Wear Track for Al-2 vol.\% GNP after RT Tribological Test

\subsubsection{Wear mechanism of Al-2 vol.\% $\mathrm{WS}_{2}$ at room temperature}

The addition of nanosize $\mathrm{WS}_{2}$ particles resulted in homogeneous dispersion and a dense microstructure as observed in section 4.1. It is expected that uniform dispersion of nanosize $\mathrm{WS}_{2}$ would facilitate the formation of a uniform tribofilm, which will promote the reduction of COF and improved wear resistance. Fig 4.15 presents the schematic of the wear mechanism of Al-2 vol.\% $\mathrm{WS}_{2}$ at RT. During the wear test, a chemical reaction occurs 
between freshly exposed $\mathrm{WS}_{2}$ nano-particles and surrounding humid air forming $\mathrm{H}_{2} \mathrm{~S}$ gas with a foul odor.

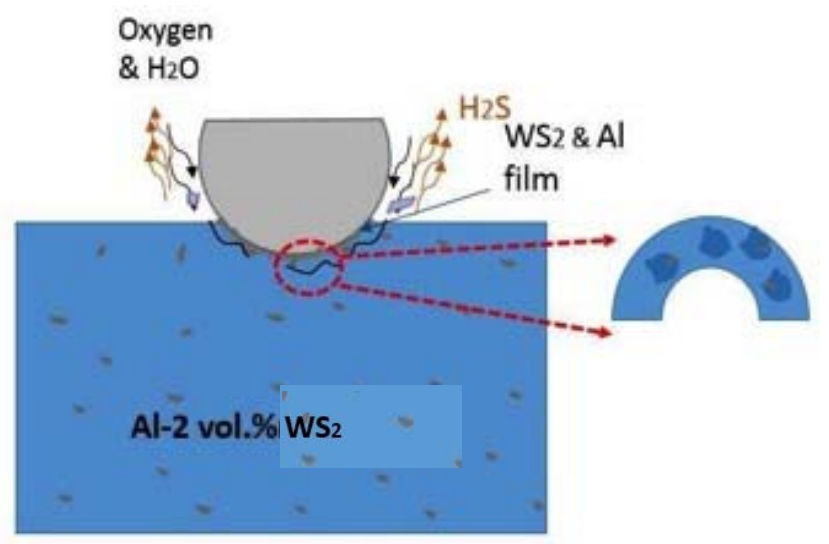

Fig 4.15. Schematic Representation of Behavior of Al-2vol.\% $\mathrm{WS}_{2}$ at RT

Figure 4.16a shows wear track of Al-2 vol.\% $\mathrm{WS}_{2}$ which is rough in appearance and looks similar to that obtained of pure $\mathrm{Al}$ at room temperature. This is due to the nanosize of $\mathrm{WS}_{2}$ particles, which allows these nano-particles to act as solid lubricants without altering the matrix's properties. Two different debris sizes are found, one in which the average size of the wear particles is $\sim 1 \mu$ and for bigger particles the average size is around $20 \mu \mathrm{m}$ (Fig 4.16b). All the wear debris is adhered to the counterball and in order to be collected these debris were peeled off from the $\mathrm{Al}_{2} \mathrm{O}_{3}$ counterball. The tribofilm is formed by small clusters of $\mathrm{WS}_{2}$ particles homogeneously distributed as shown in Fig 4.16d. A crack is seen in sub-surface which shows the delamination under shear contact stresses. The thickness of the tribofilm is $\sim 7 \mu \mathrm{m}$ and it is pointed out by the red arrow in Fig 4.16c The same can be seen in Fig 4.16d, in addition this figure shows the cracks propagating all along the tribofilm similar to that behavior observed in pure $\mathrm{Al}$ at room temperature conditions.. 

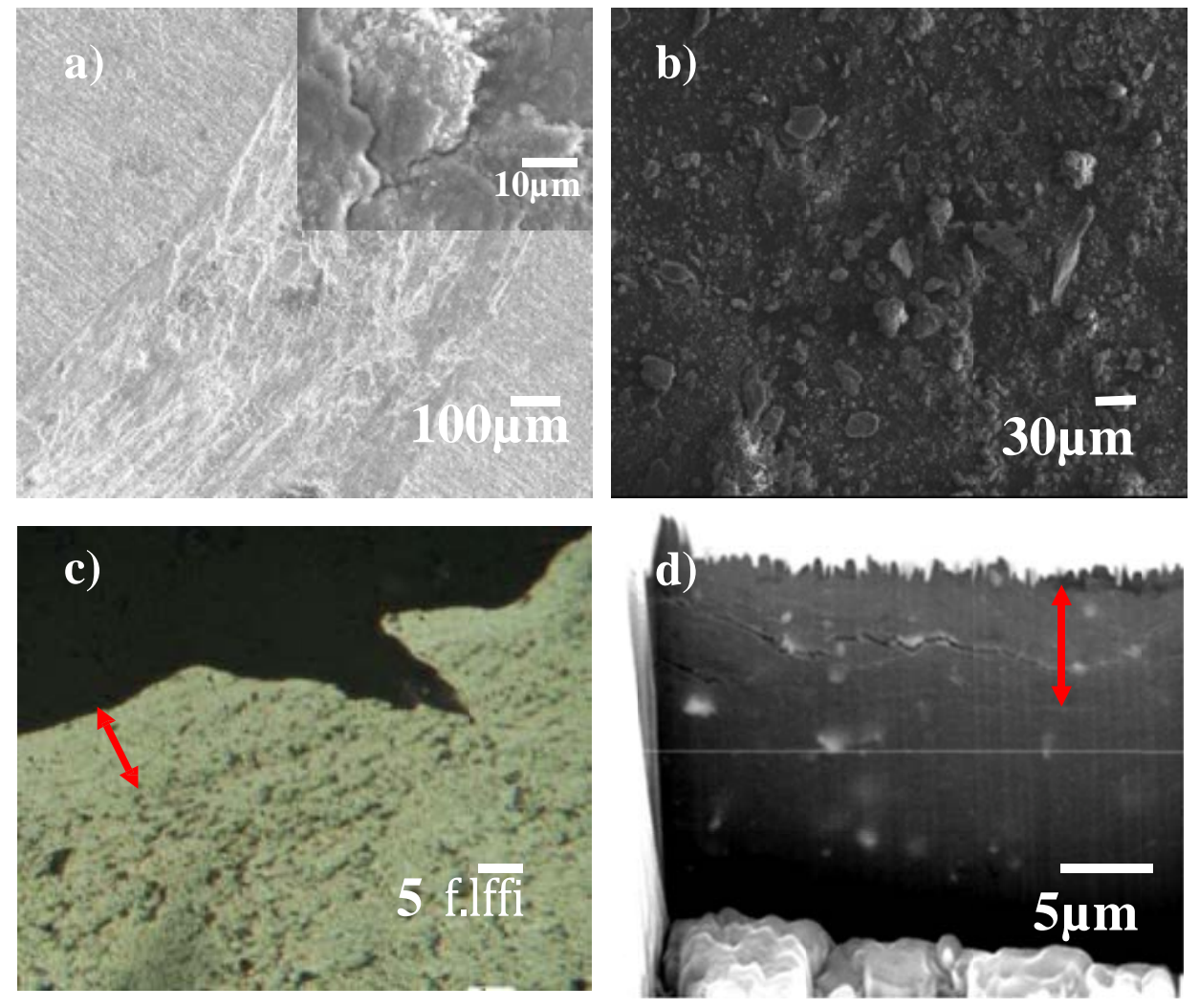

Fig 4.16. SEM images of the a) Wear Track and b) Wear Debris, c) Optical Microscope Image of the Sub-surface of the Wear Track, d) FIB Image of the Subsurface of the Wear track for Al-2 vol.\% $\mathrm{WS}_{2}$ after RT Tribological Test

It is summarized that at RT the addition of both GNP and $\mathrm{WS}_{2}$ solid lubricants leads to reduction in COF during sliding wear. However, the distribution of GNPs particles is not as homogeneous as $\mathrm{WS}_{2}$ nano-particles resulting in poor density and lowest wear resistance. The composite with $\mathrm{WS}_{2}$ additives presents few wear debris with small size mostly located around the counter ball as mentioned before. This demonstrated that $\mathrm{WS}_{2}$ nano-particles can effectively provide lubricious and anti-wear properties in aluminum creating a tribofilm and a transferfilm when a tribological test is performed at room temperature conditions. 


\subsection{Wear Mechanisms at $200^{\circ} \mathrm{C}$}

\subsubsection{Wear mechanism of Al at $200^{\circ} \mathrm{C}$}

It is expected that high temperature would result in aggressive wear which is also reflected by wear rates shown in Table 4.1. Fig 4.17 presents schematic of wear mechanism for pure $\mathrm{Al}$ at high temperature. Due to higher temperature, oxygen diffusion would be faster resulting in larger amount of $\mathrm{Al}_{2} \mathrm{O}_{3}$ layer formation on the surface. $\mathrm{The} \mathrm{Al}_{2} \mathrm{O}_{3}$ phase in tribofilm is confirmed by $\mathrm{x}$-ray diffraction spectrum of the wear track shown in Fig 4.10.

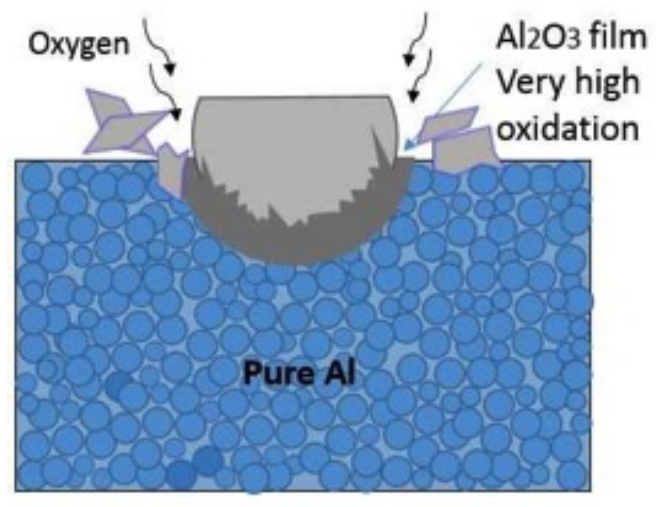

Fig 4.17. Schematic Representation of Behavior of Pure $\mathrm{Al}$ at $200^{\circ} \mathrm{C}$

Fig 4.18a shows a smooth wear surface which is due to slight softening of aluminum at $200^{\circ} \mathrm{C}$. The wear debris presents some small particles but predominantly is composed by big particles with average size of $\sim 100 \mu \mathrm{m}$, what refers to high surface stress with heavy deformation on the surface. The thickness of tribofilm is $\sim 15 \mu \mathrm{m}$ as it is pointed out in Fig $4.18 \mathrm{c}$ by the red arrow. The large thickness of the deformed film demonstrates high plastic deformation. No signal of grains or cracks are observed in higher magnification image of the sub-surface obtained from FIB (Fig 4.18d). 

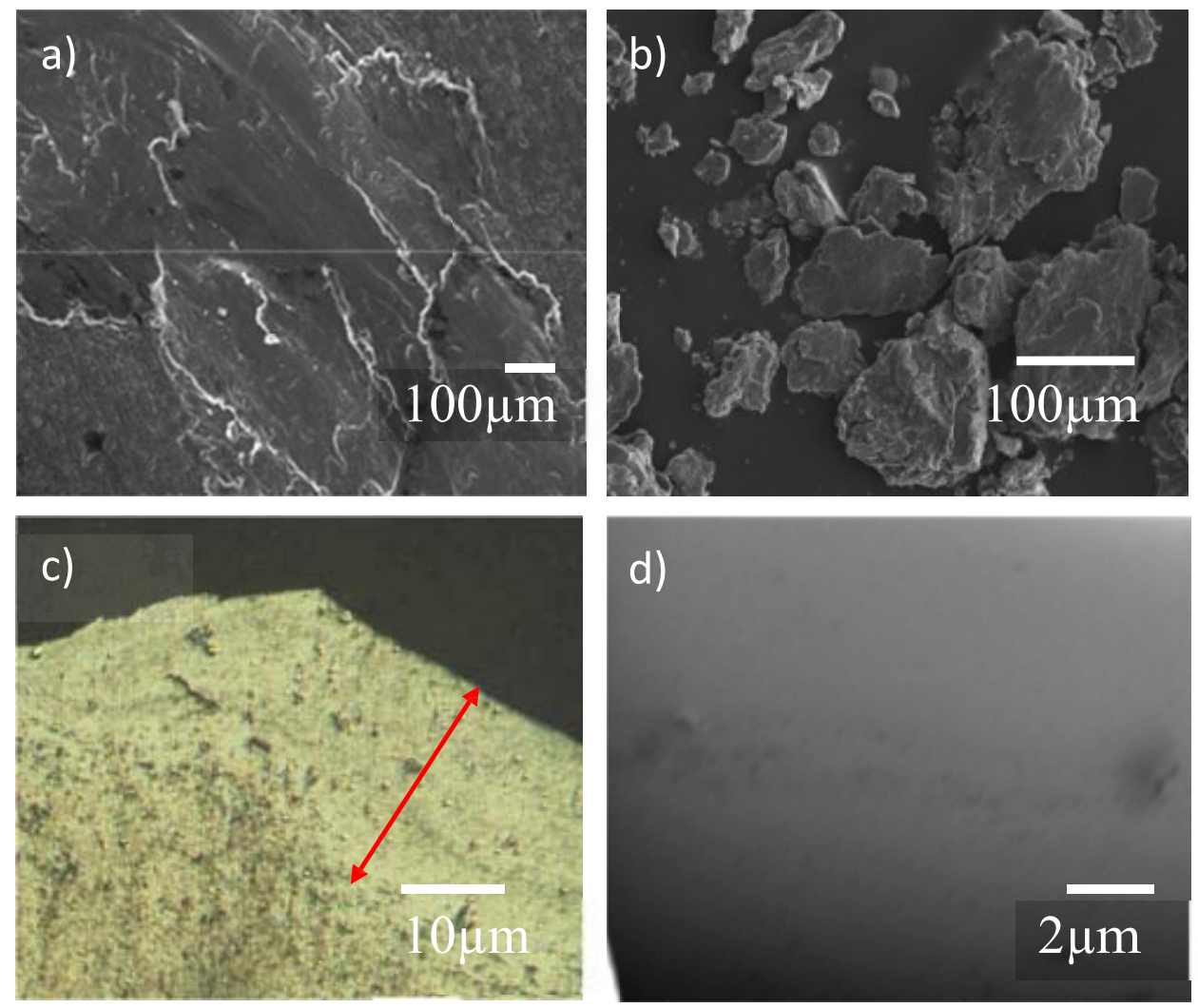

Fig 4.18. SEM images of the a) Wear Track and b) Wear Debris, c) Optical Microscope Image of the Sub-surface of the Wear Track, d) FIB Image of the Subsurface of the Wear Track for Pure Al after HT Tribological Test.

\subsubsection{Wear mechanism of Al-2 vol.\% GNP at $200^{\circ} \mathrm{C}$}

The tribological behavior for Al-2 vol.\% GNP at $200^{\circ} \mathrm{C}$ is largely similar to that described at RT with an exception of more severe oxidation. Fig 4.19 presents the schematic representation of the behavior of GNP in the Al matrix at $200^{\circ} \mathrm{C}$. It has been reported GNPs can act as sealers preventing oxygen diffusion through the grain boundaries [119]. At high temperature more oxidation is present on the surface which is also proven by EDS on the wear track (Appendix 1). Figure 4.20a shows the wear track of Al-2 vol.\% 


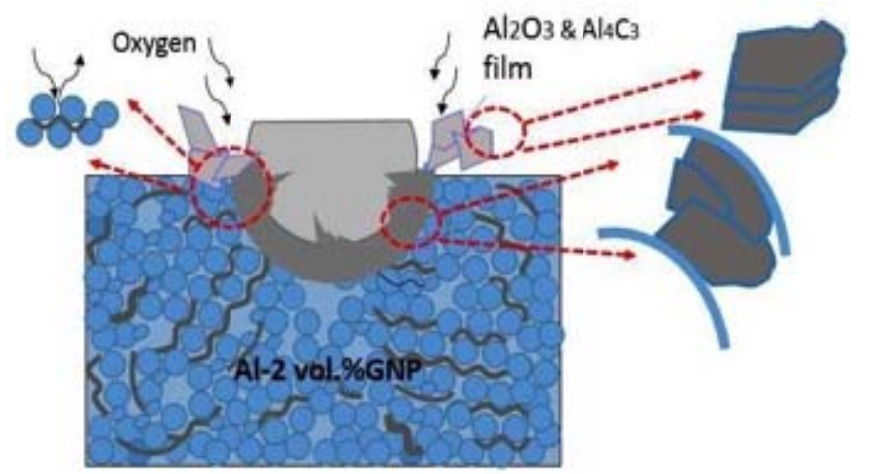

Fig 4.19. Schematic Representation of Behavior of Al-2vol.\%GNP at HT.

GNP. A smooth surface with mixed layered morphology is observed. The wear debris presents a sheet-like form that works as a mechanism of stress dissipation, allowing
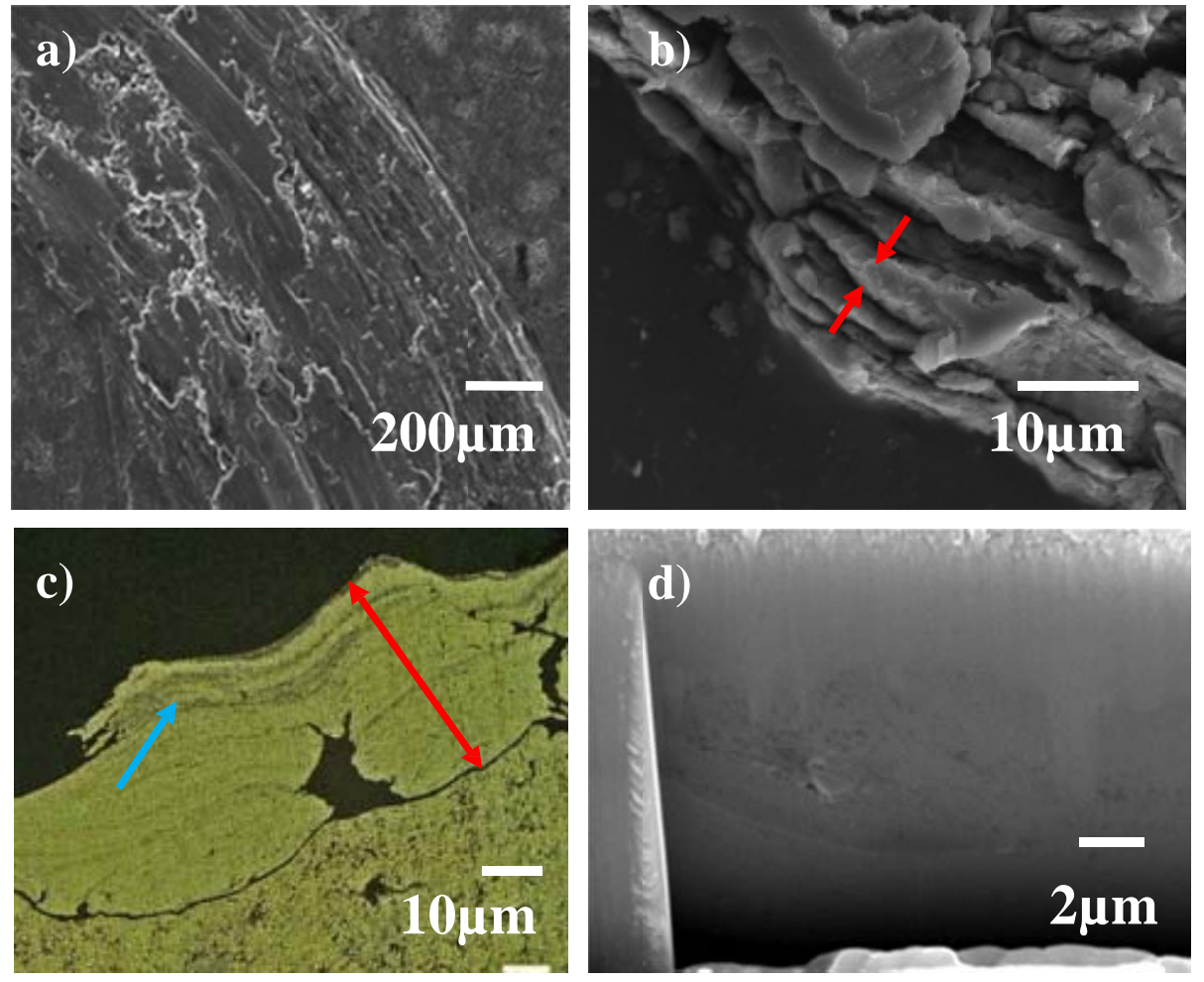

Fig 4.20. SEM Images of the a) Wear Track and b) Wear Debris, c) Optical Microscope Image of the Sub-surface of the Wear Track, d) FIB Image of the Subsurface of the Wear Track for Al- 2vol.\%GNP after HT Tribological Test. 
themselves to slip upon the movement of the shear stress (Fig 4.20). The tribofilm is formed by $\mathrm{Al}_{2} \mathrm{O}_{3}$ and $\mathrm{Al}_{4} \mathrm{C}_{3}$ phases (Fig 4.10b) that are wrapped by GNP sheets. The thickness of the tribofilm is $\sim 20 \mu \mathrm{m}$ (Fig 4.20c) which is the largest observed in this study and it is pointed out by the red arrow. This figure reflects the ability of GNPs (which are the grey lines pointed out by the blue arrow) to act as sealers being located parallel to the sliding motion. This ability of acting as inhibitors of oxygen help to reduce wear as well as the fact of being compressed by the counterball reducing porosity, thus improving wear rate as compared with room temperature. Different from at RT, at HT no cracks are observed on the sub-surface (Fig 4.20d), and this can be attributed to the ability of GNPs to wrap that have reflected to contribute on reducing crack propagation [78].

\subsubsection{Wear mechanism of Al-2 vol.\% $\mathrm{WS}_{2}$ at $200^{\circ} \mathrm{C}$}

At high temperature it is expected that $\mathrm{Al}-2$ vol.\% $\mathrm{WS}_{2}$ would have higher wear rate than at RT due to accelerated oxidation and formation of $\mathrm{WO}_{3}$. The results point out that this sample presented the lowest $\mathrm{COF}$ at $200^{\circ} \mathrm{C}$. However, the wear rate is higher at $200^{\circ} \mathrm{C}$ than at RT, as expected. Appendix 1 shows low amount of oxygen on the wear

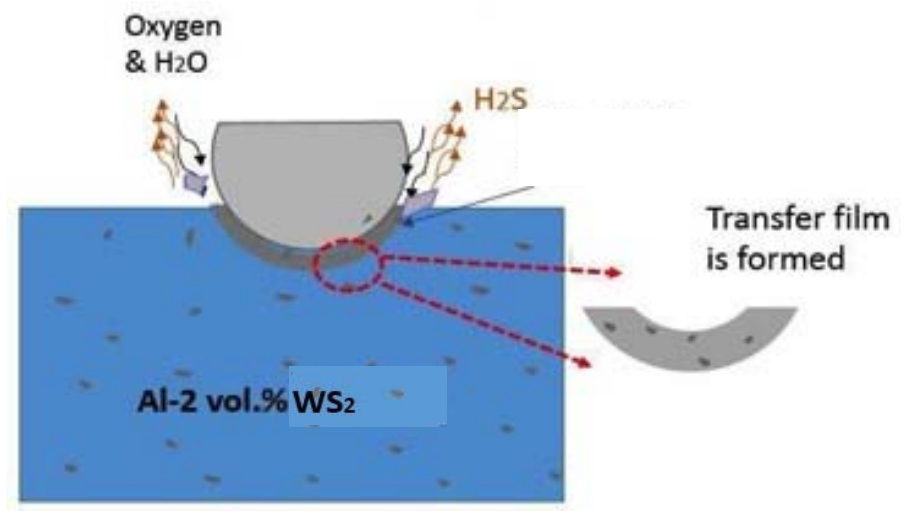

Fig 4.21. Schematic Representation of Behavior of Al-2vol.\%WS 2 at HT. 
surface and the XRD (Fig 4.10c) reflects the formation of $\mathrm{WO}_{3}$. Fig 4.21 represents the mechanism developed during tribological test at HT. The worn surface obtained after HT test is observed in Fig 4.22a. This figure confirms the formation of the tribofilm to protect the surface. This tribofilm is smooth, however it is not homogeneously distributed on the surface. The wear debris got stuck on the countersurface $\left(\mathrm{Al}_{2} \mathrm{O}_{3}\right.$ ball) which suggest that sliding occurred between the tribolayer and the transfer film on the counterface, resulting in a very stable and low COF.

From Fig 4.22b, it can be inferred a very dense wear debris, with a smooth surface and well distributed $\mathrm{WS}_{2}$ particles is formed. The smooth and lamellar morphology of wear debris confirm that the detachment is due to delamination. Some amount of oxygen is found on the wear track. The tribofilm is mainly formed of $\mathrm{WO}_{3}$ and $\mathrm{WO}_{2}$ (Fig 4.10c). This tribofilm is the dense part and has been pointed out by the red arrows, it has a thickness of 5-10 $\mu \mathrm{m}$ as can be observed in Fig 4.22c and d. A FIB image in Fig 4.22d, shows the subsurface of the tribofilm, $\mathrm{WS}_{2}$ nanoparticles can be seen as white spots with intact shape as it is observed as well on the wear debris images, reflecting the ability of $\mathrm{WS}_{2}$ nanoparticles to transfer and cleaves to the counterface due to the weak bonding forces between sandwiches of Sulfur-Tungsten-Sulfur (S-W-S). The wear mechanism is schematically summarized in Fig. 4.23. Fig 4.10 depicts the phases formed for each sample after SPS, room temperature test and high temperature test.

The schematic representation of the wear mechanisms observed during this study for GNP and $\mathrm{WS}_{2}$ are depicted in Fig $4.23 \mathrm{a}$ and $\mathrm{b}$ respectively. When a GNP sheet experiences shear the weak van der Waals forces break apart and few layers of GNP tend 
to wrap the deformed material forming sheet-like structures that facilitate shear sliding with one another. Also, as the counterball has contact with the surface, the GNP provides the surface with the ability to deflect. It must be noted that this is possible only in thin GNP and not thick graphite as ability to wrap and deflect is more difficult to be achieved (Fig 4.23a) when large number of layers are present. Another mechanism present in this sample, is the ability of the GNPs to act as inhibitor at $200^{\circ} \mathrm{C}$ [119], preventing oxygen to go through the sample as observed from Appendix 3. On the other hand, Fig $4.23 \mathrm{~b}$ describes the wear mechanism for $\mathrm{WS}_{2}$. A tribofilm is formed on the surface due to breaking of the weak van der Walls forces that hold the S-W-S structure. Due to shear forces, a portion of the tribofilm is transferred on the counter surface. The wear occurs between transfer film and tribolayer providing lubrication properties and helping to reduce COF. 
a)
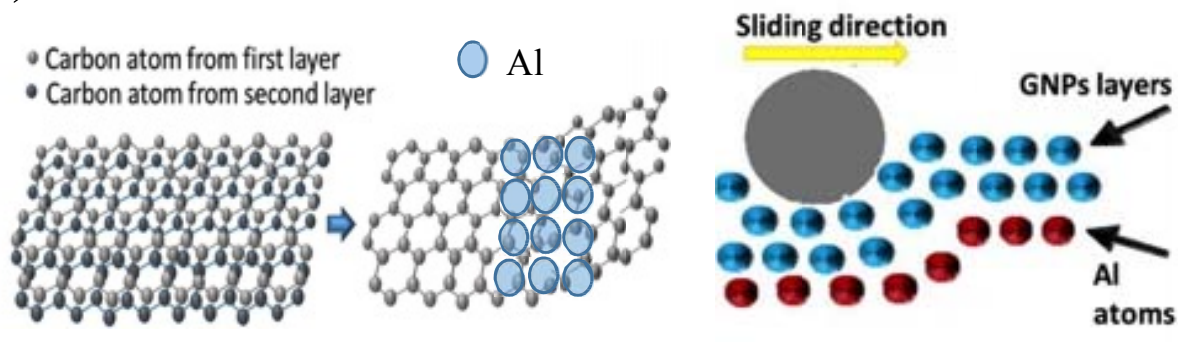

b)
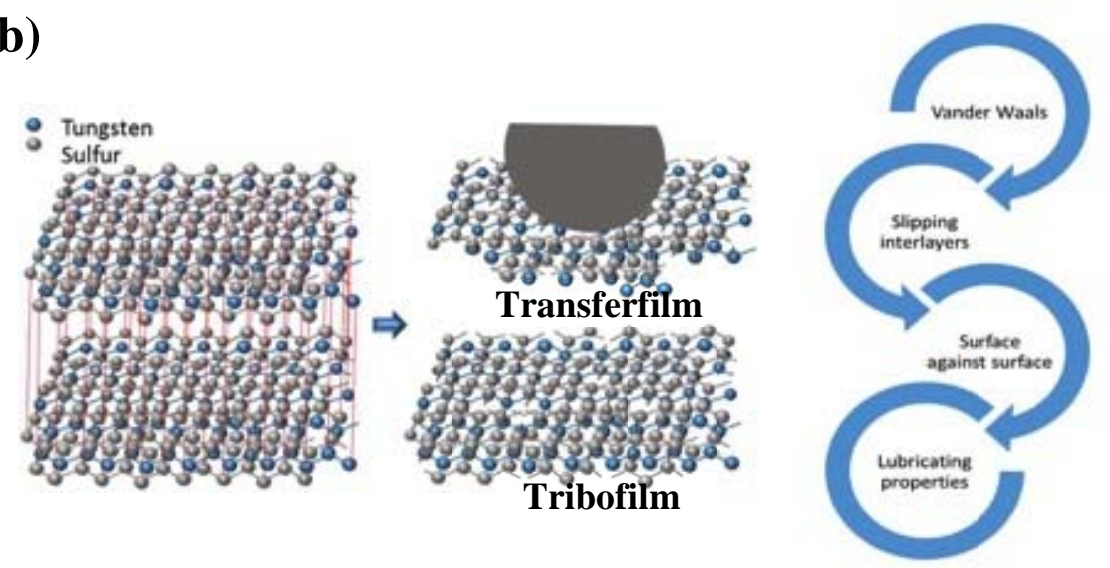

Fig 4.23. Schematic Representation of a) GNP and b) $\mathrm{WS}_{2}$ Wear Mechanism. 


\section{CHAPTER V: CONCLUSIONS}

This thesis presents a detailed investigation on using GNP and $\mathrm{WS}_{2}$ based 2D materials to aluminum as solid lubricant additives for improved tribological properties. 2 vol.\% 2D material was added to aluminum and consolidated as pellets by spark plasma sintering (SPS). Ball-on-disk wear tests in dry sliding conditions were carried out at room temperature and $200^{\circ} \mathrm{C}$. The overall finding of this thesis suggests that $W_{2}$ is an excellent 2D solid lubricant additive which not only reduces coefficient of friction (COF) but also improved the wear resistance of aluminum. GNPs also provide a good alternative for reducing coefficient of friction, but show poor wear resistance. The overall finding of this thesis is suggested by following specific conclusions:

$\star$ Al-2 vol.\% GNP composite displayed poor densification (91\% dense) and low hardness due to agglomeration of GNPs which resulted in insufficient sintering of spherical aluminum powder that lead to poor wear resistance.

Al-2 vol. $\% \mathrm{WS}_{2}$ composite displayed excellent densification (99\% dense) and high hardness as nano-size $\mathrm{WS}_{2}$ particles filled the void between spherical aluminum particles resulting in full densification.

At room temperature (RT), the wear rate of $\mathrm{Al}-2$ vol.\% $\mathrm{WS}_{2}$ composite reduced by $54 \%$ as compared to pure aluminum. Al-2 vol. $\% \mathrm{WS}_{2}$ has the lowest $\mathrm{COF}$ (0.66) at room temperature whereas pure Aluminum has a highest COF of 0.87.

At room temperature (RT), the wear rate of Al-2 vol.\% GNP composite increased by $233 \%$ as compared to pure aluminum. The COF for Al-2 vol. $\%$ GNP at room temperature was 0.79 . 
At $200^{\circ} \mathrm{C}$, the wear rate of $\mathrm{Al}-2$ vol. $\% \mathrm{WS}_{2}$ composite reduced by $29 \%$ as compared to pure aluminum. $\mathrm{Al}-2$ vol.\% $\mathrm{WS}_{2}$ has the lowest $\mathrm{COF}(0.55)$ at $200^{\circ} \mathrm{C}$ whereas pure Aluminum has a highest COF of 0.82 .

At $200^{\circ} \mathrm{C}$, the wear rate of Al-2 vol.\% GNP composite increased by $48 \%$ as compared to pure aluminum. The COF for Al-2 vol. \% GNP at room temperature was 0.69 .

* The wear mechanism in pure Al is adhesive in initial stages but becomes brittle due to formation of $\mathrm{Al}_{2} \mathrm{O}_{3}$ tribolayer at the surface.

* The wear mechanism in Al-2 vol.\% GNP involves formation of excessive wear debris due to poor densification. However, GNPs from the debris form a tribofilm on the surface resulting in lower COF as compared to pure Al. This is possible due to slippage of interlayers of GNP which makes the surface more slippery, and thus, lower friction. At $200^{\circ} \mathrm{C}$, GNPs act as inhibitors to oxygen diffusion resulting in larger oxide content at the surface.

The wear mechanism of Al-2 vol.\% $\mathrm{WS}_{2}$ involves the formation of the protective transfer film. Thus the sliding occurs between the tribolayer and the transfer film located on the counterface, resulting in a very stable and low COF. 


\section{CHAPTER VI: FUTURE WORK}
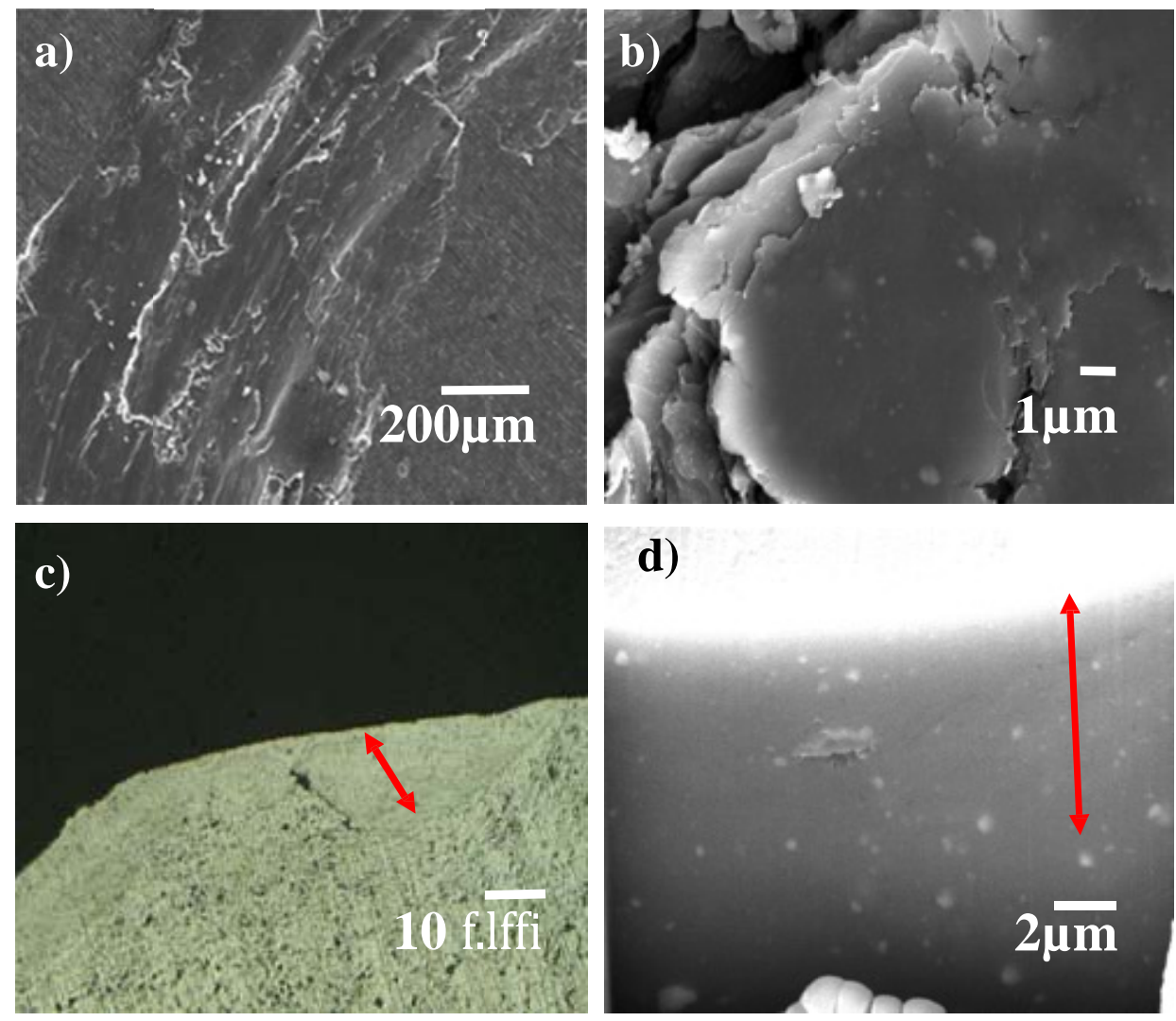

Fig 4.22. SEM Images of the a) Wear Track and b) Wear Debris, c) Optical Microscope Image of the Sub-surface of the Wear Track, d) FIB Image of the Sub-surface of the Wear Track for Al- 2vol.\% $\mathrm{WS}_{2}$ after HT Tribological Test.

The aim of the current research was to explore the potential of GNP and $\mathrm{WS}_{2}$ as $2 \mathrm{D}$ solid lubricant additives to Aluminum alloys for reducing coefficient of friction (COF) and improving energy efficiency. The findings of this study establish $\mathrm{WS}_{2}$ as an excellent option as a solid lubricant additive. However, some of the topics need further investigation to progress towards use of GNP and $\mathrm{WS}_{2}$ as solid lubricant additives. Following is the list of recommendation for advancing the research in this thesis towards the final goal. 
\&rocessing: The density of Al-GNP composite needs to be improved to match that of Al-WS 2 composite. This can possibly be achieved by using smaller GNPs which will fill the voids of $\mathrm{Al}$ spherical particles similar to $\mathrm{WS}_{2}$. However, delamination of graphene layers from a smaller GNP could be a challenge and may not provide sufficient reduction in COF. The packing density of starting powder blend of Al-GNP could also be improved by using irregular shaped aluminum powder mixed with both larger and smaller GNPs. This thesis employed 2 vol.\% additive to aluminum matrix. Composition should be varied to evaluate the effect of concentration.

* Characterization: TEM analysis of $\mathrm{Al} / \mathrm{GNP}$ and $\mathrm{Al} / \mathrm{WS}_{2}$ should be carried out to better understand the nature of interfacial bonding as it will influence the wear behavior.

Wear Behavior: The wear tests in the present thesis were conducted at constant load and sliding distance at RT and $200^{\circ} \mathrm{C}$. It is recommended that wear tests should be conducted at multiple loads and sliding distances to create a larger envelope of operating parameters to evaluate efficacy of GNP and $\mathrm{WS}_{2}$ as solid lubricant additives. It will also enable a deeper understanding of wear mechanism such as tribofilm formation. 


\section{$\underline{\text { LIST OF REFERENCES }}$}

[1] Chris Evans. "Strategy for energy conservation through tribology". American Society of Mechanical Engineers 6 (1977) 170-172

[2] Peter J. Blau. "Fifty years of research on the wear of metals" Tribology international 30 (1997) 321-331

[3] Kenneth Holmberg, PeterAndersson, Ali Erdemir. "Global energy consumption due to friction in passenger cars". Journal of Materials Science - Tribology International 47 (2012) $221-234$

[4] Simon C. Tung, Michael L. McMillan. "Automotive tribology overview of current advances and challenges for the future" Tribology International 37 (2004) 517-536

[5] Yeow-Chong Tan, Zaidi Mohd Ripin."Technique to determine instantaneous piston skirt friction during piston slap" Tribology International 74 (2014) 145-153

[6] Yeow-Chong Tan, Zaidi Mohd Ripin. "Frictional behavior of piston rings of small utility two-stroke engine under secondary motion of piston" Volume 44, Issue 5, May 2011, Pages 592-602

[7] Dongfang Bai. "Solving Piston Secondary Motion of Internal Combustion Engines" Sloan Automotive Laboratory, (2008) Massachusetts Institute of Technology

[8] H. Allmaier, C. Priestner, F.M. Reich, H.H. Priebsch, F. Novotny-Farkas. "Predicting friction reliably and accurately in journal bearings - extending the EHD simulation model to TEHD” Tribology International 58 (2013) 20-28

[9] Masahiko Nakada. "Trends in engine technology and tribology" Tribology International 27 (1994) 3-15

[10] H. Allmaier, C. Priestner, F.M. Reich, H.H. Priebsch, C. Forstner, F. Novotny-Farkas. "Predicting friction reliably and accurately in journal bearings - The importance of extensive oil-models" Tribology International 48 (2012) 93-101

[11] M. Priest, C.M. Taylor. "Automobile engine tribology — approaching the surface" Wear 241 (2000) 193-203

[12] Andrew Roberts, Richard Brooks, Philip Shipway. "Internal combustion engine coldstart efficiency: A review of the problem, causes and potential solutions" Energy Conversion and Management 82 (2014) 327-350 
[13] Heather L. MacLeana, Lester B. Lave. "Evaluating automobile fuel/propulsion system technologies" Progress in Energy and Combustion Science 29 (2003) 1-69

[14] Yoshiro Iwai, Hidetomo Yoneda, Tomomi Honda. "Sliding wear behavior of Sic whisker-reinforced aluminum composite”. Journal Wear 181-183 (1995) 594-602

[15] S. Kumar, M. Chakraborty, V. Subramanya Sarma, B.S. Murty. "Tensile and wear behaviour of in situ Al-7Si/TiB2 particulate composites” Wear 265 (2008) 134-142

[16] S. Gopalakrishnan, N. Murugan. "Production and wear characterisation of AA 6061 matrix titanium carbide particulate reinforced composite by enhanced stir casting method" Composites: Part B, 43 (2) (2012), pp. 302-308

[17] H.B. Michael Rajan, S. Ramabalan, I. Dinaharan, S.J. Vijay. "Effect of $\mathrm{TiB}_{2}$ content and temperature on sliding wear behavior of $\mathrm{AA} 7075 / \mathrm{TiB}_{2}$ in situ aluminum cast composites"

[18] XG Sciences, "xGnP® Graphene Nanoplatelets Carbon Nanoparticles with Multifunctional Capability", XG Sciences Documentation (2009)

[19] Zengshi Xu, Xiaoliang Shi, Wenzheg Zhai, Jie Yao, Siyuan Song, Qiaoxin Zhang. "Preparation and tribological properties of TiAl matrix composites reinforced by multilayer graphene". Carbon (2013)

[20] Diana Berman, Ali Erdemir, Anirudha V. Sumant. "Few layer graphene to reduce wear and friction on sliding steel surfaces". Journal Carbon Volume 54 (2013), Pages 454 459

[21] Monica Ratoi, Vlad Bogdan Niste, John Walker, Jurgita Zekonyte. "Mechanism of action of $\mathrm{WS}_{2}$ lubricant nanoadditives in high preassure contacts". Tribol Lett (2013) 52: $81-91$

[22] J.Ph. Nabot, A. Aubert,."Cathodic sputtering for preparation of lubrication films". Surf. Coat. Technol. 43/44 (1990) 629

[23] O.D. Greenwood, S.C. Moulzolf, P.J. Blau, R.J. Lad. "The influence of microstructure on tribological properties of WO thin films" Journal Wear 232 (1999) 84-90

[24] Stephen F. Bartolucci, Joseph Paras, Mohammad A. Rafiee, Javad Rafiee, Sabrina Lee, Deepak Kapoor, Nikhil Koratkar. "Graphene-aluminum nanocomposites" Materials Science and Engineering A (2011) 7933-7937

[25] P.X. Feng, M. Sajjad. "Few-atomic-layer boron nitride sheets syntheses and applications 
for semiconductor diodes" Materials Letters 89 (2012) 206-208

[26] ZhuLi-naa, WangCheng-biao, WangHai-doub,,XuBin-shib, ZhuangDa-mingc, LiuJia-junc ,LiGuo-lu. "Microstructure and tribological properties of $\mathrm{WS}_{2} / \mathrm{MoS}_{2}$ multilayer films. Applied Surface Science 258 (2012) 1944-1948

[27] M. Priest, D. Dowson, C.M. Taylor. "Predictive wear modelling of lubricated piston rings in a diesel engine" Wear 231 _1999. 89-101

[28] Jirang CUI, Hans J. ROVEN. "Recycling of automotive aluminum” Trans. Nonferrous Met. Soc. China 20 (2010) 2057-2063

[29] European Aluminium Association. "Alumimium in cars" http://www.alueurope.eu/pdf/Aluminium_in_cars_Sept2008.pdf (2007)

[30] Daniel Carle, Gordon Blount. "The suitability of aluminium as an alternative material for car bodies" Materials and Design 20 (1999) $267-272$

[31] Varuzan M. Kevorkijan. "An economic evaluation of aluminum-based weight reduction in current and future generations of passenger cars" KZLTET 33(6)413(1999)

[32] W.S. Miller, L. Zhuang, J. Bottema, A.J. Wittebrood, P. De Smet, A. Haszler, A. Vieregge. "Recent development in aluminum alloys for the automotive industry" Materials Science and Engineering A280 (2000) 37-49

[33] G. S. Cole and A. M. Sherman. "Lightweight Materials for Automotive Applications" Ford Motor Company, Dearborn, Ml 48121-20 53 (1995)

[34] M. Kathiresan and T. Sornakumar. "Friction and wear studies of die cast aluminum alloy-aluminum oxide-reinforced composites" Industrial Lubrication and Tribology 62/6 (2010) 361-371

[35] Z.Y. Liu, B.L. Xiao, W.G. Wang, Z.Y. Ma. "Developing high-performance aluminum matrix composites with directionally aligned carbon nanotubes by combining friction stir processing and subsequent rolling" Carbon 62 (2013) 35-4 2

[36] Bharat Bhushan. "Introduction to tribology" New York: John Wiley \& Sons, (2002)252,267 , 
[37] William W Scott, Bharat Bhushan. "Micro/nano-scale differential wear of multiphase materials: pole tip recession in magnetic-tape heads" Volume 252, Issues 1-2, January 2002, Pages 103-122

[38] Vilas N. Koinkar, Bharat Bhushan. "Microtribological studies of Al203, Al203-TiC, polycrystalline and single-crystal Mn-Zn ferrite, and SiC head slider materials" Wear 202 (1996) 110-122

[39] B. Podgornik, T. Kosec, A. Kocijan, C. Donik. "Tribological behaviour and lubrication performance of hexagonal boron nitride (h-BN) as a replacement for graphite in aluminium forming" Tribology International 81 (2015) 267-275

[40] A. Baradeswaran, A. Elaya Perumal. "Effect of Graphite on Tribological and Mechanical Properties of AA7075 Composites” Tribology Transactions, 58: 1-6, (2015)

[41] Jen Fin Lin, Ying Chong Wng, Chi Yuan Tsao. "Tribological Performance of 6061 Aluminum AlloyIGraphite Materials under Oil-Lubricated and Dry Sliding Conditions" Tribology Transactions 41 (1998) 2, 251-261

[42] G. Rajaram, S. Kumaran, T. Srinivasa Rao. "Sliding Wear Behavior of Al-Si/Graphite Composite" Tribology Transactions, 54: 115-121, 2011

[43] Francis J. Clauss. "Solid Lubricants and Self-Lubricating Solids" ACADEMIC PRESS, INC. (1972) 42, 75

[44] Sidney R. Cohen, Y. Feldman, H. Cohen, R. Tenne. "Nanotribology of novel metal dichalcogenides” Applied Surface Science 144-145 (1999) 603-607

[45] Jengyue Wu, Jeffrey H. Harwell and Edgar A. O Rear. "Two-dimensional reaction solvents: Surfactant Bilayers in the formation of Ultrathin Films" Langmuir 3 (1987) 531537 
[46] C. Donnet, A. Erdemir. "Historical developments and new trends in tribological and solid lubricant coatings" Surface and Coatings Technology $180-181$ (2004) 76-84

[47] Kenneth Holmberg, Helena Ronkainen, Anssi Laukkanen, Kim Wallin. "Friction and wear of coated surfaces - scales, modelling and simulation of tribomechanisms" Surface \& Coatings Technology 202 (2007) 1034-1049

[48] Hermann A. Jehn. "Multicomponent and multiphase hard coatings for tribological applications" Surface and Coatings Technology 131 (2000) 433-440

[49] Qing Tang, Zhen Zhou. "Graphene-analogous low-dimensional materials" Progress in Materials Science 58 (2013) 1244-1315

[50] Keith E. Whitener, and Paul E. Sheehan. "Graphene synthesis" Diamond \& Related Materials (2014)

[51] T. Filleter, J. L. McChesney, A. Bostwick, E. Rotenberg, K. V. Emtsev, Th. Seyller, K. Horn, R. Bennewitz. "Friction and dissipation in epitaxial graphene films" Physical review letters (2009) 102, 086102

[52] Mikhail L. Katsnelson. "Graphene - Carbon in two dimensions" Cambridge University (2012) 6, ISBN 978-0-521-19540-9

[53] Virendra Singh, Daeha Joung, Lei Zhai, Soumen Das, Saiful I. Khondaker, Sudipta Seal. "Graphene based materials: Past, present and future" Progress in Materials Science 56 (2011) 1178-1271

[54] C. Lee, X. Wei, J.W. Kysar, J. Hone. "Measurement of the Elastic Properties and Intrinsic Strength of Monolayer Graphene” Science (2008) Vol. 321 no. 5887 pp. 385-388

[55] Strem Chemicals, Inc. Graphene Nano-platelets 1211. Retrieved from: http://www.strem.com/uploads/resources/documents/graphene_nanoplatelets.pdf 
[56] Muhammad Rashada, Fusheng Pana, Aitao Tanga, Muhammad Asif. "Effect of Graphene Nanoplatelets addition on mechanical properties of pure aluminum using a semipowder method” Progress in Natural Science: Materials International 24 (2014) 101-108

[57] Santosh Kumar Yadav, JaeWhan Cho. "Functionalized graphene nanoplatelets for enhanced mechanical and thermal properties of polyurethane nanocomposites" Applied Surface Science 266 (2013) 360-367

[58] Monika Michálkováa, Monika Kasiarová, Peter Tatarkoc ,Ján Duszac, Pavol Sajgalík. "Effect of homogenization treatment on the fracture behavior of silicon nitride/graphene nanoplatelets composites" Journal of the European Ceramic Society (2014). Volume 34, Issue 14, November 2014, Pages 3291-3299

[59] X.Z. Yu, C.G. Hwang, C.M. Jozwiak, A. Köhl, A.K. Schmid, A. Lanzara "New synthesis method for the growth of epitaxial graphene" Journal of Electron Spectroscopy and Related Phenomena 184 (2011) 100-106

[60] Charrier, A., Coati, A., Argunova, T., Thibaudau, F., Garreau, Y., Pinchaux, R., "Solid State decomposition of $\mathrm{SiC}$ for growing ultra-thin heteroepitaxial graphite films", Journal of Applied Physics (2002), 2479-2484

[61] Lingling Wang, Jinghuai Gao, Zongben Xu, Bing Weng, Xiudi Jiang. "Hydrocarbon detection using adaptively selected spectrum attenuation" Journal of Applied Geophysics 105 (2014) 59-66

[62] Samuel Iwarere, Vandad Rohani, Deresh Ramjugernath, Frédéric Fabry, Laurent Fulcheri. "Hydrocarbons synthesis from syngas by very high pressure plasma" Chemical Engineering Journal 241 (2014) 1-8

[63] Sarah Goler, Camilla Coletti, Vincenzo Piazza, Pasqualantonio Pingue, Francesco Colangelo, Vittorio Pellegrini, Konstantin V. Emtsev, Stiven Forti, Ulrich Starke, Fabio Beltram, Stefan Heun "Revealing the atomic structure of the buffer layer between $\mathrm{SiC}(0001)$ and epitaxial graphene" Carbon 51 (2013) 249-254 
[64] Jianjun Wang, Mingyao Zhu, Ron A. Outlaw, Xin Zhao, Dennis M. Manos, Brian C. Holloway. "Synthesis of carbon nanosheets by inductively coupled radio-frequency plasma enhanced chemical vapor deposition". Carbon 42 (2004) 2867-2872

[65] Qingbin Zheng, Zhigang Li, Junhe Yang, Jang-Kyo Kim. "Graphene oxide-based transparent conductive films" Progress in Materials Science 64 (2014) 200-247

[66] Daniel R. Dreyer, Sungjin Park, Christopher W. Bielawski and Rodney S. Ruoff. “The chemistry of graphene oxide" Chem. Soc. Rev. (2010) 39, 228-240

[67] Soldano, C., Mahmood, A., Dujardin, E., "Production, properties, and potential of graphene", Carbon 48 (2010), 2127-2150

[68] Huc, V., Bendiab, N., Rosman, N., Ebbesen, T., Delacour, C., Bouchiat, V., "Large and flat graphene flakes produced by epoxy bonding and reverse exfoliation of highly oriented pyroltic graphite", Nanotechnology 19 (2008)

[69] Dong-Hun Kim, Soo-Young Park. "Facile in-situ preparation of polyaniline/graphene nanocomposites using methanesulfonic acid" Polymer (2014), doi: 10.1016

[70] J.H. Lee, D.W.Shin, V.G. Makotchenko, A.S. Nazarov, V.E. Fedorov, J.H. Yoo, S.M. Yu, J.Y. Choi, J.M. Kim, J.B. Yoo. "The superior dispersion of easily soluble graphite" ,Small 6(2010)58-62.

[71] Zheng Liu, Kazu Suenaga, Peter J. F. Harris, and Sumio Iijima, "Open and Closed Edges of Graphene Layers” PRL 102, 015501 (2009)

[72] Jong Min Yuk, Jungwon Park, Peter Ercius, Kwanpyo Kim, Daniel J. Hellebusch, Michael F. Crommie, Jeong Yong Lee, A. Zettl, A. Paul Alivisatos. "High-Resolution EM of Colloidal Nanocrystal Growth Using Graphene Liquid Cells" SCIENCE VOL 3366 (2012)

[73] Dimitrios Tasis, Kostas Papagelis, Panagiotis Spiliopoulos, Costas Galiotis. "Efficient exfoliation of graphene sheets in binary solvents” Materials Letters 94 (2013) 47-50 
[74] A. C. Ferrari, J. C. Meyer,V. Scardaci, C. Casiraghi, M. Lazzeri, F. Mauri, S. Piscanec, D. Jiang, K. S. Novoselov, S. Roth, and A. K. Geim. "Raman Spectrum of Graphene and Graphene Layers" Physical review letters (PRL) 97, 187401 1-4 (2006)

[75] J.S. Park, A. Reina, R. Saito, J. Kong, G. Dresselhaus, M.S. Dresselhaus. "G'band Raman spectra of single, double and triple layer graphene" Carbon 47 (2009) 1303-1310

[76] Georgia Tsoukleri, John Parthenios, Konstantinos Papagelis, Rashid Jalil, Andrea C. Ferrari, A. K. Geim, Kostya S. Novoselov and Costas Galiotis. "Subjecting a graphene monolayer to tension and compression" Small 5 (2009), No. 21, 2397-2402

[77] Wenzheng Zhai, Xiaoliang Shi, Mang Wang, Zengshi Xu, Jie Yao, Siyuan Song, Yufu Wang. "Grain refinement: A mechanism for graphene nanoplatelets to reduce friction and wear of $\mathrm{Ni}_{3}-\mathrm{Al}$ matrix self-lubricating composites"

[78] Andy Nieto, Debrupa Lahiri, Arvind Agarwal "Synthesis and properties of bulk graphene nanoplatelets consolidated by spark plasma sintering" Carbon 50 (2012) 40684077

[79] Shusheng Xu, Xiaoming Gao, Ming Hu, Jiayi Sun, Dong Jiang, DeshengWang, Feng Zhou, LijunWenga, Weimin Li. "Dependence of atomic oxygen resistance and the tribological properties on microstructures of $\mathrm{WS}_{2}$ films" Applied Surface Science 298 (2014) 36-43

[80] Emre Selvi, Yanzhang Ma, Resul Aksoy, Atila Ertas, Allen White. "High pressure Xray diffraction study of tungsten disulfide" Journal of Physics and Chemistry of Solids 67 (2006) 2183-2186

[81] Zhuangzhi Wu, Dezhi Wang, Xiuqi Zan, Aokui Sun. "Synthesis of WS2 nanosheets by a novel mechanical activation method" Materials Letters 64 (2010) 856-858

[82] Shusheng Xu, Xiaoming Gao, Ming Hu, Jiayi Sun, Dong Jiang, Feng Zhou, Weimin Liu, LijunWeng "Nanostructured WS2-Ni composite films for improved oxidation, resistance and tribological performance” Applied Surface Science 288 (2014) 15-25 
[83] Hui Fang, Steven Chuang, Ting Chia Chang, Kuniharu Takei, Toshitake, Takahashi1, Ali Javey. "High Performance Single Layered WSe2 p-FETs with Chemically Doped" Nano Lett., (2012), 12 (7) 3788-3792

[84] Ana Laura Elías, Néstor Perea-López, Andrés Castro-Beltrán, Ayse Berkdemir, Ruitao Lv, Simin Feng, Aaron D. Long, Takuya Hayashi, Yoong Ahm Kim, Morinobu Endo, Humberto R. Gutiérrez, Nihar R. Pradhan, Luis Balicas, Thomas E. Mallouk, Florentino López-Urías, Humberto Terrones, Mauricio Terrones. "Controlled Synthesis and Transfer of Large-Area WS2 Sheets: From Single Layer to Few Layers" ACS Nano, (2013), 7 (6), 5235-5242

[85] Dong-Won Lee, O. V. Tolochko, Farkhod R. Turaev, Dongsoo Kim, Byoung-Kee Kim. "Synthesis and characterization of WS2 nanoparticles by chemical vapor condensation” J. Nanosci. Nanotechnol. (2009), Vol. 9, doi:10.1166/jnn.2009.1534

[86] Jonathan N. Coleman, Mustafa Lotya, Arlene O’Neill, Shane D. Bergin,1,6 Paul J. King, Umar Khan, Karen Young, Alexandre Gaucher, Sukanta De, Ronan J. Smith, Igor V. Shvets, Sunil K. Arora, George Stanton, Hye-Young Kim, Kangho Lee, Gyu Tae Kim, Georg S. Duesberg, Toby Hallam, John J. Boland, Jing Jing Wang, John F. Donegan, Jaime C. Grunlan, Gregory Moriarty, Aleksey Shmeliov, Rebecca J. Nicholls, James M. Perkins, Eleanor M. Grieveson, Koenraad Theuwissen, David W. McComb, Peter D. Nellist, Valeria Nicolosi. "Two-Dimensional Nanosheets Produced by Liquid Exfoliation of Layered Materials” Science 331, 568 (2011)

[87] Xingze Mao, Yan Xu, Qixin Xue, Weixiao Wang and Daqiang Gao. "Ferromagnetism in exfoliated tungsten disulfide nanosheets" Mao et al. Nanoscale Research Letters (2013), $8: 430$

[88] Salman Alfihed, Mohammad Hossain, Abdulaziz Alharbi, Ahmed Alyamani, Fahhad H. Alharbi. "PLD Grown Polycrystalline Tungsten Disulphide (WS2) Films" Journal of Materials Volume 2013 (2013), Article ID 603648, 5 pages

[89] J.S Zabinski, M. S Donley, S. V Prasad. "Synthesis and characterization of tungsten disulphide films growth by pulsed-laser deposition” Journal of Materilas science 29 (1994) 4834-4839 
[90] P.P. Hankare, A.H. Manikshete, D.J. Sathe, P.A. Chate, A.A. Patil, K.M. Garadkar. "WS 2 thin films: Opto-electronic characterization" Journal of Alloys and Compounds 479 (2009) 657-660

[91] P.G. Li, M. Lei, X.F. Wang, H.L. Tang, W.H. Tang. "Thermal conversion of tungsten oxide nanorods to tungsten disulfide nanoflakes" Journal of Alloys and Compounds 474 (2009) 463-467

[92] T. W. Scharf, D. R. Diercks, B. P. Gorman, S. V. Prasad, M. T. Dugger. "Atomic Layer Deposition of Tungsten Disulphide Solid Lubricant Nanocomposite Coatings on Rolling Element Bearings” Tribology Transactions, 52: 284-292, 2009

[93] S.V. Prasad, N.T. McDevitt, J.S. Zabinski. "Tribology of tungsten disulfidenanocrystalline zinc oxide adaptive lubricant films from ambient to $500^{\circ} \mathrm{C}$ " Wear 237 , (2000) 186-196

[94] A. Smolyanitsky, J. P. Killgore, V. K. Tewary. "Effect of elastic deformation on frictional properties of few-layer graphene" Physical Review B 85, 035412 (2012)

[95] S.V. Prasad, N.T. McDevitt, J.S. Zabinski. "Tribology of tungsten disulfide films in humid environments:The role of a tailored metal-matrix composite substrate" Wear 230 _1999. 24-34

[96] S.K. Georgantzinos, G.I. Giannopoulos, N.K. Anifantis. "Numerical investigation of elastic mechanical properties of graphene structures", Journal of Materials and Design 31 (2010) 4646-4654

[97] Andy Nieto, Debrupa Lahiri, Arvind Agarwal. "Graphene NanoPlatelets reinforced tantalum carbide consolidated by spark plasma sintering” Materials Science \& Engineering A $582(2013) 338-346$

[98] Jibin Pu, Shanhong Wan, Wenjie Zhao, Yufei Mo, Xiaoqian Zhang, Liping Wang and Qunji Xue. "Preparation and Tribological Study of Functionalized Graphene Nanocomposite Ultrathin Lubrication Films on Si Substrates”. J. Phys. Chem. C (2011) $115,13275-13284$ 
[99] Wen-Shyong Kuo, Nyan-Hwa Tai, Ting-Wei Chang. "Deformation and fracture in graphene nanosheets" Composites: Part A 51 (2013) 56-61

[100] T.W Scharf, S.V Prasad, M.T. Dugger, P.G. Kotula, R.S Goeke, R.K. Grubbs. "Growth, structure, and tribological behavior of atomic layer-deposited tungsten disulphide solid lubricant coatings with applications to MEMS”. Acta Materialia 54 (2006) $4731-4743$

[101] Somuri Prasad, Jeffrey Zabinski "Lubricants Super Slippery solids" Nature (1997) Vol 387 761-763.

[102] J.S. Zabinski, M.S. Donley, N.T. McDevitt. "Mechanistic study of the synergism between $\mathrm{Sb} 2 \mathrm{O} 3$ and MoS2lubricant systems using Raman spectroscopy” Volume 165, Issue 1, 1 May 1993, Pages 103-108

[103] Young I. Jhon, Young Min Jhon, Geun Y. Yeom b, Myung S. Jhon,. “Orientation dependence of the fracture behavior of graphene" Carbon 66 (2014) 619-628

[104] Yan Zhao, Kang Ning Sun, Wei Li Wang, Yu Xiang Wang, Xiao Lin Sun, Yan Jie Liang, Xiao Ning Sun, Peng Fei Chui. "Microstructure and anisotropic mechanical properties of graphene nanoplatelets toughened biphasic calcium phosphate composite" Ceramics International 39 (2013) 7627-7634

[105] L. Wang, Q. Zhang. "Elastic behavior of bilayer under in-plane loadings" Current Applied Physics 12 (2012) 1173-1177

[106] Zhao Deng, Alex Smolyanitsky, Qunyang Li, Xi-Qiao Feng, J. Cannara. "Adhesiondependent negative friction coefficient on chemically modified graphite at the nanoscale" Nature Materials(2012) Vol 12 1032-1037

[107] Xiaoliang Shi, Siyuan Song, Wenzheng Zhai, Mang Wang, Zengshi Xu, Jie Yao, Abid Qamar ud Din, Qiaoxin Zhang. "Tribological behavior of Ni3Al matrix selflubricating composites containing $\mathrm{WS}_{2}, \mathrm{Ag}$ and $\mathrm{hBN}$ tested from room temperature to 800 ${ }^{\circ} \mathrm{C}$ " Materials and Design 55 (2014) 75-84 
[108] Monica Ratoi, Vlad Bogdan Niste, John Walker, Jurgita Zekonyte. "Mechanism of Action of $\mathrm{WS}_{2}$ Lubricant Nanoadditives in High-Pressure Contacts" Tribol Lett (2013) 52:81-91

[109] U. Anselmi-Tamburini, J.E. Garay, Z.A. Munir. "Fundamental investigations on the spark plasma sintering/synthesis process III. Current effect on reactivity" Materials Science and Engineering A 407 (2005) 24-30

[110] A. V. Ragulya. "Fundamentals of Spark Plasma Sintering" Encyclopedia of Materials: Science and Technology. ISBN: 978-0-0804-3152-9. Pages 1-5

[111] The AccuPyc II 1340 Gas Displacement Pycnometry System. Retrieved from: http://www.micromeritics.com/Product-Showcase/AccuPyc-II-1340.aspx. On 5/28/2014

[112] P.G. Klemens, B. Cort. "Thermodynamic properties of helium bubbles in aged plutonium. Journal of Alloys and Compounds" 252 (1997) 157-161

[113] Gwidon W, Andrew W. "Experimental methods in tribology" ISBN 0-444-51589-5. Tribology Series 44 (2004)

[114] Emil Jose Sandoz-Rosado "The tribological behavior of graphene and its role as a protective Coating" Submitted in partial fulfillment of the requirements for the degree of Doctor of Philosophy in the Graduate School of Arts and Sciences. COLUMBIA UNIVERSITY (2013)

[115] Jieun Yang, Damien Voiry, Seong Joon Ahn, Dongwoo Kang, Ah Young Kim, Manish Chhowalla, and Hyeon Suk Shin "Two-Dimensional Hybrid Nanosheets of Tungsten Disulfide and Reduced Graphene Oxide as Catalysts for Enhanced Hydrogen Evolution” Angew. Chem. Int. Ed. (2013), 52, 1 - 5

[116] Ayse Berkdemir, Humberto R. Gutierrez, Andres R. Botello, Nestor Perea-Lopez, Ana Laura Elias, Chen-Ing Chia, Bei Wang, Vincent H. Crespi, Florentino Lopez-Urias, Jean-Christophe Charlier, Humberto Terrones, Mauricio Terrones. "Identification of individual and few layers of $\mathrm{WS}_{2}$ using raman spectroscopy" Scientific Reports (2013) 3:1755 DOI: $10.1038 /$ srep01755 
[117] R.L Deuis, C. Subramanian, J. M. Yellup. "Dry sliding wear of aluminum composites - A review” Composites Science and Technology 57 (1997) 415-435

[118] J.F. Archard. "Contact and Rubbing of Flat Surfaces" Journal of Applied Physics Vol.24, 8 (1953) 981-988

[119] Andy Nieto, Amit Kumar, Debrupa Lahiri, Cheng Zhang, Sudipta Seal, Arvind Agarwal. "Oxidation behavior of graphene nanoplatelets reinforced tantalum carbide composites in high temperature plasma flow" Carbon 67 (2014) $398-408$

[120] Nam P. Suh. "An overview of the delamination theory of wear" Wear 44 (1977) 116

[121] A. T Alpas, H. Hu, J. Zhang. "Plastic deformation and damage accumulation below the worn surfaces" Wear, 162-164 (1993) 188-195 


\section{APPENDICES}

\section{Appendix 1- EDS of Worn Surface at RT and HT}

APPENDIX 1

AMOUNT OF OXIGEN ON THE WEAR TRACK

\begin{tabular}{lcc}
\hline \multicolumn{1}{c}{ Sample Composition } & RT (wt\%) & HT (wt\%) \\
\hline Pure Al & 31.43 & 19.56 \\
Al- 2 vol.\% GNP & 14.72 & 31.24 \\
Al-2 vol.\% $\mathrm{WS}_{2}$ & 35.30 & 14.67
\end{tabular}

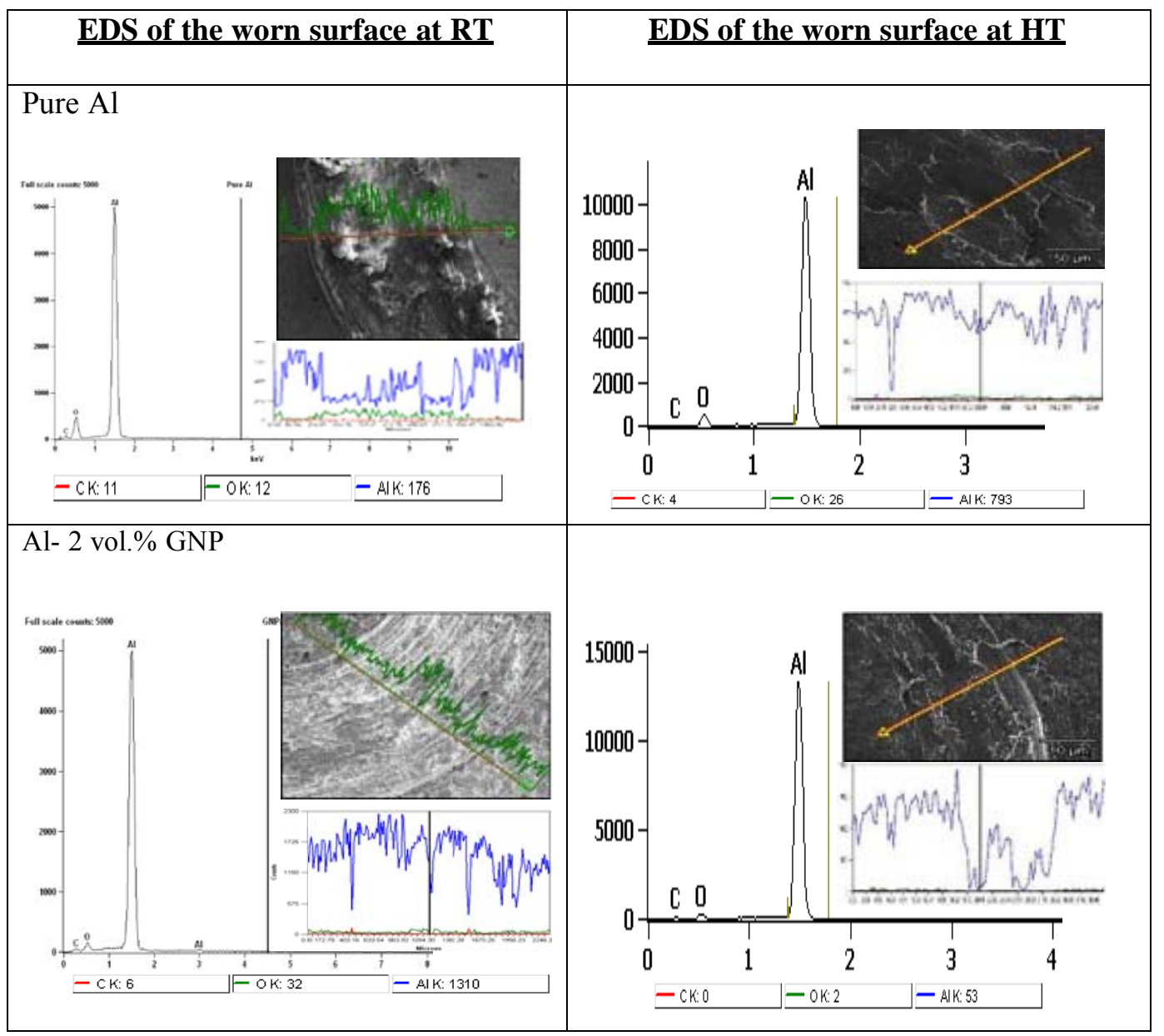


$\mathrm{Al}-2$ vol. $\% \mathrm{WS}_{2}$

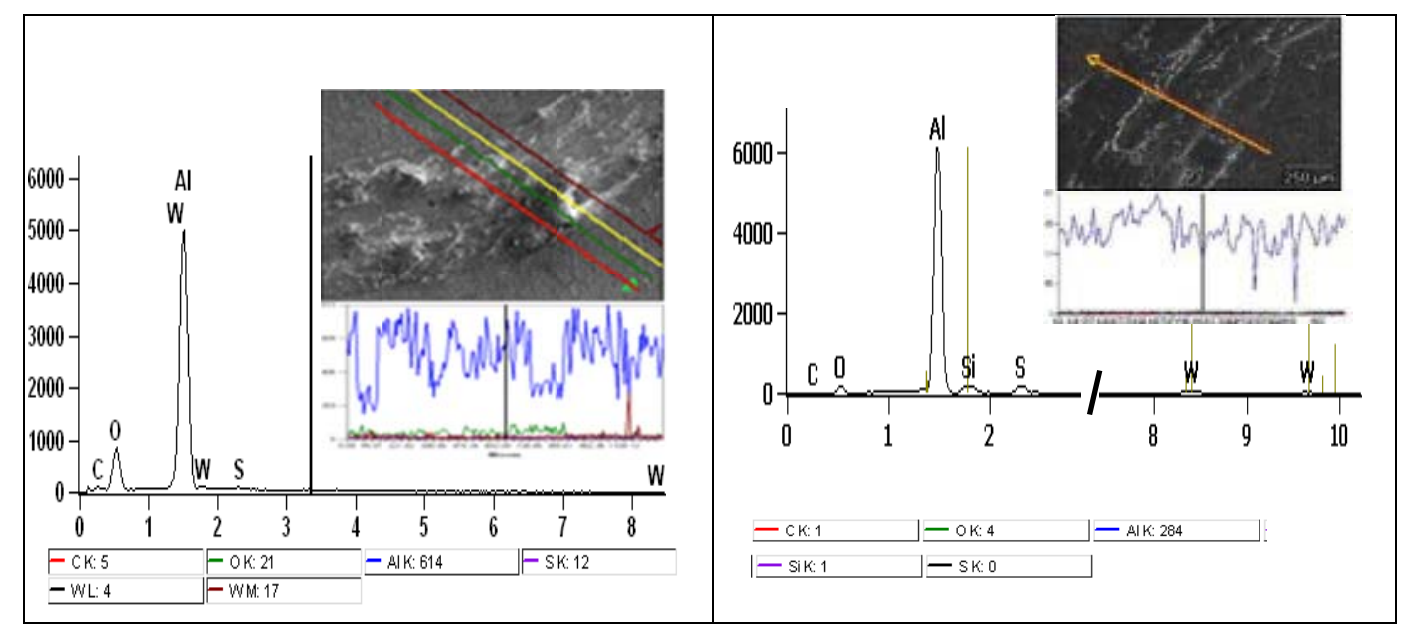


Appendix 2- TEM and SAED of Wear Debris

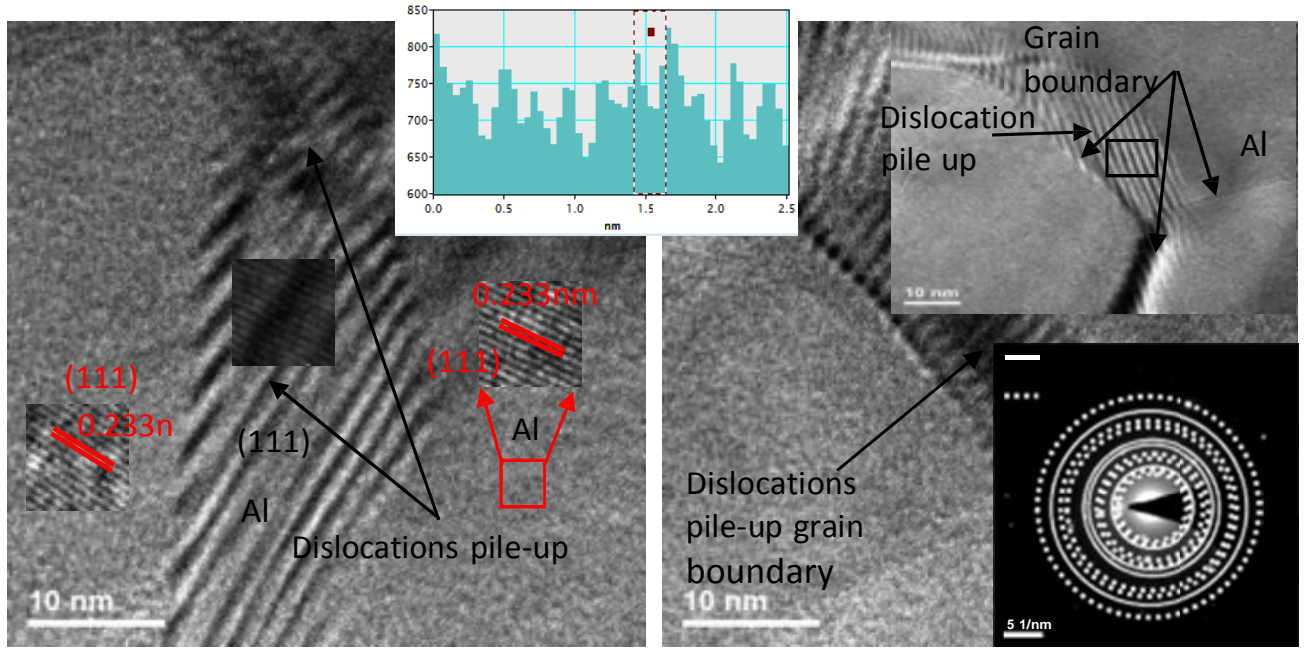

TEM and SAED of wear debris of pure Al after RT test.
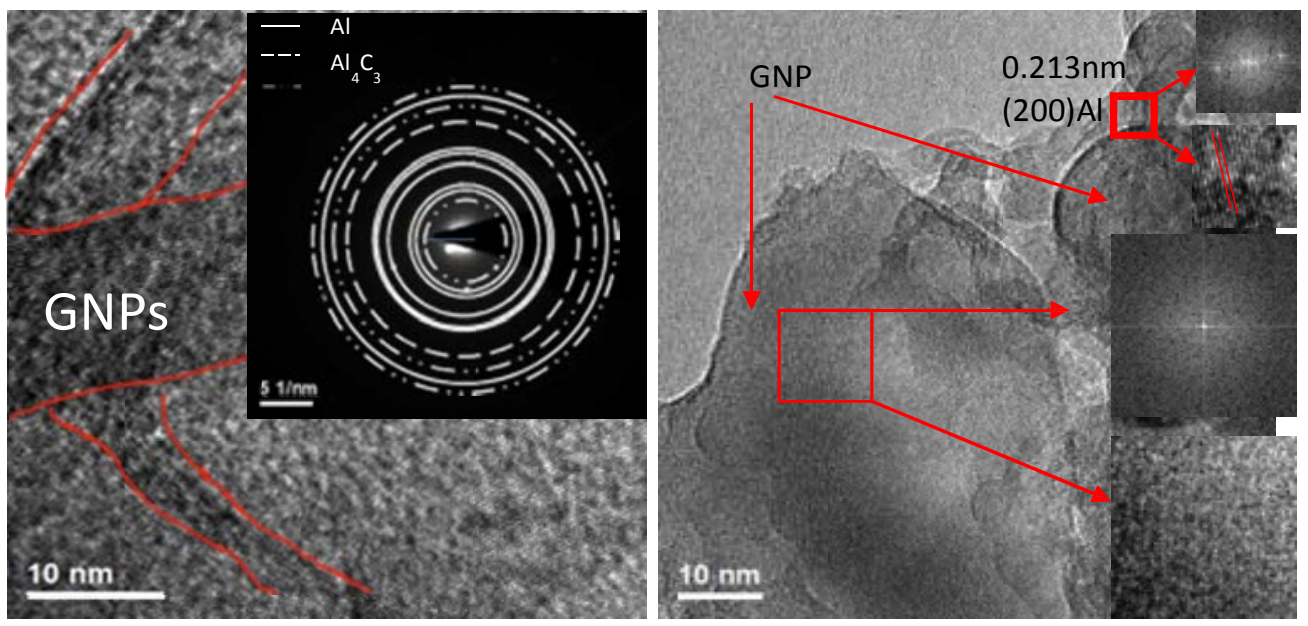

TEM and SAED of wear debris of Al-2vol.\%GNP after RT 

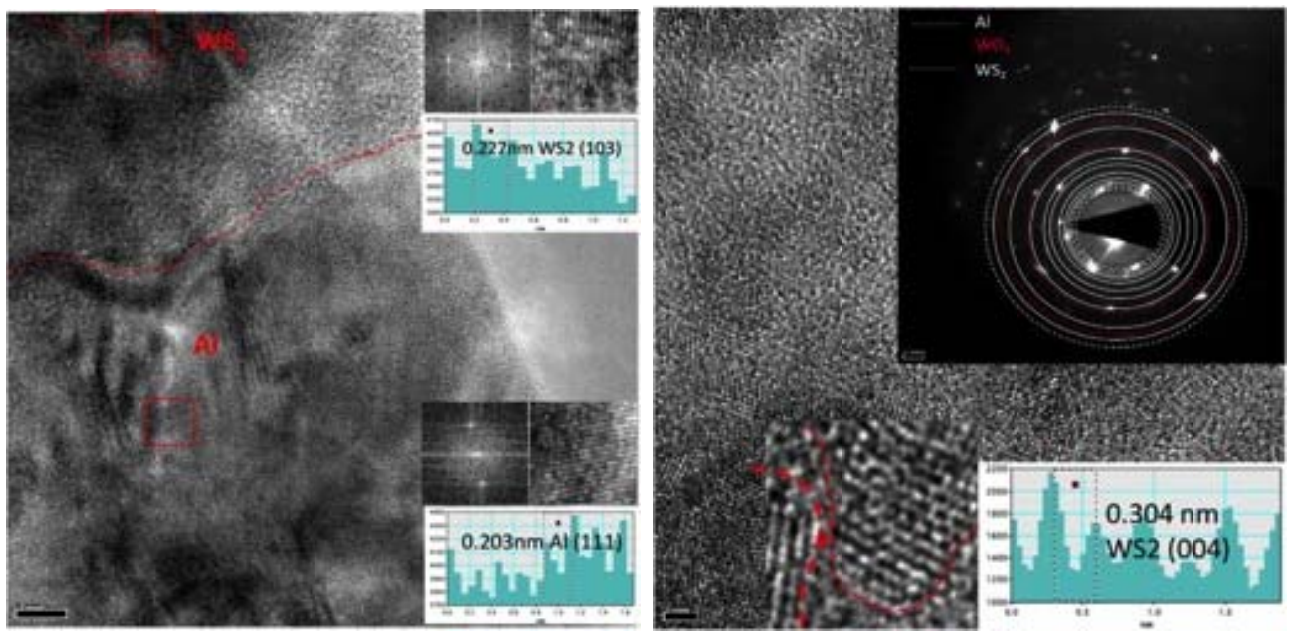

TEM and SAED of wear debris of Al-2vol. $\% \mathrm{WS}_{2}$ after RT test.
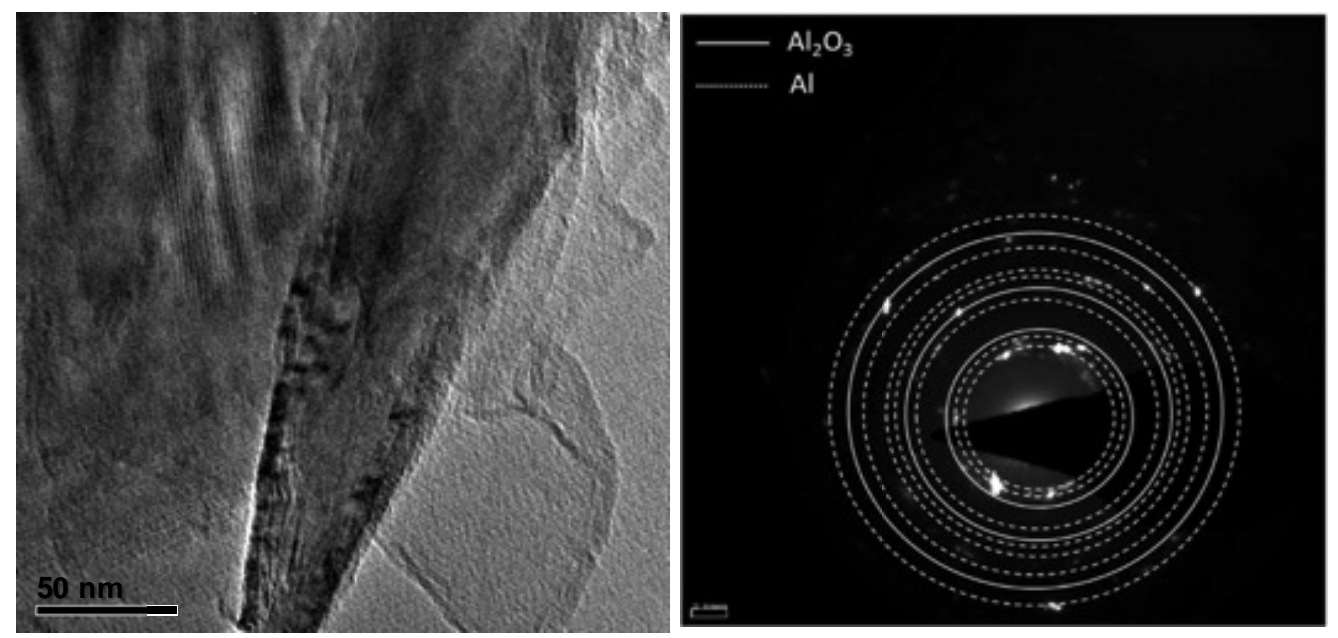

TEM and SAED of wear debris of pure Al after HT test. 

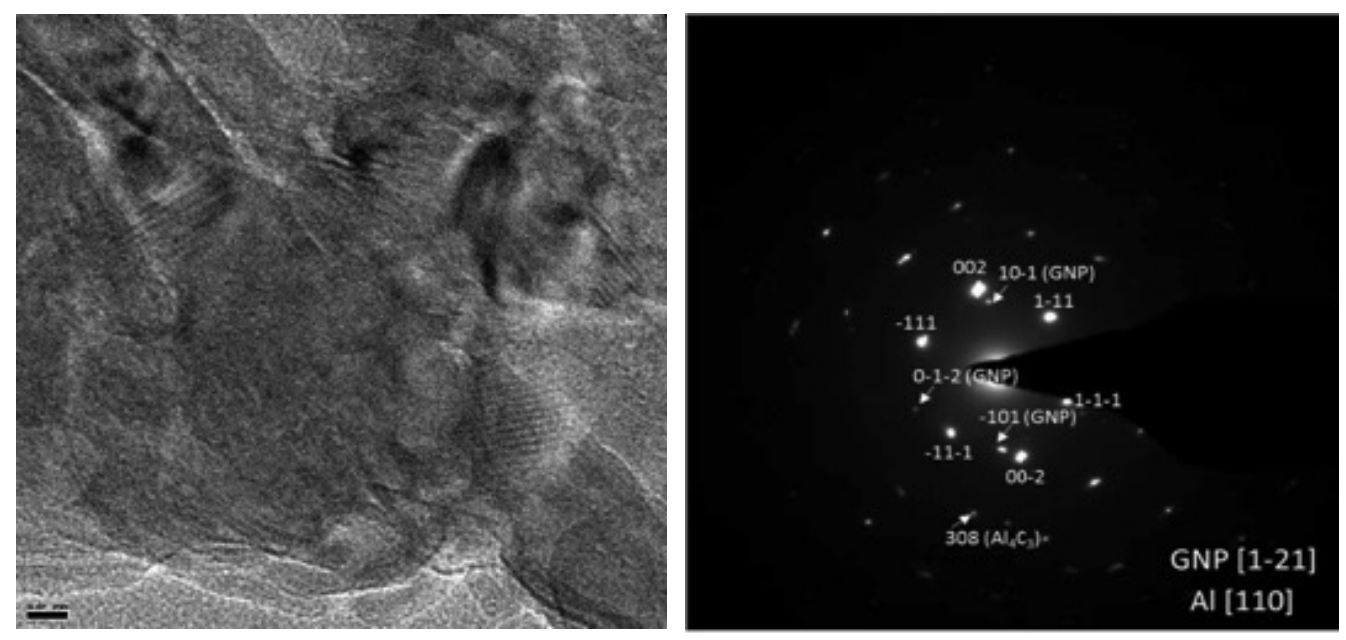

TEM and SAED of wear debris of Al-2vol.\%GNP after HT test.
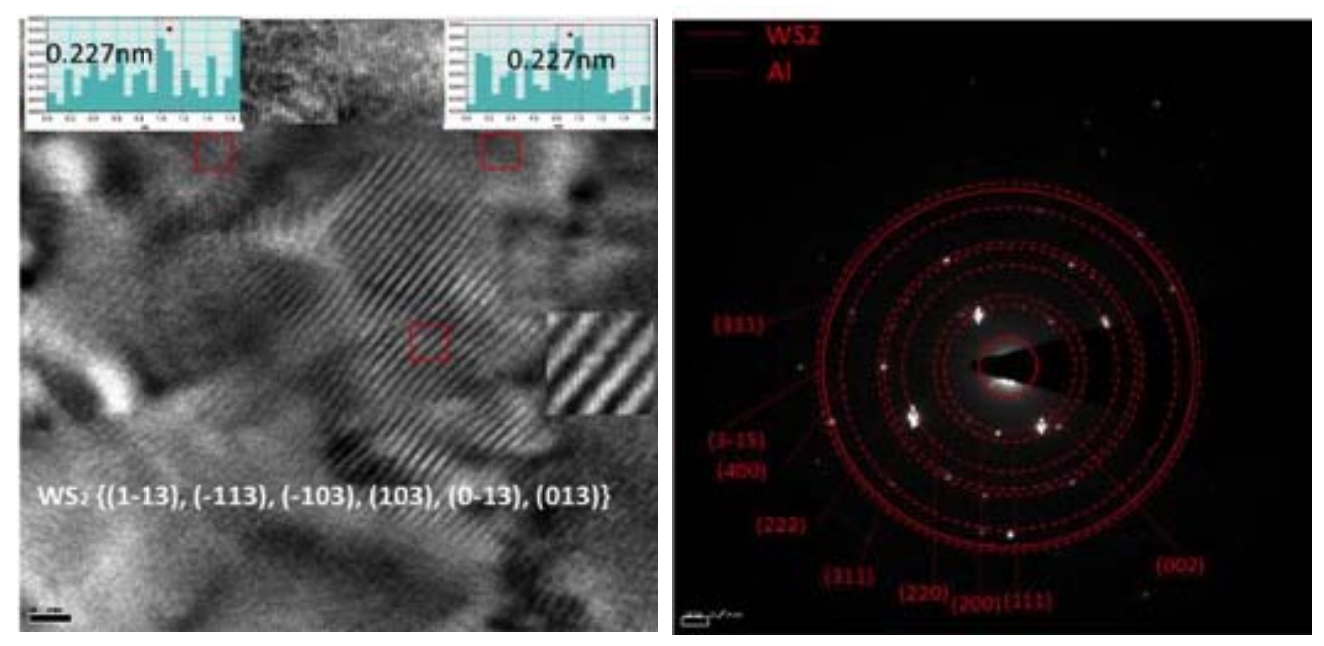

TEM and SAED of wear debris of Al-2vol. $\% \mathrm{WS}_{2}$ after HT test. 


\section{Appendix 3- EDS to Study Oxidation Behavior of GNP on the Tribofilm}

Cross-section of the Al-2vol.\% GNP wear track at room temperature:
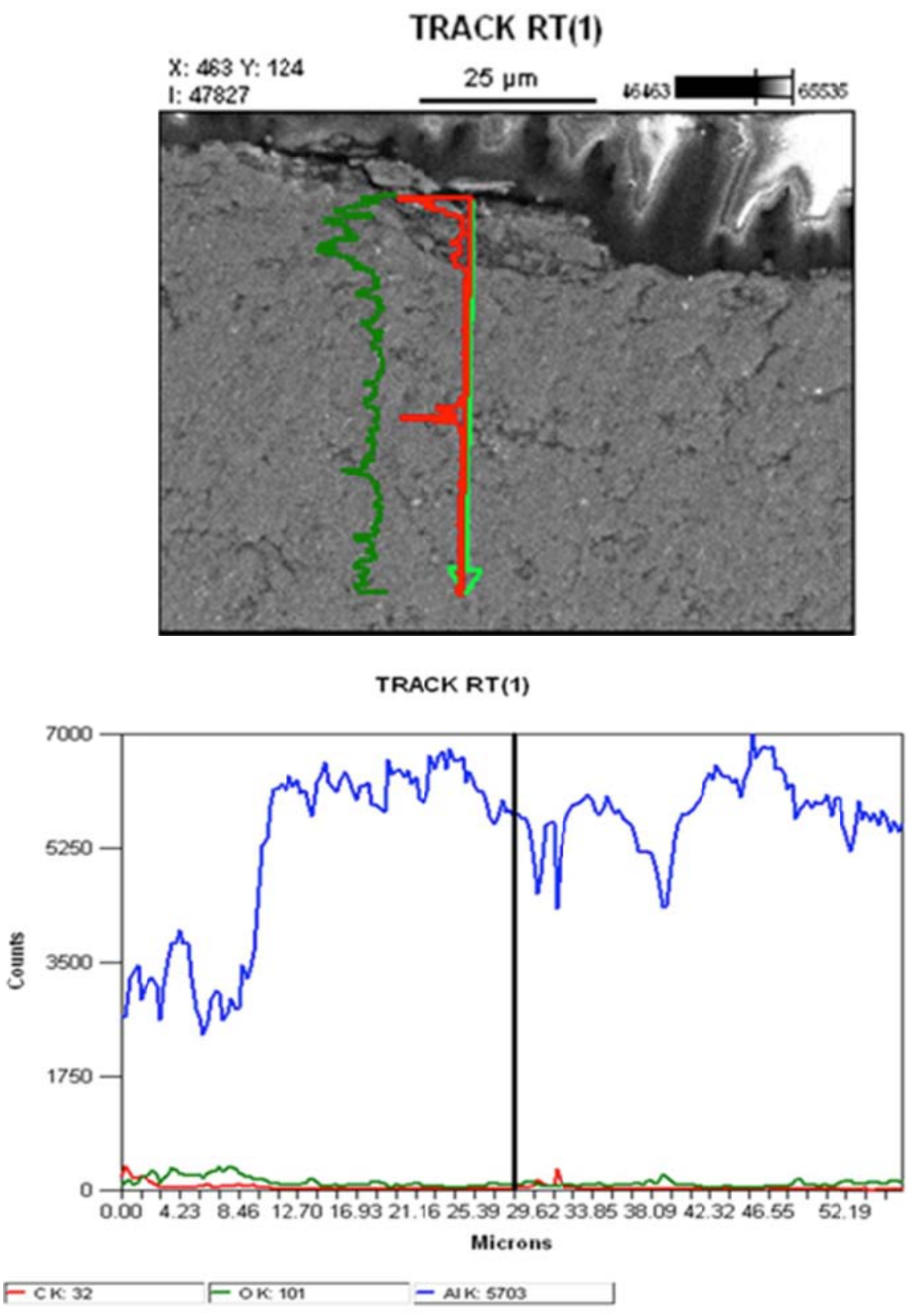
Cross-section of the Al-2vol.\% GNP wear track at high temperature:

\section{TRACK HT(2)}

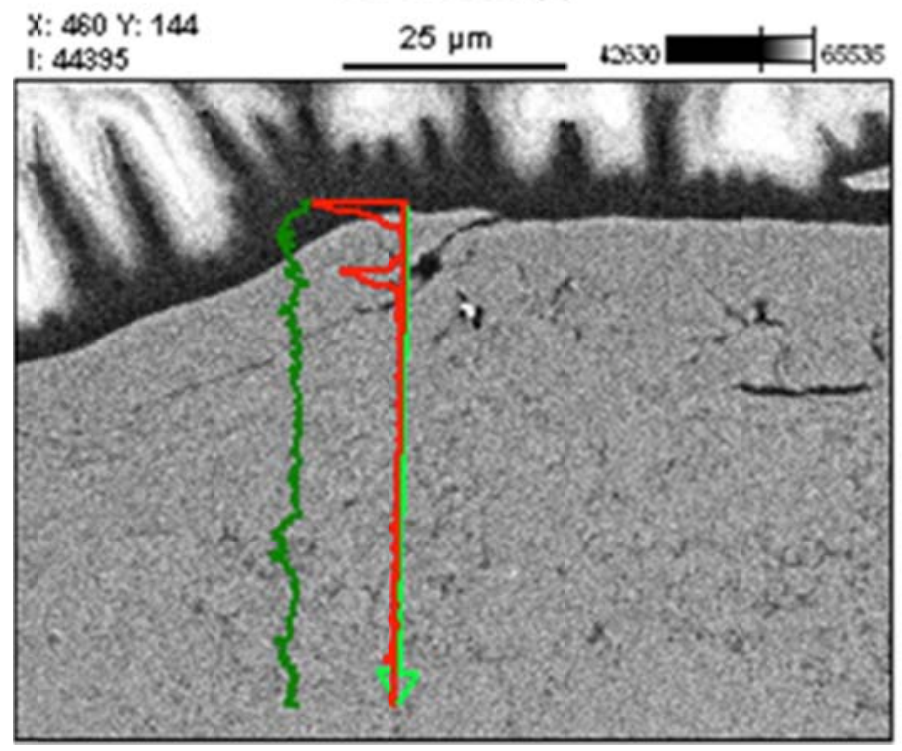

TRACK HT(2)

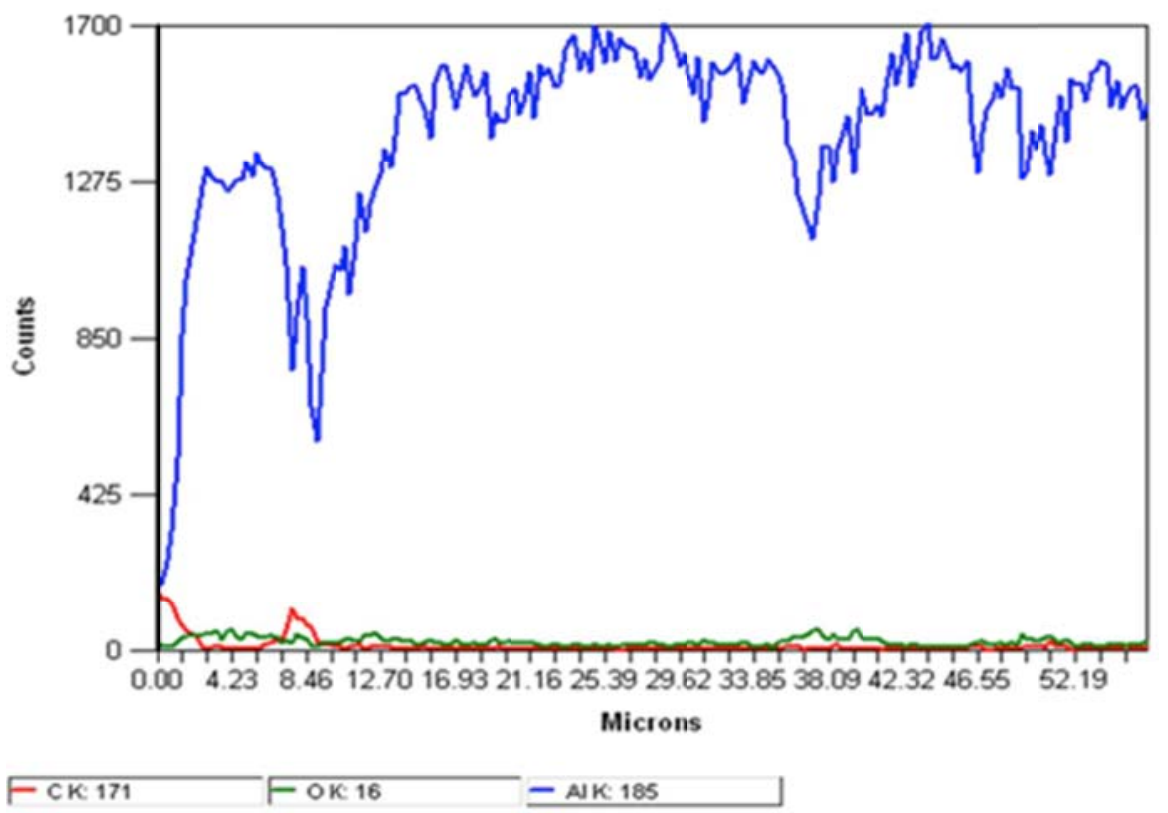




\begin{tabular}{|c|c|c|}
\hline \multicolumn{3}{|c|}{ Oxygen content through the sample (cross section of the tribofilm) } \\
\hline $\begin{array}{c}\text { From } 0 \mu \mathrm{m} \\
\text { (surface) to } 25 \mu \mathrm{m} \text { depth }\end{array}$ & $\begin{array}{c}\text { Room } \\
\text { Temperature (wt \%) }\end{array}$ & $\begin{array}{l}\text { High Temperature } \\
\left(200^{\circ} \mathrm{C}\right)(\mathrm{wt} \%)\end{array}$ \\
\hline 0 & 12.86 & 12.20 \\
\hline $1-2$ & 16.01 & 7.13 \\
\hline 3 & 27.95 & 13.85 \\
\hline $4-8$ & 28.20 & 18.46 \\
\hline 14-19 & 31.08 & 5.74 \\
\hline 25 & 1.55 & 0.83 \\
\hline
\end{tabular}

